\title{
Sex Hormones and Adult Hippocampal Neurogenesis: Regulation, Implications, and Potential Mechanisms
}

Rand Mahmoud $^{1}$, Steven R. Wainwright ${ }^{1}$, and Liisa A.M. Galea ${ }^{2,3}$

Graduate Program in Neuroscience ${ }^{1}$, Department of Psychology², Centre for Brain Health ${ }^{3}$, University of British Columbia, Vancouver Canada

Corresponding author:

Dr. Liisa Galea

Department of Psychology

University of British Columbia

2136 West Mall

Vancouver, BC

Canada, V6T $1 \mathrm{Z4}$

Tel: +1 (604) 8226536

Fax: +1 (604) 8226923

Email: lgalea@psych.ubc.ca 


\begin{abstract}
Neurogenesis within the adult hippocampus is modulated by endogenous and exogenous factors. Here, we review the role of sex hormones in the regulation of adult hippocampal neurogenesis in males and females. The review is framed around the potential functional implications of sex hormone regulation of adult hippocampal neurogenesis, with a focus on cognitive function and mood regulation, which may be related to sex differences in incidence and severity of dementia and depression. We present findings from preclinical studies of endogenous fluctuations in sex hormones relating to reproductive function and ageing, and from studies of exogenous hormone manipulations. In addition, we discuss the modulating roles of sex, age, and reproductive history on the relationship between sex hormones and neurogenesis. Because sex hormones have diverse targets in the central nervous system, we overview potential mechanisms through which sex hormones may influence hippocampal neurogenesis. Lastly, we advocate for a more systematic consideration of sex and sex hormones in studying the functional implications of adult hippocampal neurogenesis.
\end{abstract}


The hippocampus retains substantial plasticity throughout the lifespan, and this malleability is essential to hippocampal function (Jessberger et al., 2007; Scharfman and Myers, 2015; Surget et al., 2011; Wainwright et al., 2015). Considerable research suggests that the hippocampus is compromised in multiple neuropsychiatric and neurodegenerative disorders, including depression (McKinnon et al., 2009) and dementia (Henneman et al., 2009). This is perhaps not surprising given the importance of the hippocampus in cognition (Sweatt, 2004) and mood regulation (Campbell and Macqueen, 2004). Importantly, the hippocampus is a region in which neurogenesis persists throughout the lifespan in a wide variety of species including humans (Eriksson et al., 1998; Gould et al., 1999b; Gross, 2000; Spalding et al., 2013).

The majority of research efforts devoted to understanding the functional implications of adult hippocampal neurogenesis have been focused on learning and memory (Yau et al., 2015) and mood regulation (Sahay and Hen, 2007). Indeed, alterations in hippocampal neurogenesis are reported in post-mortem tissue from patients with depression (Boldrini et al., 2012) and Alzheimer's disease (Crews et al., 2010; K. Jin et al., 2004), and in animal models of these disorders (Bessa et al., 2009; Green and Galea, 2008; Mu and Gage, 2011; Wainwright et al., 2011). Although we first expand on the role of the hippocampus in the neurobiology of depression and cognitive function in this review, we direct the reader to other reviews with a primary focus on these topics (Broadbent et al., 2010; Campbell and Macqueen, 2004; MacQueen and Frodl, 2011; Sweatt, 2004). The current review focuses on the influence of sex and sex hormones on adult hippocampal neurogenesis, and explores ramifications to cognition and mood in health and disease.

Robust sex differences exist in the incidence rates of depression, where at least twice as many women are affected than men (Gutiérrez-Lobos et al., 2002; Angst et al., 2002). Similarly, Alzheimer's disease is more prevalent in women than men (Baum, 2005), in contrast to other forms of dementia (Gao et al., 1998). Sex differences in these neuropsychiatric and neurodegenerative disorders extend beyond incidence rates. The manifestation of a disorder can differ by sex, where in the case of depression, women are more likely to be diagnosed with atypical depression, and to present with co-morbid anxiety (Angst et al., 2002; Silverstein, 2002; Young et al., 1990). The severity of disease is also linked to sex, as Alzheimer's disease follows a more severe progression in women relative to men (Irvine et al., 2012). It is beyond the scope of this review to delve into why these sex differences in disease incidence and severity exist, but 
the reader is directed to other reviews on this subject (Hammarström et al., 2009; Mielke et al., 2014; Vest and Pike, 2013). Beyond the context of disease, sex differences exist in certain domains of cognition, as reviewed in (Hamson et al., in press), and in neurogenesis, as reviewed in (Galea et al., 2013). In instances where sex differences are observed in a phenotype of interest, whether it is in the context of health or pathology, it is essential to examine whether sex hormones are involved. The role of sex hormones in any given phenotype can arise from effects early in development, during the pubertal transition, throughout adulthood, or across a combination of developmental windows in both males and females.

In light of the sex differences in cognitive function and mood regulation in health and disease, and the potential role of neurogenesis in these domains, the influence of sex hormones on adult hippocampal neurogenesis is essential to consider and will be the focus of our current review. After giving a brief overview of neurogenesis in the adult hippocampus, we expand on the role of the hippocampus, and links to hippocampal neurogenesis, in the neurobiology of depression and learning and memory. We then discuss evidence indicating that sex hormones are potent modulators of neurogenesis within the dentate gyrus. We highlight the complexities of sex hormone modulation of neurogenesis, in how it may be affected as a function of sex, age, and reproductive history. Further, we discuss potential implications of sex hormone regulation of hippocampal neurogenesis, with particular attention to affective and cognitive functions in health and disease. Lastly, we highlight potential mechanisms through which sex hormones may mediate their effects on neurogenesis within the dentate gyrus.

\section{Adult Hippocampal Neurogenesis}

Altman first found neural stem cells in the brain of adult rodents more than fifty years ago (Altman, 1962) and neural stem cells have since been identified in a number of species, including humans (Eriksson et al., 1998). The production of new neurons in the adult brain is typically limited the subventricular zone (SVZ), which lines the lateral ventricles and sends newly generated cells along the rostral migratory stream to the olfactory bulb, and the subgranular zone of the hippocampus (Kaplan and Hinds, 1977). However, studies in humans indicate that adult neurogenesis may not occur in the SVZ, and is limited to the hippocampus (Sanai et al., 2011; Spalding et al., 2013). Multipotent neural stem cells are capable of producing multiple types of both neurons and glia and are located in the SVZ, while neural progenitor cells 
located in the SGZ divide more frequently, in a finite manner, and into a limited number of cell types, as they may only produce daughter cells of either a defined glial or neuronal lineage (Gage, 2000; Seaberg and van der Kooy, 2003; 2002; van der Kooy and Weiss, 2000).

Newly generated neurons may be identified through the administration of DNA-markers such as ${ }^{3} \mathrm{H}$-thymidine, or a synthetic nucleoside such as 5-bromo-2-deoxyuridine (BrdU). Each marker is incorporated into the DNA of dividing cells during DNA synthesis, replacing thymidine nucleotides. The addition of BrdU into the DNA provides a unique epitope for antibody binding using immunocytochemistry. The controlled addition of the exogenous markers allows for a definitive timeline of neural development, as every cell undergoing DNA synthesis during the two hours after injection will be labelled. Labelled cells may be examined at time points ranging from hours, weeks, or even years later depending on the research question (Dayer et al., 2003; Eriksson et al., 1998; Kempermann et al., 2003).

There are limitations, however, in the use of exogenous markers, as they become diluted as cells undergo mitosis and are only distinguishable from background for 4-5 divisions following administration, thereby limiting the population of cells that may be labelled (Prickaerts et al., 2004; Stone et al., 1965); however, this limitation also provides the benefit of generating a “time stamp" for the occurrence of cell proliferation. Factors such as dose, toxicity, or the permeability of the blood-brain barrier may also disrupt the detection of true cell counts when using exogenous markers of DNA synthesis (Taupin, 2007). Exogenous markers must also be used in conjunction with endogenous markers, such as neuronal nuclei (NeuN) for mature neurons or glial fibrillary acidic protein (GFAP) for glial cells, in order to phenotype newlylabelled cells with BrdU or ${ }^{3} \mathrm{H}$-thymidine. It is therefore essential that BrdU or ${ }^{3} \mathrm{H}$-thymidine labelled cells be assessed with endogenous markers in order to demonstrate that neurogenesis has occurred (Ming and Song, 2005; Wojtowicz and Kee, 2006).

The measurement of neurogenesis may also be achieved through the assessment of endogenous protein expression. Measurement of the Ki67 protein, which is expressed throughout the active phases of the cell cycle but absent in quiescent cells, may be used as a marker of cell proliferation (Kee et al., 2002). The use of Ki67 in the measurement of cell proliferation also precludes issues with toxicity encountered with exogenous markers, however Ki67 is limited by the short timeline of expression - approximately 24 hours in rats, but is not limited to cells that 
will become neurons (Cameron and McKay, 2001; Kee et al., 2002). Endogenous markers may also be used to identify and characterize both immature and mature neurons. Doublecortin (DCX) is a neuron-specific protein that functions in the stabilization of microtubules in early mitotic neurons which may be used to measure immature neurons and assess immature neuronal morphology (Bechstedt et al., 2014), and in the rat hippocampus is expressed from a few hours to 21 days after the production of a new neuron (Brown et al., 2003). The NeuN protein is expressed by most mature neurons and functions in RNA splicing within the nucleus, and may be used in the characterization of mature neurons (Kim et al., 2009; von Bohlen und Halbach, 2011). It is important to note that while NeuN is expressed in most neuronal cell types, it is not expressed in certain neuronal populations such as the cerebellar purkinje cells and retinal photoreceptor cells (Mullen et al., 1992). Importantly, expression patterns differ in the SVZ and in mice, with other species likely also differing from the rat (Ming and Song, 2005; Snyder et al., 2009).

It is important to note that neurogenesis, as defined here, requires the proliferation, migration, survival, and differentiation of newly generated cells into neurons (see Figure 1). Any number of internal and/or external factors may independently affect the proliferation of progenitor cells, migration, their differentiation into neurons, or their survival rates; including stress, gonadal hormones, or pharmaceuticals (Kempermann et al., 1998; van Praag et al., 1999; Malberg et al., 2000; Barker and Galea, 2008; Burgess et al., 2008; Pariante and Lightman, 2008; Anacker et al., 2011; Surget et al., 2011; Wainwright et al., 2011). It is therefore essential to understand which aspects of neurogenesis are being examined, and when they are being examined, in relation to experimental manipulation. For example, treatment prior to injections with a DNA synthesis marker may result in opposing effects on neurogenesis compared to treatments given just after injection of a DNA synthesis marker (Barker and Galea, 2008; Chan et al., 2014; Malberg et al., 2000; McClure et al., 2013; see figures 2 and 3). The differential effects depending on timing of DNA synthesis marker administration may relate to the manipulation itself (e.g. antidepressants do not independently alter the survival of new neurons (Malberg et al., 2000), and/or may be due to different populations of progenitor cells that respond at different times or in response to homeostatic disruptions (Hayes and Nowakowski, 2002).

\section{The Hippocampus in the Neurobiology of Depression}


The hippocampal formation is an area rich in mineralocorticoid (MR) and glucocorticoid receptors (GR) (McEwen, 1973). These receptors function in the maintenance of basal hypothalamic-pituitary-adrenal (HPA) axis tone, and in the regulation of negative feedback of glucocorticoid release during a stress response (Sapolsky et al., 1985). Briefly, as illustrated in figure 4, negative feedback refers to the inhibition of HPA axis activity by circulating glucocorticoids, acting on glucocorticoid and mineralocorticoid receptors in regions such as the hypothalamus, pituitary, and hippocampus (Smith and Vale, 2006). As some depressed patients show disrupted HPA negative feedback, diurnal rhythms and hypersecretion of cortisol (Pariante and Lightman, 2008), it is not surprising that the hippocampus is particularly vulnerable to the effects of stress and depression (Sapolsky, 1986; Sapolsky et al., 1988).

Imaging studies shown that depressed patients have smaller hippocampal volumes which co-vary with the number of episodes and duration of the illness (Sheline et al., 1996; Sheline et al., 2003; McKinnon et al., 2009). Similarly, post-mortem studies of depressed patients have shown alterations in gray matter density, reductions in neuropil, decreased neuron soma size, and decreased hippocampal neurogenesis; demonstrating significant changes in both the number and connectivity of hippocampal neurons, which may contribute to the observed reductions in hippocampal volume (Stockmeier et al., 2004; Boldrini et al., 2009; Hercher et al., 2009; Boldrini et al., 2012b; Boldrini et al., 2013a; Cobb et al., 2013). Alternations to both neurogenesis and neuroconectivity have been associated with the etiology and amelioration of depression (see Wainwright and Galea, 2013; Wainwright et al., 2015).

Interestingly, the meta-analysis by McKinnon et al., (2009) showed that only patients with depression persisting longer than two years, or had greater than one episode of depression, showed significantly smaller hippocampal volume. The evidence for smaller hippocampal volume was, however, only found in children and middle-aged to older adults, where young adults showed no significant difference between depressed patients and control subjects. Thus the periods during life that the hippocampus is most vulnerable to the effects of chronic or recurrent depression are also the times when gonadal hormones are lower. Importantly, gonadal hormones function in then feedback regulation of the HPA axis in both males and females (see figure 4). Lastly, and importantly, men are more likely than women to present with a small hippocampal volume with depression (Frodl et al., 2002). It is important to note that reductions in hippocampal volume with depression are not solely due to neurogenesis, and may be due to a 
number of factors such as reduced neuropil, glia, or neurons. An exhaustive review of factors that could contribute to the reduced volume is beyond our current scope, but the reviewer is directed to another review on the subject (Czéh and Lucassen, 2007).

\section{Adult Hippocampal Neurogenesis and Depression}

The neurogenic hypothesis of depression is predicated not only on the findings, reviewed above, that chronic stress decreases hippocampal neurogenesis in animal models of depression (Gould et al., 1997; Santarelli et al., 2003; Bessa et al., 2009), but that antidepressant drugs can both prevent (Czeh et al., 2001; Alonso et al., 2004) and reverse (Malberg and Duman, 2003; Santarelli et al., 2003; Bessa et al., 2009) this effect (see Wainwright and Galea, 2013). The enhancement of adult hippocampal neurogenesis via antidepressant treatment is dependent on chronic exposure, and occurs in a manner that temporally coincides with the delayed time to substantial remission in depressed patients (Malberg et al., 2000; Santarelli et al., 2003; Mitchell, 2006). This delayed enhancement of neurogenesis is mediated through the increased proliferation of neural progenitor cells, while the proportion of cells that survive and differentiate into neurons remains constant (Malberg et al., 2000). Several classes of antidepressant drugs, including selective serotonin reuptake inhibitors (SSRI)s, tricyclic antidepressants (TCA)s, and monoamine oxidase inhibitors (MAOI)s, increase neurogenesis in the hippocampus (Banasr et al., 2006; Dagyte et al., 2010). Moreover, a rodent model of the non-pharmacological antidepressant treatment of electroconvulsive therapy (ECT), which shows the greatest clinical efficacy against treatment-resistant depression (Pagnin et al., 2004), enhances neurogenesis to levels nearly twice that of pharmacological antidepressants in animal models (Madsen et al., 2000; Hellsten et al., 2002). Post-mortem studies have also shown antidepressant treatment enhances hippocampal neurogenesis in humans (Boldrini et al., 2009; Boldrini et al., 2012; Epp et al., 2013). Interestingly, one study shows treatment with TCAs increases cell proliferation levels beyond that of SSRIs (Boldrini et al., 2009), while another by the same research group shows a greater enhancement of proliferation by SSRIs over TCAs (Boldrini et al., 2012). There is a similar discrepancy in studies measuring hippocampal volume following antidepressant treatment, where SSRIs enhance hippocampal volume over TCA treatment (Boldrini et al., 2012; Boldrini et al., 2013; Boldrini et al., 2009). It is important to note that the majority of pre-clinical research described above has been conducted exclusively in male rodents (Bessa et al., 2009; Malberg et al., 2000; Santarelli et al, 2003), while post-mortem studies typically analyse both 
men and women together (Boldrini et al.,2009; 2012; 2014). Thus, one factor that may contribute to the disparate findings above that is not always considered in the effects of antidepressants or classes of antidepressants is biological sex.

There is some evidence that men respond better to TCAs while women respond better to SSRIs (Kornstein) and this may be seen in terms of hippocampal volume and/or neurogenesis (Lorenzetti). Indeed women responders were more likely to show increased hippocampal volume over non-responders compared to men (Vakili et al., 2000). One recent study has shown that antidepressant treatment only enhances the expression of DCX/NeuN ratio in women, but not men, thereby demonstrating that pro-neurogenic effects of antidepressant treatment may not only depend on the mechanism of antidepressant action, but the sex of the person taking a particular antidepressant (Epp et al., 2013). Unfortunately, that study did not examine type of antidepressant treatment to determine whether the sex effects were also dependent on antidepressant mechanism of action. The age of the research subjects is also important, as two studies have shown that antidepressants fail to enhance neurogenesis in older patients (Lucassen et al., 2010; Epp et al., 2013). Thus, it is important to distinguish between findings in males versus females and with attention to age in order to fully understand the role of neurogenesis in depression.

The modulation of neurogenesis via antidepressant treatment is well defined in the preclinical literature, however the specific role, and thereby the potentially essential nature of neurogenesis, is less clear. The reduction of hippocampal neurogenesis via irradiation, disrupts antidepressant efficacy on novelty-induced hypophagia in a model of depression (Santarelli et al., 2003). However, reduction of neurogenesis via the cytostatic agent methylazoxymethanol (MAM) failed to disrupt the behavioural efficacy antidepressant treatment on sucrose preference, or in the forced swim test (Bessa et al., 2009). Furthermore, the reduction of neurogenesis via MAM did not eliminate the antidepressant treatment-induced increases in hippocampal volume and synaptic protein expression in the hippocampus (Bessa et al., 2009). Thus, there are thought to be neurogenesis-dependent and -independent effects of antidepressant treatment, where hippocampal neurogenesis is required for the alleviation of anxiety-like behaviours, at least in males (Holick et al., 2008; Surget et al., 2008; David et al., 2009). Indeed, hippocampal neurogenesis buffers the acute stress response and normalizes glucocorticoid release after acute stress in male mice (Snyder et al., 2011). Snyder and colleagues found that the reduction of 
hippocampal neurogenesis, either transgenically or via irradiation, attenuated both the recovery of basal HPA tone following acute restraint stress and the normal suppression of glucocorticoid release during the dexamethasone suppression test (Snyder et al., 2011). Importantly, the ablation of neurogenesis does not alter the ability of the HPA axis to mount a response to stress (Santarelli et al., 2003). However, the ability of an antidepressant (fluoxetine) to improve negative feedback and normalize HPA tone in a chronic unpredictable stress (CUS) model of depression is abolished by the ablation of hippocampal neurogenesis in adult male mice (Surget et al., 2011). Further, the transgenic enhancement of hippocampal neurogenesis is sufficient to ameliorate some measures of anxiety- and depressive-like behaviour in a chronic CORT administration model of depression (Hill et al., 2015). As such, there is likely a role for hippocampal neurogenesis in re-establishing normal HPA tone and regulating a normal HPA response to stressors; possibly through GR-mediated feedback regulation, at least in males. The preponderance of depression research, including each of the aforementioned studies, is conducted in males and therefore, it is important to acknowledge that the functional significance of hippocampal neurogenesis may be different in females. Although previous work that directly examined the role of neurogenesis in depressive-like behaviour and antidepressant efficacy has been performed in males, there are a few studies that have examined depressive-like behaviour and antidepressant efficacy in females, and in some instances have examined alterations in neurogenesis (Lagunas et al., 2010; Mahmoud et al., in press; for review see: Dalla et al., 2010; Gobinath et al., 2015).

Experimental evidence has aligned to indicate a specific functional contribution of neurogenesis in stress reactivity and antidepressant action. However, there is also ample evidence demonstrating the importance of forms of neuroplasticity beyond neurogenesis in depression. The monoaminergic facets of antidepressant action, namely the modulation of serotonergic and dopaminergic neurotransmission, are unaffected by the ablation of neurogenesis (Bessa et al., 2009; David et al., 2009). The modification of receptor expression, synaptic weight, synaptic density, and neural connectivity, are tied to the antidepressant-induced modulation of neurotransmission and subsequently antidepressant efficacy (Shakesby et al., 2002; Duman and Aghajanian, 2012). In fact a study from our laboratory demonstrated that the enzymatic ablation of the polysialylated neural cell adhesion molecule (PSA-NCAM) disrupted antidepressant efficacy across neurogenesis-dependent and -independent behavioural measures (Wainwright et 
al., 2015). The ablation of PSA-NCAM causes broad a disruption of neuroplasticity, including long-term potentiation (LTP), long-term depression (LTD), dendritic outgrowth, and synaptic density (Burgess et al., 2008; McCall et al., 2013; Muller et al., 1996; Rutishauser, 2008; for review see Wainwright and Galea, 2013). Taken together, these findings demonstrate the limited contribution of neurogenesis alone in antidepressant efficacy while demonstrating the essential contributions of all facets of neuroplasticity.

\section{The Hippocampus in the Neurobiology of Learning and Memory}

There is little dispute that the hippocampus is involved in some aspects of learning and memory, however it is important to acknowledge that not all researchers agree to the degree of hippocampal involvement in learning and memory. The nuances and complexities are beyond the scope of this review and the reader is directed to many excellent reviews on the topic (Josselyn et al., 2015; Leal and Yassa, 2015; Rosenbaum et al., 2001; Winocur et al., 2013). Certainly a large amount of evidence, including the existence of place and grid cells, points to a role of the hippocampus in spatial memory (Moser et al., 2015). Indeed, the integrity of the hippocampus is important for pattern separation and completion (Clelland et al., 2009; Kesner and Rolls, 2015). However, it is also important to understand that the hippocampus, while vital in some forms of spatial cognition, is only part of a larger network of structures that are involved in various aspects of learning and memory, such as decision making and/or executive functions such as planning/shifting strategies (Orsini et al., 2015). The hippocampus does not act as a single, homogenous, structure; rather, there appears to be a functional dissociation along the dorsoventral axis (Moser and Moser, 1998). Anatomical, gene expression, and behavioural studies point to a primary role in cognition for the dorsal hippocampus, while the ventral hippocampus is primarily involved in affective functions (Fanselow and Dong, 2010), although whether or not this is a true double dissociation is up for debate (Strange et al., 2014). The dorsal region shows a greater density of place cells involved in the coding of spatial location and reciprocal connections with regions prominently involved in cognitive processing and locomotion, while the ventral region shares connections with the amygdala, medial prefrontal cortex (mPFC), and hypothalamus in a manner primarily associated with neuroendocrine regulation, stress, and affect (Herman and Cullinan, 1997; Fanselow and Dong, 2010). Few studies in neurogenesis research, however, have dichotomized the dentate gyrus, but those that do often find differences in the effects of treatment on neurogenesis in the dorsal 
versus ventral dentate gyrus (O'Leary and Cryan, 2014; Surget et al., 2011; Tanti and Belzung, 2013; Yagi et al., 2015).

\section{Adult Hippocampal Neurogenesis and Learning and Memory}

Neurogenesis in the hippocampus has been linked to cognition, and while the debate continues as to how much it is involved and in what types of learning and memory, it is certainly less disputed that neurogenesis is required for spatial pattern separation (Clelland et al., 2009). Indeed, new neurons, but not older neurons, in the dentate gyrus are needed for pattern separation (Nakashiba et al., 2012). However, ablation of neurogenesis does not lead to disruptions in acquisition in a spatial reference memory version of Morris Water Maze (Shors et al., 2002), but does lead to long-term disruption in spatial memory (Snyder et al., 2005). Ablation of neurogenesis has also lead to deficits in contextual fear and trace conditioning (Shors et al., 2002; Winocur et al., 2006). Other studies have indicated that an optimal level of neurogenesis is needed for optimal learning and memory (Akers et al., 2014; Jessberger et al., 2007; Scharfman and Myers, 2015). For example, computational models and empirical data suggest that large fluctuations in cell proliferation will be disruptive to the network and thus new neurons that have not fully integrated into the system disrupt new learning (Akers et al., 2014; Butz et al., 2006; Jessberger et al., 2007; Scharfman and Myers, 2015). The reader should be aware that the nature of the disruption of neurogenesis may have very different effects on cognition, as new neurons created under exercise versus seizure-like conditions have different properties (Jakubs et al., 2006), and depending on whether neurogenesis disruptions are affecting new or older memories (Epp et al., 2016).

Hippocampus-dependent learning (acquisition) influences neurogenesis and the activation of newly generated neurons in response to memory retrieval (Epp et al., 2013b). A study by Gould et al (1999) was the first to demonstrate that the number of BrdU-labeled cells was increased in male rats by training on the hippocampus-dependent Morris Water Maze (Gould et al., 1999a). Further work corroborated these findings (Epp et al., 2007), but also revealed that several factors including sex, strain, and methodological differences can affect the relationship between learning and neurogenesis (Epp et al., 2013 for review). An extensive review of the involvement of hippocampal neurogenesis in cognition is beyond the scope of this 
review and the reader is directed to many other reviews on the subject (Abrous and Wojtowicz, 2015; Deng et al., 2010; Frankland and Josselyn, 2016; Johnston et al., 2015).

\section{Hippocampal Neurogenesis and Androgens}

Accumulating evidence indicates a role for androgens, and androgenic signalling, in the modulation of adult hippocampal neurogenesis (Galea et al., 2013). In the following sections, we will review studies that have investigated the influence of endogenous fluctuations and exogenous manipulations of androgens on neurogenesis within the dentate gyrus (summarized in Figure 2). We will discuss potential implications for affective and cognitive function, and in turn depression and dementia.

\section{Androgens and Androgen Signalling: A Brief Overview}

Androgens are the predominant gonadal hormones in men, derived from cholesterol via progestins, they include among others testosterone, androstenedione, and the testosterone metabolite produced via $5 \alpha$-reductase, $5 \alpha$-dihydrotestosterone (DHT). Testosterone and androstenedione may also be converted, via aromatase, to $17 \beta$-estradiol. $17 \beta$-estradiol is the most biologically active of the estrogens in men and women (Nelson, 2011). Androgens are produced primarily in the Leydig cells of the testes, and transported through the circulatory system via sex hormone-binding globulin produced in the liver (Waterman and Keeney, 1992). Androgens act via the androgen receptor (AR), which is classically expressed in the cytoplasm then, when bound by either testosterone or the higher-affinity DHT, translocates to the nucleus and functions as a transcription factor to directly regulate gene expression via AR binding domains (Heinlein and Chang, 2002; Bennett et al., 2010). ARs also have a non-genomic pathway to induce rapid signalling following the binding of a ligand (Heinlein and Chang, 2002). Though DHT does not bind or activate estrogen receptors (ERs), it can be further metabolised by cytochrome P450

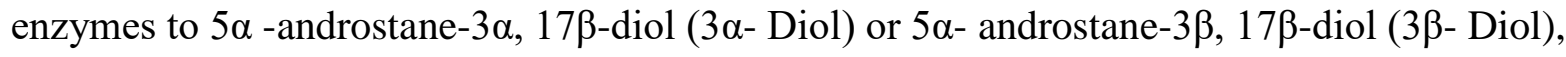
both of which show affinity for ERs (Handa et al., 2008).

The androgen receptor protein contains an N-terminal domain, a hormone-binding domain, and a DNA-binding domain. The AR gene encoding the AR protein is located on the X chromosome and has a polymorphic CAG microsatellite that encodes variable-length glutamine repeats in the N-terminal domain (Lubahn et al., 1988). The CAG repeat length normally ranges 
from 6 to 39 repeats, with a mean of 22, where CAG repeat length negatively correlates with the amount of AR transactivation (Seidman et al., 2001b). Androgen receptors are expressed throughout the rat brain, including the hippocampal formation in both males and females (Simerly et al., 1990). Sex differences are present however, as the density of AR expression in the hippocampus is greater in intact males than intact females, as may be expected (Xiao and Jordan, 2002). Within the hippocampal formation AR is expressed throughout Ammon's horn, with particularly high expression in the stratum pyramidale of CA1 and stratum lucidum of CA3 (Simerly et al., 1990; Kerr et al., 1995; Tabori et al., 2005). Interestingly, there is no apparent expression of AR in the dentate gyrus of adult male rats (Simerly et al., 1990; Kerr et al., 1995; Xiao and Jordan, 2002; Tabori et al., 2005), including findings from our laboratory indicating no expression of AR in the dentate gyrus or on adult-generated immature hippocampal neurons (Hamson et al., 2013; see figure 5).

\section{Hippocampal Neurogenesis and Androgens}

Despite the fact that there is an absence of AR in the dentate, there is evidence showing that androgens influence neurogenesis in the adult male hippocampus (see Figure 2). In adult male rodents, long-term exposure to androgens reliably increase hippocampal neurogenesis via the modulation of the survival of new neurons (for review see Galea et al., 2013). Several studies have shown that the removal of testicular hormones, via castration, or a reduction of testicular hormone levels during the non-breeding season, is associated with a reduction in the number of newly generated neurons that survive to maturity in adult rodents (Ormerod and Galea, 2003; Spritzer and Galea, 2007; Spritzer et al., 2011a; Wainwright et al., 2011; Hamson et al., 2013). On the other hand, supplementation with either testosterone or dihydrotestosterone (DHT), but not estradiol, ameliorates the effect of castration on the survival of new neurons in males (Spritzer and Galea, 2007; Hamson et al., 2013). However, some studies have shown no effect of testosterone supplementation to increase the survival of new neurons after castration (Spritzer et al., 2011a; Carrier and Kabbaj, 2012a), or in intact males (Buwalda et al., 2010). The duration of androgen treatment appears to be critical in promoting the survival of new neurons. The studies that show enhanced survival of new neurons have used 30 or 90 days of androgen administration (Spritzer and Galea, 2007; Spritzer et al., 2011a; Wainwright et al., 2011; Hamson et al., 2013; Hannan and Ransome, 2012), while those failing to enhance the survival of new neurons use 15 or 21-day courses of androgen treatment in male rodents (Spritzer et al., 2011; Carrier and 
Kabbaj, 2012b; Wainwright et al., 2016; see figure 2). Given the length of exposure required to elicit an increase in the survival of new neurons, the effect is likely mediated through a genomic mechanism. It is unclear why the effects on neurogenesis are not seen with 15 or 21 days of treatment, considering that these windows would also allow for the activation of genomic mechanisms. However, as we discuss later in the review, we speculate that androgens may act on the CA3 region to induce retrograde signalling of survival factors that ultimately influence the survival of new cells. This process, that likely requires the synthesis, release and action of survival factors emitted from the CA3, may therefore explain the length of exposure required to elicit an increase in neurogenesis.

Androgenic regulation of the survival of new neurons within the dentate gyrus has been specifically attributed to the activation of the AR in rodents, as estrogenic metabolites of testosterone such as estradiol, produce no significant effect on survival of new neurons (Spritzer and Galea, 2007; Carrier and Kabbaj, 2012a). Indeed, testosterone exerts an effect on neurogenesis via an AR-dependent mechanism, as treatment with the testosterone metabolite DHT, which has a higher affinity for AR than testosterone, produces an increase in neurogenesis. Moreover, the enhancement of neurogenesis by DHT is blocked by the AR antagonist flutamide (Hamson et al., 2013). Similarly, testosterone treatment fails to enhance neurogenesis in Tfm (testicular feminization mutation) rats containing a mutation of the AR that renders it nonfunctional (Hamson et al., 2013). Given the absence of ARs in the dentate gyrus of most rodent strains, the site of androgen action to influence neurogenesis cannot be directly within the dentate gyrus. We have postulated that the binding of ARs in the CA3 region induces retrograde signalling of survival factors from CA3; however, a mechanism still needs to be delineated (Galea et al., 2013; Hamson et al., 2013).

While androgens, but not estrogens, modulate the survival of new neurons, estradiol has some effects on neurogenesis in males (Ormerod et al., 2004). Although 29 days of exposure to estradiol does not alter neurogenesis, 5 days of estradiol administered 6-10 days after BrdU does increase the survival of new neurons, one week after castration in male rodents (Ormerod et al., 2004). Furthermore, while 60 days of estradiol treatment did not affect the survival of new neurons, it did increase the density of immature doublecortin-expressing neurons (Saravia et al., 2007). This suggests that while long-term exposure of estradiol does not affect the survival of new neurons in the male rodent, short-term exposure to estradiol, limited to the axon extension 
phase, does promote the survival of new neurons in adult male rodents. Collectively, these findings demonstrate that long-term androgen treatment has pro-neurogenic effects on cell survival via the AR in agonadal males, while short-term targeted (5 day; during axon extension), or very long term (60 day) estradiol treatment may promote increased survival of new neurons in adult males. It is also possible that the length of castration may influence these findings but as of yet this has not been examined in the literature.

Androgens have less of an influence on adult hippocampal cell proliferation as neither castration, nor repeated androgen supplementation (administration of testosterone or DHT) produced any significant change in cell proliferation using either exogenous or endogenous markers (Spritzer and Galea, 2007; Carrier and Kabbaj, 2012b; Hamson et al., 2013; Allen et al., 2015; Hannan and Ransome, 2012). Furthermore, neither the administration of the ARantagonist flutamide, nor the expression of the insensitive androgen receptor in TfM rats given vehicle, altered levels of cell proliferation (Hamson et al., 2013). Though not a significant effect, there was a trend toward testosterone supplementation reducing cell proliferation in intact male rats (Buwalda et al., 2010). Interestingly, another study has found that administration of finasteride - a $5 \alpha$-reductase inhibitor that functions to inhibit the metabolism of testosterone to DHT- in intact male mice actually serves to reduce cell proliferation and the expression of DCXimmunoreactive neurons in the hippocampus (Romer et al., 2010). Collectively these findings demonstrate that while androgen treatment may have modest effects on cell proliferation, it may potentially have deleterious effects on cell proliferation in intact males. It is therefore possible that optimal androgen levels may be required to support hippocampal neurogenesis in rodents. On the other hand, estradiol treatment may have pro-proliferative effects in the hippocampus of male rodents, as 10 or 60 days of estradiol treatment (using continuous-release pellets) increased cell proliferation in middle aged (10-12 month old) male C57Bl/6 mice (Saravia et al., 2007).

A study in non-human primates showed gonadectomised males had increased survival of new neurons and enhanced differentiation of new cells to a neural phenotype (Allen et al., 2014). However, it is important to note that the Rhesus Macaques used in that study were gonadectomised prior to puberty, and neurogenesis was not measured until over two years after surgery. This is very different from the findings in rodents demonstrating that castration in adulthood can suppress the survival of new neurons (Spritzer and Galea, 2007). Given the prepubertal removal of gonadal hormones, and the long absence from testicular hormones, any 
differences in hippocampal neurogenesis cannot be solely attributed to an AR-dependent neurogenic mechanism. Furthermore, new cells are produced during puberty in at least three sexually dimorphic regions in the rat brain; the medial amygdala, the anteroventral periventricular nucleus of the hypothalamus, and the sexually dimorphic nucleus of the preoptic area (Ahmed et al., 2008). Gonadectomy prior to puberty prevents the production of these new cells indicating that these effects are modulated by gonadal hormones during puberty (Ahmed et al., 2008). This indicates that pre-pubertal gonadectomy likely alters the numbers of neurons in many regions of the brain and manipulations in these animals, while informative to pubertal effects, are not likely to mirror effects seen in adults that were gonadectomised after puberty.

The modulation of androgens also alters the expression of neurotrophic factors and structural proteins associated with neuroplasticity in the hippocampus. Gonadectomised rats show reductions in genes associated with neurogenesis, neuroplasticity, and cell adhesion (Quintela et al., 2015). Conversely, 4-weeks of testosterone supplementation via silastic capsule in GDX male rats enhances the expression of the calcium-dependent cell adhesion molecule, Ncadherin, in the hippocampus (Monks et al., 2001). However, a study from our laboratory has shown that testosterone supplementation in GDX male rats for 3-weeks via daily injection failed to enhance the expression of the calcium-independent cell adhesion molecule PSA-NCAM (Wainwright et al., 2016). Given the differences in methodology and the proteins measured, conclusions are difficult to draw regarding the influence of androgens on cell adhesion molecule expression. These findings indicate, however, that androgens modulate hippocampal plasticity in the adult hippocampus beyond their influence on hippocampal neurogenesis.

\section{Androgens and Neurogenesis: Potential Implications for Cognitive Function}

There is equivocal data to support that androgens significantly affect cognition in young adult males. Although studies show that testosterone or androgen manipulation does not influence acquisition of the Morris Water Maze (Sandstrom et al., 2006; Spritzer and Galea, 2007; Benice and Raber, 2010; Spritzer et al., 2011b), short-term testosterone supplementation can influence early (7 days) but not later (15 days) spatial memory retrieval in this task (Sandstrom et al., 2006; Spritzer and Galea, 2007; Spritzer et al., 2011b). These findings are clearly uncoupled with the findings of testosterone-induced increases in hippocampal neurogenesis as it takes at least 30 day of testosterone treatment to see an upregulation in 
neurogenesis (Spritzer and Galea, 2007). However, shorter-term AR manipulations can modulate spatial acquisition and memory in the Morris water Maze, as the AR antagonist flutamide impaired MWM acquisition and memory retrieval when administered into the CA1 region (Naghdi et al., 2001; Edinger and Frye, 2007), and Tfm male rats showed impaired acquisition of the Morris water Maze (Jones and Watson, 2005). These studies collectively suggest that shortterm exposure to testosterone may enhance spatial memory via an AR-dependent mechanism occurring within the CA1 region. Intriguingly, one study showed that short-term estradiol, given only during the axon-extension phase, not only increased the survival of new neurons in adult male meadow voles but also improved spatial memory in the Morris Water Maze (Ormerod et al., 2004). Together, this suggests that, at least in males, androgens and estradiol can improve spatial memory if given in limited duration.

There is also evidence that loss of androgens may contribute to memory decline in aging men and in men with Alzheimer's disease (Moffat et al., 2004). Lower brain and serum levels of testosterone are detected in men with AD (Moffat et al., 2004; Rosario et al., 2011), and these reductions are apparent 10 years prior to a diagnosis (Moffat et al., 2004). Interestingly, androgens may interact with APOE4 allele, a genetic risk factor for Alzheimer's disease, to enhance the risk for pathological cognitive ageing (Panizzon et al., 2010; 2014). For example, a smaller hippocampus is evidenced in middle-aged men with lower serum testosterone levels possessing an APOE4 allele (Panizzon et al., 2010). Further, better verbal memory in middleaged men with APOE4 was found in those with higher levels of testosterone (Panizzon et al., 2014). Increased amyloid burden was associated with decreased testosterone levels in men with mild cognitive impairment (MCI) carrying at least one APOE4 allele (Verdile et al., 2014). Although some studies indicate that androgen supplementation in older men with MCI or AD can improve spatial memory (Cherrier et al., 2005), others find testosterone supplementation in men with MCI or AD did not have a significant effect on cognition (Cherrier et al., 2015; Lu et al., 2006). However, these studies did not account for APOE4 status, which may have contributed to the negative findings, and/or the duration or dose of testosterone may not have been adequate. Taken together, androgens may be neuroprotective against cognitive ageing in men, but may be less efficacious in aiding cognitive function after a diagnosis with Alzheimer's disease. Further, the interaction of testosterone with known genetic predispositions, such as APOE, should be considered in research on cognitive ageing in men. 


\section{Androgens and Neurogenesis: Potential Implications for Mood Regulation}

Numerous studies suggest an influence of androgens on mood and affect, both clinically and preclinically. There is evidence showing that androgen levels in men are associated with depression; for example, there is an increased incidence of depression in males coinciding with the agerelated decline in testosterone levels (Shores et al., 2004; Shores et al., 2005; McIntyre et al., 2006; Shores et al., 2009). Similarly, young and middle-aged men in a hypogonadal state are far more susceptible to developing depression (Veras and Nardi, 2010; Westley et al., 2015), portending protective effects of testosterone against the development of depression. Testosterone has also shown antidepressant effects, as testosterone replacement therapies have some efficacy in alleviating depressive symptoms in hypogonadal men (Seidman and Rabkin, 1998; Shores et al., 2009; Zarrouf et al., 2009). A meta-analysis in men indicated that testosterone therapy improved overall depression scores (Hamilton depression rating scale; HAM-D) after examining 7 studies that fulfilled their criteria (Odds ratio 0.40). Testosterone therapy also showed improvement in depression scores in hypogonadal men, men with HIV/AIDS, and a mild improvement in eugonadal men (Zarrouf et al., 2009). Testosterone replacement has also shown efficacy as an adjunct treatment to clinical antidepressants in cases of treatment-resistant depression (Seidman and Rabkin, 1998; Pope et al., 2003). While other androgen supplementation is available, and new selective androgen receptors (SARMs) are being developed, to our knowledge no research has been published using SARMs to treat mood in men to date (Omwancha and Brown, 2006).

Androgen therapies are not always seen to be effective for men suffering depression (Seidman et al., 2001a; Pope et al., 2010). Studies differ widely on the administration of testosterone (topical gel appears more efficacious than intramuscular injections), time course, age of participants, depression scales, and what is considered an effective response rate (the meta-analysis used 50\% effective change in HAM-D), which may all contribute to findings related to the efficacy of testosterone treatment (Zarrouf et al., 2009). Furthermore, individual differences, such as the glutamine (CAG) polymorphism of the AR, are also related to the effects of testosterone on depression incidence, dependent on age (Seidman et al., 2001b; Harkonen et al., 2003). For example, testosterone levels correlate negatively with depressed mood in men with short CAG repeat length but not in men with longer CAG repeats (Seidman et al., 2001b). However, greater CAG repeat length is positively correlated with depressed mood in older men 
with no significant difference in serum testosterone levels (Harkonen et al., 2003). Thus, while there is controversy over the antidepressant-like action of testosterone supplementation in depressed patients, the majority of randomized control trials show some effectiveness of testosterone supplementation that may be limited to subpopulations and subtypes of depression (Rodgers et al., 2014).

The effects of testosterone supplementation, though less numerous, also indicate a positive effect on mood in women. Testosterone treatment in premenopausal women with low circulating levels of testosterone improved mood scores (Goldstat et al., 2003). Similarly, women that underwent oophorectomy showed decreased depressive mood scores when treated with a combination of conjugated equine estrogens and testosterone compared to treatment with estrogens alone (Shifren et al., 2000). Women presenting with treatment resistant depression showed improved mood scores or completely remitted in response to low-dose testosterone treatment as an adjunct therapy (Miller et al., 2009). Moreover, a meta-analysis of postmenopausal women shows testosterone treatment improves mood scores; both alone, and in combination with estrogens (Zweifel and O'Brien, 1997). These findings add credence to the supposition that androgens may function to improve mood in both men and women.

Animal studies support the clinical literature in demonstrating anxiolytic and antidepressant-like effects of androgens. Studies have shown that the removal of testicular hormones potentiates the stress response in males following acute stress (Viau et al., 1999; Viau et al., 2003), and testosterone replacement, or supplementation, is associated with a recovery of the stress response (Seale et al., 2004). Indeed, androgens function to directly inhibit HPA output at the level of the hypothalamus (Viau and Meaney, 1996) and the administration of DHT decreases the expression of GR in the CA1 region of GDX males (Kerr et al., 1996). In the NSF test, classically a test for anxiety-like behaviour and anxiolytic drugs, treatment with exogenous testosterone produces anxiolytic effects (Aikey et al., 2002). Similarly, research from our laboratory shows that testosterone treatment in gonadectomised males exposed to chronic stress ameliorates the anxiety/depressive-like behaviours in the NSF test (Wainwright et al., 2016). Gonadectomy has anxiogenic effects in rodents, which are ameliorated by testosterone treatment (Carrier and Kabbaj, 2012b; Khakpai, 2014). The anxiolytic effects of testosterone are blocked by the administration of the AR antagonist flutamide (Fernandez-Guasti and Martinez-Mota, 2005; Hodosy et al., 2012), suggesting these effects are mediated by the AR. However, several 
metabolites of testosterone, including estradiol and $3 \alpha$-diol, also produce anxiolytic effects independent of the AR (Frye and Edinger, 2004; Edinger and Frye, 2005; Carrier et al., 2015).

Androgens are also associated with depressive-like endophenotypes in rodent models. Research from our laboratory shows that gonadectomised male rats exposed to chronic unpredictable stress (CUS) show greater time spent immobile in the FST, a putative measure of depressive-like behaviour compared to intact males (Wainwright et al., 2011). Moreover, within this study, stress-exposed gonadectomised males had higher basal levels of corticosterone, indicative of disrupted HPA tone, and greater reductions in hippocampal neurogenesis and PSANCAM expression compared to intact males. Conversely, treatment with exogenous testosterone attenuated effects of CUS on gonadectomised male rats in the FST(Wainwright et al., 2016). In fact, androgen treatment serves to reduce immobility behaviour in both intact and GDX males, as well as female rats (Buddenberg et al., 2009; Frye and Walf, 2009; Carrier and Kabbaj, 2012b, a). Testosterone treatment also potentiates the effects of the tricyclic antidepressant drug imipramine in the FST when co-administered(Wainwright et al., 2016). Androgens also modulate the presentation of depressive-like behaviour in the sucrose preference test; gonadectomy serves to reduce sucrose preference, an effect reversed by testosterone supplementation (Carrier and Kabbaj, 2012a; Carrier et al., 2015), though not in male rats exposed to CUS (Wainwright et al., 2016). However, testosterone treatment facilitates the antidepressant effects of imipramine in CUS exposed male rats in the sucrose preference test (Wainwright et al., 2016).

There is ample evidence to support anxiolytic- and antidepressant-like effects of androgen treatment, alone and as an adjunct therapy, in both clinical and preclinical studies. Androgen-mediated modulation of hippocampal neurogenesis and neuroplasticity likely plays a roll conferring mood-altering actions resulting from the disruption or supplementation of endogenous androgens; both through the alteration of HPA reactivity and monoamergic neurotransmission. However, these effects may ultimately be mediated via the metabolization of testosterone into other active steroid hormones, which then exert their effects via estrogenic mechanisms or the direct modulation of neurotransmission.

\section{Hippocampal Neurogenesis and Estrogens}


There is convincing evidence that estrogens are important players in the regulation of adult hippocampal neurogenesis (Galea et al., 2013; Pawluski et al., 2009). Below, we will review studies that have investigated the influence of endogenous fluctuations and exogenous manipulations of estrogens on neurogenesis within the dentate gyrus (summarized in Figure 3). We will discuss potential implications for affective and cognitive function, and in turn depression and dementia. Finally, we highlight potential cellular and molecular mechanisms that may underlie the effects of estrogens on neurogenesis and identify areas that necessitate further investigation.

\section{Estrogen classes and estrogen signalling in the CNS: a brief overview}

Estradiol, estrone, and estriol are the major naturally occurring estrogens. Estradiol exists in two optical isomers, $17 \beta$-estradiol and $17 \alpha$-estradiol, with $17 \beta$-estradiol being the more potent of the two (Shappell et al., 2010). In premenopausal women, estradiol, the most potent of the three major estrogens, is also the most abundant (Rannevik et al., 1986). After the menopausal transition, and while all circulating estrogens decline, the ratio of estrone to estradiol is gradually reversed and estrone becomes the more abundant estrogen (Rannevik et al., 1986). Estrogen signalling in the CNS is highly complex (Toran-Allerand, 2004), however, the actions of estrogens can be roughly categorized into genomic and non-genomic mechanisms. Estrogens can bind with estrogen receptors (ERs), $\mathrm{ER} \alpha$ or $\mathrm{ER} \beta$, which are typically located in the cytoplasm or nucleus. The bound receptors act as transcription factors to regulate gene expression; they form homo or heterodimers that translocate to the nucleus and bind to estrogen response elements (EREs) located in the promoter regions of target genes. However, approximately one third of genes regulated by ERs do not include estrogen response element sequences (O'Lone et al., 2004), therefore it is becoming increasingly clear that bound ERs can regulate gene expression through other mechanisms, such as via protein-protein interactions with other transcription factors and their respective response elements (Björnström and Sjöberg, 2005). On the other hand, rapid, non-genomic effects are mediated through membrane associated ERs, such as the Gprotein coupled estrogen receptor (GPER) (Olde and Leeb-Lundberg, 2009; Revankar et al., 2005; Thomas et al., 2005). While the terms genomic and non-genomic are used it is also important to note that even non-genomic signalling pathways can result in gene transcription indirectly through downstream cascades, and these genes may differ from those directly activated through EREs (Marino et al., 2006). The hippocampus contains ER- $\alpha$, ER- $\beta$ and GPER 
receptors (Shima et al., 2003; Shughrue et al., 1997). Intracellular ERs are located in the CA1, CA3, and the dentate gyrus in males and females, while GPER is most dense in the CA3 region in female rats (Duarte-Guterman et al., 2015a; Loy et al., 1988; Maggi et al., 1989). ERs are regulated by age, hormone exposure and reproductive experience (M. Jin et al., 2005; Pawluski et al., 2010), but while there is less work done on GPER, GPER expression is reduced by estradiol in the GCL, but not in the CA1 and CA3 regions in females (Duarte-Guterman et al., 2015a).

\section{Endogenous fluctuations in ovarian hormones influence hippocampal neurogenesis}

Females exhibit natural fluctuations in ovarian hormones across the lifespan; this is evident across the menstrual and estrous cycles, in women and rodents respectively, but also in relation to reproductive events, and in the transition to reproductive senescence (Butcher et al., 1974; Rannevik et al., 1986; Rosenblatt et al., 1988; Sherman and Korenman, 1975; Yoshinaga et al., 1969). It is also important to note that menstrual cycle and estrous cycle fluctuations in hormones can differ dramatically with age (Klein et al., 1996) and parity (Barrett et al., 2014).

\section{Estrous cycle and breeding seasons}

The rodent estrous cycle follows a 4-5 day periodicity and is divided into four phases; metestrus, diestrus, proestrus, and estrus. The cycle is characterized by distinct fluctuations in ovarian hormones, in which estradiol and progesterone peak during proestrus then fall sharply following ovulation and remain low during other phases of the estrous cycle (Butcher et al., 1974). These fluctuations in ovarian hormone milieu are transient and are accompanied by changes in the levels of cell proliferation within the subgranular zone (Rummel et al., 2010; Tanapat et al., 1999; Tzeng et al., 2014). In both rats and mice, highest levels of cell proliferation occur in proestrous females relative to estrous and diestrous controls (Lagace et al., 2007; Rummel et al., 2010; Tanapat et al., 1999; Tzeng et al., 2014), reaching levels 50\% higher than during diestrus (Tanapat et al., 1999). In comparison to the estrous phase, the survival of new neurons generated during proestrus is increased at 14 but not 22 days (Tanapat et al., 1999), suggesting that the upregulation of cell proliferation during proestrus results in a transient increase in the survival of these new neurons. Some studies have failed to find a significant effect of estrous cycle phase on cell proliferation in rodents (Lagace et al., 2007), but it should be noted that estradiol levels during the estrous cycle can change rapidly over the course of a few hours, and thus some studies 
may miss the peak of estradiol levels. Thus, it appears that the effects of endogenous fluctuations of ovarian hormones are primarily on cell proliferation rather than an independent effect on the survival of these new neurons.

Female meadow voles, on the other hand, are seasonal breeders and induced ovulators, in which circulating estradiol levels are high during the breeding season and low during the nonbreeding season (Sawrey and Dewsbury, 1985). As such, they exhibit a different profile of endogenous hormone fluctuations than mice and rats. Seasonal differences are also evidenced in cell proliferation levels within the dentate gyrus, in which female meadow voles captured during the non-breeding season had higher levels of cell proliferation relative to those captured during the breeding season (Galea and McEwan, 1999). In the same study, plasma levels of estradiol were negatively correlated with cell proliferation levels (Galea and McEwan, 1999). Although seemingly contradictory to the studies discussed above indicating increased cell proliferation during periods of higher estradiol in rats and mice, additional work clarified that the effects of estradiol on cell proliferation are time-dependent (Ormerod et al., 2003), and this will be discussed below.

Although beyond the emphasis of the current review, it is important to note that besides neurogenesis, substantial plasticity has been detected in the hippocampus driven by estrous cyclicity. For example, an approximately 30\% difference in the density of hippocampal synapses is observed between the estrous and proestrous phases in rats, with estradiol levels being positively correlated to synaptic density (Woolley and McEwen, 1992). In addition, there is increased excitability in the CA1 and CA3 regions of the hippocampus during phases of the estrous cycle that are characterized by highest estradiol levels (Scharfman et al., 2003). Estrous cycle phase also influences long-term potentiation (LTP) in the CA1 region of the hippocampus, as evidenced by significantly greater potentiation during proestrus (Warren et al., 1995), although this is dependent on time of day (Sabaliauskas et al., 2015). Contrary to the idea that greater LTP would be correlated with better learning, proestrus is correlated with impaired spatial learning (Tada et al., 2015; Warren et al., 1995), again dependent on time of day (Sabaliauskas et al., 2015). Furthermore, inhibitory avoidance task conditioning failed to drive LTP during proestrus in rats (Tada et al., 2015). Taken together, the evidence suggests that proestrus is associated with structural and functional adaptations in the hippocampus of female 
rodents, including enhanced excitability and potentiation, and increased synaptic density and cell proliferation.

\section{Ageing and the effects of exogenous estrogen manipulations}

In ageing female rats, the estrous cycle becomes irregular and prolonged, with most rats eventually reaching an acyclic stage of persistent-diestrus (LeFevre and McClintock, 1988). Although adult neurogenesis persists throughout the lifespan, ageing is accompanied by a decrease in cell proliferation levels (Driscoll et al., 2006; Kuhn et al., 1996; Nacher et al., 2003). In female rats, this decline begins at middle age but plateaus thereafter, as levels of cell proliferation do not significantly differ between middle aged and old female rats (Driscoll et al., 2006; Kuhn et al., 1996; Nacher et al., 2003). Likewise, the survival of newly generated neurons also declines in ageing female rats (Kuhn et al., 1996; Merrill et al., 2003). This age-related decline in neurogenesis may be in part related to the natural reductions in ovarian hormone levels.

Most studies have used ovariectomized rats to model menopause in women, and to study the effects of hormone treatment on neurogenesis in older age. In a study using 12-month-old nulliparous (i.e. never pregnant) ovariectomized rats, a single dose of estradiol, given one week after ovariectomy, was not effective in increasing cell proliferation (Barha and Galea, 2011). On the other hand, cell proliferation was increased in 22-month-old nulliparous rats that were ovariectomized at 10 months of age, following 10 weeks of estradiol treatment or of supplementation with the phytoestrogen-rich soybean extract (Perez-Martin et al., 2005). Together, these findings indicate that progenitor cells in the ageing female hippocampus may become less responsive to the acute effects of estradiol, but retain a level of responsiveness to chronic estradiol treatment. Thus, it appears that the ability of estradiol to influence neurogenesis is altered across the lifespan. The mechanism behind this altered plasticity potential is yet to be elucidated, but it may relate to changes in receptor levels, or alterations that are downstream of receptor activation.

\section{Ovarian hormone depletion and replacement influence hippocampal neurogenesis}

\section{Hormone depletion and acute replacement}


Additional evidence for the role of estrogens in neurogenesis is derived from studies of exogenous hormone manipulation in adult ovariectomized animals. Following the removal of the ovaries, serum levels of estradiol plummet within twenty-four hours (Woolley and McEwen, 1993). Short-term ovariectomy (6-7 days) reduces cell proliferation (Tanapat et al., 1999), but long-term ovariectomy (3-4 weeks) does not influence cell proliferation in rats or mice (Green and Galea, 2008; Lagace et al., 2007; Tanapat et al., 2005). This points to the existence of some unknown mechanism that restores cell proliferation levels after longer periods of ovariectomy. De novo, or local, synthesis of estrogens may be one mechanism, but we feel that it is an unlikely mechanism given that plasma and hippocampal estradiol levels correlate during the estrous cycle in female rodents (Kato et al, 2013). Furthermore, because steroid hormones are lipophilic and hydrophobic, the better comparison to demonstrate significant de novo synthesis of estradiol in the hippocampus would be to show significant levels of estradiol post-ovariectomy in the hippocampus. Indeed, studies indicated that estradiol within the hippocampus was undetectable or very low when examined 2-3 weeks post-ovariectomy in adult rat and mice (Barker and Galea, 2009; Fester et al., 2012; Kato et al., 2013). However, because estrogens have stimulatory effects on the HPA axis (Goel et al., 2014), and corticosterone can reduce cell proliferation (Brummelte and Galea, 2010), it is possible that reduced circulating levels of corticosterone following long-term ovariectomy may play a role in the return of cell proliferation to preovariectomy levels. Further, a transient decrease in serotonin turn-over is observed in the hippocampus following ovariectomy (J. Zhang et al., 1999), coinciding with the transient decrease in neurogenesis. As will be discussed below, this indicates that the normalization of neurogenesis after longer periods of ovariectomy may be related to a normalization of serotonin turnover.

In young adult female rats, acute estradiol replacement after short-term ovariectomy (1 week) restores cell proliferation to levels of sham controls, and this effect is dose dependent and non-linear (Barha et al., 2009; Tanapat et al., 2005). For example, a single injection of $0.3 \mu \mathrm{g}$ (Barha et al., 2009) or $10 \mu \mathrm{g}$ (Barha et al., 2009; Tanapat et al., 2005; 1999) of estradiol restores the ovariectomy-induced reduction in cell proliferation, while doses of $1 \mu \mathrm{g}$ (Barha et al., 2009; Tanapat et al., 2005) or $50 \mu \mathrm{g}$ (Tanapat et al., 2005) are ineffective at restoring cell proliferation levels. Below we will provide evidence indicating that the duration of hormone exposure is an important determinant of estradiol's effects on cell proliferation. In these studies, Tanapat and 
colleagues administered 17 $\beta$-estradiol two hours prior to BrdU, and perfused the animals two hours after BrdU. Barha and colleagues, on the other hand, administered 17 $\beta$-estradiol treatment either 30 minutes or 4 hours before BrdU, and perfused the animals 24 hours later. Importantly, the $0.3 \mu \mathrm{g}$ and $10 \mu \mathrm{g}$ doses of estradiol are physiologically relevant as they result in circulating levels comparable to diestrus and proestrus, respectively (Sohrabji et al., 1994; Viau and Meaney, 1991). The same acute dose of $10 \mu \mathrm{g}$ estradiol fails to rescue cell proliferation levels 4 weeks post-ovariectomy (Tanapat et al., 2005), indicating that progenitor cells in the hippocampus may become less sensitive to the effects of estradiol after a longer duration of ovarian hormone deprivation.

The duration of hormone exposure is also critical as it affects the outcome of estrogen exposure on cell proliferation in the dentate gyrus of female rodents (Ormerod et al., 2003). Indeed, acute administration of estradiol benzoate in female meadow voles results in an initial enhancement of cell proliferation at 4 hours post-administration, followed by a suppression in cell proliferation at 48 hours post-administration (Ormerod et al., 2003). This estradiol-induced suppression of cell proliferation was mediated by the stimulatory effects of estradiol on adrenal steroids as it was shown to be reversed by adrenalectomy (Ormerod et al., 2003).

Relatively less is known about the effects of other estrogens on adult hippocampal neurogenesis. However, in female rats, cell proliferation levels were increased 30 minutes following the administration of $17 \beta$-estradiol, estrone, and $17 \alpha$-estradiol, but not estradiol benzoate, all administered one week post-ovariectomy (Barha et al., 2009), and this relates to the faster metabolization of estradiol in comparison to the slower acting estradiol benzoate. These effects were dose-dependent, all with a similar pattern in which low and high, but not moderate doses, resulted in an upregulation in cell proliferation (Barha et al., 2009). In the same study, the hormone treatments had no significant effect of cell proliferation at 4 hours post-administration (Barha et al., 2009), thus further emphasizing importance of exposure duration and the injection of a DNA synthesis marker relative to treatment see (Taupin, 2007).

\section{Hormone depletion and chronic replacement:}

The literature on the effects of chronic estrogen replacement on hippocampal neurogenesis is much less extensive and perhaps more complex than that of acute estrogen replacement. Most studies show that chronic estradiol exposure in female rats does not affect cell 
proliferation, as seen with 21 days of treatment using continuous release pellets, injections or a cyclical regimen of injections every 4 days for 20 days, all of which were initiated approximately one week post-ovariectomy (Chan et al., 2014; Tanapat et al., 2005). On the other hand, 15 days of continuous estradiol benzoate injections, administered starting one week after ovariectomy, increased cell proliferation in female rats (Barker and Galea, 2008). Given the critical role of hormone exposure duration discussed above, the dissimilar findings may be attributed to the timeline of estradiol exposure relative to the examination of cell proliferation, or to methodological differences relating to the length of estradiol exposure (continuous vs. cyclic). It is also possible that these differences may have arisen from differential ER (including GPER) adaptation from cyclical versus continuous exposure to estrogens (Brown et al., 1996).

The effect of chronic estradiol replacement on the survival of new neurons in ovariectomized female rats depends on the timing of estradiol exposure relative to that of cell proliferation. Specifically, the survival of new neurons is enhanced in cell populations that are produced after the initiation of estradiol treatment (McClure et al., 2013), but is suppressed in cell populations that are produced prior to the initiation of estradiol treatment (Barker and Galea, 2008; Chan et al., 2014). In other words, the hormone-related environment during which the cells are generated determines the outcome of chronic estradiol treatment on cell survival. Given that the effects of estradiol to enhance cell survival are only seen when the labeled cells are produced in an estradiol-enriched environment, this effect is probably attributed to the estradiol-induced upregulation of cell proliferation. However, this pattern does not necessarily apply to all forms of estrogens. For example, the survival of new neurons generated in an estrone-enriched environment is decreased, thus, a hormone-enriched environment is not necessarily conducive to the survival of newly generated neurons. For example, in female rats, although a single dose of $10 \mu \mathrm{g}$ of estrone increased cell proliferation (Barha et al., 2009), 20 days of treatment with the same dose reduced the survival of new neurons generated after the initiation of estrone replacement (McClure et al., 2013). Intriguingly, experience affects the ability of estrogens to alter neurogenesis and spine density in the CA1 region. The estrone-based hormone replacement therapy Premarin increased the survival of new neurons in spatially trained female rats but not in cage controls (Barha and Galea, 2013), although the authors acknowledge that this effect may have been due to food deprivation. An additional example in which spatial training can interact with hippocampal plasticity comes from a study in which spatial training eliminated the effects 
of estradiol to increase CA1 spine density that is observed in behaviorally-naïve female rats (Frick et al., 2004).

\section{Progestins influence adult hippocampal neurogenesis}

Estrogens and progesterone naturally fluctuate across the estrous and menstrual cycles, and have a dynamic relationship in the CNS and the periphery (Mani and Blaustein, 2012). Thus, it is important to study the influence of progesterone on neurogenesis, both in isolation and in unison with estrogens. Although limited, the existing literature suggests that progesterone can modulate the effects of estradiol to influence neurogenesis in the hippocampus of adult female rats (Tanapat et al., 2005). Indeed, a single dose of progesterone given 24 hours after estradiol administration decreased the estradiol-induced enhancement of cell proliferation (Tanapat et al., 2005). Therefore, progesterone may antagonize the effects of estradiol on cell proliferation. It remains unknown, however, if this relationship is time- or sex-dependent. In adult ovariectomized female rats, chronic progesterone and estradiol benzoate, starting one week postovariectomy, had no significant effect on cell proliferation when given alone or on combination, but decreased the survival of new neurons that were administered BrdU prior to hormone treatment (Chan et al. 2014). Thus, the interaction of progesterone and estradiol to affect neurogenesis may differ from acute (Tanapat et al., 2005) to chronic (Chan et al., 2014) administration. Progesterone treatment for 7 days increased cell proliferation in adult male rats (Barha et al., 2011), and in vitro, progesterone dose-dependently enhanced cell proliferation in neural progenitor cell cultures derived from adult rat dentate gyrus (Liu et al., 2009), although the sex of the rats was not disclosed in the latter study. Furthermore in two models of CNS injury - cerebral ischemia and traumatic brain injury (TBI), progesterone suppressed the injury-induced enhancement of cell proliferation (Barha et al., 2011; Zhang et al., 2010), enhanced the ischemiasuppression of the survival of new neurons (Zhang et al., 2010), and reduced the injury-induced cell death in adult males (Barha et al., 2011). Collectively, these findings indicate that progesterone normalizes the injury-induced alterations in neurogenesis in male rodents. However, it is important to note that these studies were conducted in male subjects, thus it is not certain that the same findings will be observed in females. Sex differences in the effects of progesterone are important to investigate, especially given that the efficacy of progesterone for acute traumatic brain injury may differ by sex, where men may have more favorable outcomes than women (Wright et al., 2014). 


\section{Reproductive experiences influence hippocampal neurogenesis}

\section{Pregnancy and the postpartum period}

Pregnancy and the postpartum period are accompanied by dramatic changes in steroid and peptide hormones, and with behavioural changes that are necessary for offspring survival (Kinsley and Lambert, 2008). In rodents, early pregnancy is characterized by low levels of estradiol and high levels of progesterone, and this pattern is reversed towards the end of pregnancy wherein progesterone levels decline and estradiol levels rapidly increase (Garland et al., 1987; Rosenblatt et al., 1988). At parturition, estradiol levels drop abruptly and remain low during the postpartum period (Bloch et al., 2003a). Not surprisingly, the maternal brain undergoes numerous structural and functional changes, including gross neuroplastic changes such as reduced hippocampal volume in rats (Galea et al., 2000), and a transient reduction in overall brain volume in women (Oatridge et al., 2002). In addition, changes in dendritic morphology and spine densities in the CA1 and CA3 regions are detected with primiparous (pregnant once) rats exhibiting reductions compared to nulliparous and multiparous (pregnant more than once) rats (Pawluski and Galea, 2006).

Cell proliferation within the dentate gyrus is not significantly affected during gestation, as examined in early gestation, on gestation day 1 (GD1) (Pawluski et al., 2010), GD7 (Shingo et al., 2003) or late gestation (GD21) (Furuta and Bridges, 2005). However, expression of polysialylated neuronal cell adhesion molecule (PSA-NCAM), which is expressed on newly generated and migrating neurons, is increased in mid-late gestation (gestation day 18), suggesting a potential enhancement of neurogenesis in mid-late gestation (Banasr et al., 2001). Other reports suggest that the survival of new neurons produced in early gestation (GD1) is not significantly affected across gestation in rats (Pawluski et al., 2010). On the other hand, neurogenesis was suppressed in pregnant mice during mid- and late-gestation, but this suppression was transient as it normalized by postpartum day 21 (Rolls et al., 2008). Taken together, these findings suggest that while cell proliferation is not affected, the survival of new neurons may be altered during mid pregnancy (after GD7), but is normalized by late pregnancy (GD21).

More robust alterations in hippocampal neurogenesis are evidenced during the postpartum period. In rats, several studies demonstrate reduced cell proliferation in early 
postpartum in primiparous and biparous dams (Darnaudéry et al., 2007; Leuner et al., 2007a; Pawluski and Galea, 2007). Leuner and colleagues found that in comparison to nulliparous females in diestrus, cell proliferation is suppressed in primiparous females during the early postpartum period (PPD 2 and 8), but not following weaning (PPD 28; see reviews by Leuner and Sabihi (2016) and Slattery and Hillerer (2016) in this issue). This postpartum-related reduction in cell proliferation was prevented by the removal of pups, or by adrenalectomy with low-dose corticosterone replacement, suggesting that this suppression may be attributed to elevations in adrenal steroids related to maternal experience and lactation (Leuner et al., 2007a). This is in partial agreement with a study from our group, in which cell proliferation was decreased in primiparous and multiparous rats in the early postpartum (postpartum day; PD 2), compared to nulliparous controls (Pawluski and Galea, 2007). Interestingly, primiparous rats had decreased 21-day survival of BrdU-labeled cell the postpartum period (PD 22), regardless of pup-exposure, in comparison with nulliparous and multiparous groups (Pawluski and Galea, 2007). Further, in nulliparous rats exposed to pups, cell proliferation, cell survival, and cell death were all increased in comparison to parous rats and nulliparous rats not exposed to pups, indicating that pup exposure differentially influenced neurogenesis with parity (Pawluski and Galea, 2007). Another study reported decreased expression of doublecortin in the dentate gyrus of primiparous rats on PPD 21, relative to nulliparous controls (Workman et al., 2015), also indicating a reduction in neurogenesis in the later postpartum period. The contrasting effects of pup exposure between these studies may be attributed to methodological differences relating to the timing of pup removal, the timeline of BrdU administration and perfusion, or a combination of these factors. Specifically, Leuner and colleagues removed pups shortly after birth on PD0, administered BrdU on PD3, and perfused the animals 2 hours later (Leuner et al., 2007b). On the other hand, Pawluski and colleagues administered BrdU on PD1, removed pups 24 hours later, and perfused the animals on PD22 (Pawluski and Galea, 2007). Thus, in the Leuner et al study, new cells produced after pup removal would have been labelled with BrdU, while in the Pawluski and Galea study, new cells produced prior to pup removal would have been labelled with BrdU. With that design, the Pawluski and Galea experiment tested the effects of pup removal (pregnancy only) on the survival of new cells independent of effects on proliferation, while the Leuner and colleagues examined the effect of pup removal on cell proliferation. In addition, Pawluski and Galea examined the influence of pup removal on the survival of new neurons later in the postpartum period (PPD22), while the Leuner et al study examined cell 
proliferation three days after pup removal in early postpartum (PPD3). It is therefore not surprising that the effects of pup removal vary in the two studies, considering that different aspects of neurogenesis were examined (proliferation versus survival), and during different times in the postpartum period (earlier versus later).

In addition, estradiol withdrawal after a hormone simulated pregnancy in rats resulted in suppressed cell proliferation (Green and Galea, 2008). This mirrors what is seen naturally in the postpartum period, and suggests that the drop in estradiol following parturition may play a key role in the postpartum-related changes in cell proliferation. Indeed, treatment with a selective ER $\beta$ agonist during the simulated postpartum period rescued the suppression in cell proliferation (Green and Galea, 2008). Collectively, these studies provide incontrovertible evidence for the influence of pregnancy-related fluctuations in ovarian hormones on hippocampal neurogenesis.

\section{Partiy, Aging, and Neurogenesis}

Previous pregnancy and motherhood also affect the trajectory by which additional pregnancies influence hippocampal neurogenesis (Barha et al., 2015; Pawluski and Galea, 2007). While both primiparous and multiparous females show reduced cell proliferation in the early postpartum (PPD2) in comparison to nulliparous females, the survival of new neurons during the postpartum period was modulated by previous reproductive experience (Pawluski and Galea, 2007). Specifically, cell survival was suppressed in primiparous but not multiparous females in the postpartum, relative to nulliparous controls, and this effect was independent of exposure to pups (Pawluski and Galea, 2007). Interestingly, multiparous middle-aged rats had a greater density of immature neurons in the dentate gyrus than age-matched nulliparous rats (Barha et al., 2015). Thus, previous reproductive experiences have long lasting effects on hippocampal plasticity, and these studies underscore the need for considering the of role previous reproductive experience on the subsequent effects of sex hormones to influence hippocampal plasticity.

\section{Estrogens and Neurogenesis: Potential Implications for Cognitive Function}

Male rats outperform female rats in spatial acquisition, and coupled with this, male, but not female, rats show increased survival of new neurons after spatial training (Chow et al., 2013). Interestingly, the activation of newly generated neurons in the dorsal dentate gyrus in response to spatial memory retrieval was positively correlated with performance in females but not males 
(Chow et al., 2013). Similar findings were obtained from a study using a spatial pattern separation task previously shown to require hippocampal neurogenesis (Clelland et al., 2009), in which sex differences favouring males were found in spatial strategy users. Male spatial strategy users outperformed female spatial strategy users in separating similar (adjacent) patterns, and had greater neurogenesis levels compared to female spatial strategy users (Yagi et al., 2015). Interestingly, the survival of new neurons was positively correlated with the ability to separate similar patterns in female but not male rats (Yagi et al., 2015). Not all tasks show male superiority in performance; in a study using the hippocampus- and cerebellum-dependent trace eyeblink conditioning task, sex differences in conditioning favouring females was found, and this superior performance in females was accompanied by increased survival of new neurons relative to males (Dalla et al., 2009). These sex differences in the relationship between learning and neurogenesis point to a highly probable role of gonadal hormones, but to our knowledge a direct relationship is yet to be investigated. Collectively, it is clear that sex can modulate the relationship between learning and neurogenesis, dependent on the type of task.

Estrogens modulate both neurogenesis and learning and memory. An extensive review of the literature on estrogens modulation of learning is beyond the scope of this review, but the readers are directed to other reviews (Duarte-Guterman et al., 2015b; Frick et al., 2015; Korol and Pisani, 2015; Tuscher et al., 2015; Ervin et al., 2015). However, the estrone-based Premarin increased survival of new neurons but impaired both spatial working and reference memory in the spatial radial arm maze (Barha and Galea, 2013). The activation of new neurons in response to spatial memory retrieval was reduced in the lower dose of Premarin (1 ug) but not in the higher dose (2ug) used (Barha and Galea, 2013). Further, activation of new neurons was associated with poorer acquisition in the radial arm maze in Premarin-treated rats indicating that new neurons surviving under Premarin-rich conditions did not contribute to spatial memory and were associated with decrements in performance (Barha and Galea, 2013), perhaps indicating that these new neurons did not make appropriate connections within the CA3. Another study showed similar findings, in which activation of new neurons produced and surviving under estrone-rich conditions were not associated with spatial memory retrieval, while activation of new neurons produced under estradiol-rich conditions tended to be associated with enhanced spatial memory retrieval (McClure et al., 2013). Together, these studies indicate that while estrogens influence neurogenesis and cognition, there is not a direct association with number of 
new neurons or number of activated new neurons. Importantly, new neurons may not always make appropriate connections, and thus studies in the future should be directed towards investigating the targets of new neurons surviving and created under estrogens.

\section{Estrogens and Neurogenesis: Potential implications for mood regulation}

There is an abundance of literature, preclinical and clinical, indicating an intimate link between ovarian hormones and mood regulation (Steiner et al., 2003). Besides the robust sex difference in the incidence of depression favouring women, windows of heightened vulnerability to depression in women are characterized by dramatic fluctuations or sustained reductions in ovarian steroids (Cohen et al., 2006; Hendrick et al., 1998). Namely, in women, times of greatest vulnerability to develop depression are in the postpartum period, in which women are hypogonadal after experiencing sustained extreme levels of estrogens and progesterone (Hendrick et al., 1998), and in the transition to menopause (Freeman et al., 2006), which is characterised by more dramatic fluctuations in ovarian hormones preceding a persistent hypogonadal state. Rodent studies of ovariectomy demonstrate increased depressive like behaviour that is reversed by estradiol replacement (Bekku and Yoshimura, 2005). In addition, withdrawal from a hormone-simulated pregnancy resulted in increased depressive-like behaviour (Craft et al., 2010; Galea et al., 2001; Suda et al., 2008), which is reversed by estradiol treatment (Galea et al., 2001; Green and Galea, 2008). These behavioural phenotypes in animal models are also accompanied by reductions in neurogenesis (Green and Galea, 2008). Importantly, the implications of altered neurogenesis on mood regulation in these models are uncertain.

As we discuss earlier, the reduction in hippocampal volume in individuals with depression is more profound in men than women (Frodl et al., 2002; Vakili et al., 2000), and is detected only in children and middle aged to older individuals (McKinnon et al., 2009). Together these findings indicate that ovarian hormones, particularly during the reproductive years, may protect the female hippocampus from depression-related reductions in volume. Interestingly, chronic antidepressant treatment was associated with an increased hippocampal volume in women experiencing an alleviation of depression symptoms relative to non-responders, but the same effect was not seen in men (Vakili et al., 2000). Although studies investigating hippocampal volume changes in depression do not provide direct evidence for alterations in neurogenesis, there is evidence from post-mortem studies that age and sex, and thus likely sex 
hormones, are implicated in antidepressant effects on hippocampal neurogenesis (Epp et al., 2013a; Lucassen et al., 2010). Specifically, chronic antidepressant treatment increased the ratio of immature to mature neurons in depressed women but not men (Epp et al., 2013a), and the proneurogenic effects of antidepressants were not detected in older depressed individuals (Epp et al., 2013a; Lucassen et al., 2010). Together, these data indicate that sex hormones, and particularly ovarian hormones in women, may facilitate the pro-neurogenic effects of antidepressants. The specific role of sex hormones in this respect, and the implications for antidepressant efficacy, are two avenues that necessitate future investigation.

\section{Potential mechanisms for the influence of estrogens on adult hippocampal neurogenesis}

Estrogens have extremely diverse effects in the central nervous system (McEwen et al., 2012; McEwen and Alves, 1999), and the downstream signalling cascades that drive the effects of estrogens on neurogenesis in the hippocampus are largely unknown. In the following section we discuss potential mechanism that may underlie the effects of estrogens on neurogenesis in the hippocampus, and consider functional implications when appropriate. Importantly, we acknowledge that direct evidence for a mediating role of these mechanisms is scarce, and thus this section largely serves to highlight potentially mechanisms and to identify areas for future investigation.

\section{Receptor mechanisms underlying the influence of estrogens on neurogenesis}

Given the complexity of estrogen signalling, the mechanisms by which estrogens influence adult hippocampal neurogenesis have not been fully deciphered. However, the effects of estradiol on cell proliferation in the dentate gyrus appear to be at least partially mediated through ER $\alpha$ and ER $\beta$ (Mazzucco et al., 2006). In adult ovariectomized female rats, treatment with the ER $\alpha-$ selective agonist propylpyrazole-triol (PPT), or the ER $\beta$-selective agonist diarylpropionitrile (DPN) increased cell proliferation, suggesting that both nuclear estrogen receptors participate in the pro-proliferative effects of estradiol (Mazzucco et al., 2006). To further support the role of estrogen receptors, the estrogen receptor antagonist ICI 182,780 was shown to reverse the estradiol-induced upregulation of cell proliferation (Nagy et al., 2006). In addition, because both intracellular ERs colocalize with progenitor cells in subgranular zone of the dentate gyrus, albeit at low levels (Mazzucco et al., 2006), it is likely that estrogens can upregulate cell proliferation through direct interactions with intracellular ERs in progenitor cells (see figure 5). Interestingly, 
treatment with the GPER agonist (G1) decreased cell proliferating in adult ovariectomized rats (Duarte-Guterman et al., 2015a), indicating an estradiol-independent role of GPER in hippocampal neurogenesis, or alternatively an antagonistic effect of intracellular and membrane bound ER activation to maintain levels of neurogenesis. Lastly, unlike intracellular ERs, GPER did not co-localize with progenitor cells in the subgranular zone of the dentate gyrus (DuarteGuterman et al., 2015a), indicating that the effects of GPER activation on neurogenesis may be indirect.

\section{Immunoregulation: a potential role of microglia}

There is a growing awareness that neuroinflammatory processes are involved in the regulation of adult hippocampal neurogenesis (Ekdahl et al., 2009). Neuroinflammation is a complex response, however microglia, the resident immune cells of the brain, are the primary mediators of neuroinflammation. The first studies investigating the effects of inflammation on neurogenesis utilized the bacterial endotoxin lipopolysaccharide (LPS), which activates microglia and induces an inflammatory response (Kloss et al., 2001). Intracortical or systemic administration of LPS suppressed the survival of BrdU-labeled cells, but had no significant effect on cell proliferation in male rats (Ekdahl et al., 2003). Further, treatment with the microglial inhibitor minocycline prevented the suppression in the survival of new neurons (Ekdahl et al., 2003), supporting a direct role for microglia in the effects of neuroinflammation on neurogenesis. Importantly, the role of microglia in neurogenesis is not limited to pathological contexts. Indeed, ramified microglia support basal neurogenesis in the healthy hippocampus of mice (Sierra et al., 2010). A large proportion of newly generated cells in the hippocampus do not survive to maturity (Cameron and McKay, 2001), where the majority of newly born cells undergo apoptosis within the first 1-4 days, and are rapidly phagocytosed by ramified microglia mice (Sierra et al., 2010).

The anti-inflammatory effects of estrogens in the brain are well documented in a variety of CNS disorders, including stroke and neurodegenerative diseases (Pozzi et al., 2006; Spence and Voskuhl, 2012; Vegeto et al., 2008). This is corroborated by in vitro studies demonstrating that estrogens are capable of significantly altering microglial function in primary rat microglial cultures or N9 microglia lines (Bruce-Keller et al., 2000; Vegeto et al., 2001). Specifically, estradiol is capable of suppressing microglial activation induced by LPS treatment, and this effect was blocked by ER antagonists, suggesting an ER-mediated mechanism for the anti- 
inflammatory effects of estradiol on microglia, however unfortunately the sex of the subjects was not specified (Vegeto et al., 2001). This literature is corroborated by in vivo studies showing that selective estrogen receptor modulators are capable of reducing LPS-induced microglial activation in male and female rats (Arevalo et al., 2011; DonCarlos et al., 2009).

Given the role of inflammation and microglia in neurogenesis, and the anti-inflammatory effects of estrogens, it is conceivable that the effects of estrogens on neurogenesis are in part afforded through the regulation of microglia-related inflammatory processes. That is to say, it is possible that an estrogen-deficient microenvironment may contribute to a failure of proper immunoregulation and in turn alterations in neurogenesis. To our knowledge, a direct link between estrogens and inflammation on neurogenesis has not been investigated.

Importantly, peripheral and central inflammation and microglial activation are evidenced in disorders of affective and cognitive function, in which sex hormones (Bloch et al., 2003b; Paganini-Hill and Henderson, 1994; Schmidt, 2005) and alterations in neurogenesis (Crews et al., 2010; Jin et al., 2004; Sahay and Hen, 2007), are also implicated. For example, neuroinflammation and microglial alterations are found in Alzheimer's Disease and other dementias (Dickson, 2001; Mackenzie, 2000; Wyss-Coray and Rogers, 2012). In addition, depression is accompanied by central and peripheral inflammation and increased microglial activation (Kaestner et al., 2005; Miller et al., 2009; Setiawan et al., 2015). Thus, the effects of estrogens on microglia-mediated inflammatory processes, and potentially neurogenesis, may have important implications for cognitive and affective functioning.

\section{Mediation of the serotonergic system}

There is strong evidence indicating a role for the serotonergic system in the regulation of adult hippocampal neurogenesis in males and females (Djavadian, 2004). The well-established proneurogenic effects of SSRI antidepressants represent one strong line of evidence for the role of serotonin (5-HT) (Malberg et al., 2000). Further, the depletion of serotonin via the inhibition of serotonin synthesis, or the ablation of serotonin neurons, decreased cell proliferation and the expression of PSA-NCAM in the dentate gyrus of female rats (Brezun and Daszuta, 1999a).

Estrogens have substantial effects on the serotonergic system, and those effects are most often stimulatory in females (Amin et al., 2005). For example, acute estradiol administration to 
ovariectomized rats increased serotonin turnover in several brain regions, as seen by increased 5HT and its metabolite 5HIAA (Johnson and Crowley, 1983; Morissette et al., 1990). Given this evidence, it is not surprising that effects of estrogens on serotonin may mediate estrogens' influence on neurogenesis. In fact, although the inhibition of serotonin synthesis decreased cell proliferation (Brezun and Daszuta, 1999a; 1999b), the ovariectomy-induced reductions in cell proliferation were not further affected by serotonin synthesis inhibition (Banasr et al., 2001), suggesting that the effects of ovariectomy on cell proliferation may be mediated, at least in part, through effects on serotonergic transmission. Indeed, stimulation of serotonin synthesis in ovariectomized rats restored levels of cell proliferation, but estradiol did not reverse cell proliferation reductions induced by 5-HT synthesis inhibition (Banasr et al., 2001). Thus, alterations in serotonergic transmission downstream of estradiol signalling may be involved in the regulation of hippocampal neurogenesis. Interestingly, the transient decrease in neurogenesis after ovariectomy coincides with a transient decrease in 5-HT turn-over in the hippocampus (Zhang et al., 1999), suggesting that the normalization of neurogenesis levels following longer periods of ovariectomy may be related to a normalization of 5-HT turnover in the hippocampus.

\section{Regulation of Neurotropic factors: a focus on BDNF}

Brain-derived neurotrophic factor (BDNF), is a member of the neurotrophin family; a group of small proteins involved in both the survival and function of neurons. Interestingly, estrogens and BDNF show remarkable interactions and parallel effects in the CNS, and this is particularly well described in the hippocampus (see Scharfman and MacLusky, 2006 for review). There is substantial evidence for a direct modulation of BDNF by estrogens, including the identification of an estrogen receptor element on the BDNF gene (Sohrabji et al., 1995). In addition, studies using estradiol replacement in ovariectomized rodents show that ovariectomy reduced BDNF mRNA and this is reversed by estradiol treatment (Cavus and Duman, 2003; Singh et al., 1995; Sohrabji et al., 1995). Because BDNF facilitates neurogenesis in the adult dentate gyrus in males (Lee et al., 2002; Scharfman et al., 2005; Waterhouse et al., 2012), it is conceivable that the effects of estrogens on adult hippocampal neurogenesis may be in part mediated through the modulation of BDNF. Finally, alterations in BDNF levels are implicated in men and women with Alzheimer’s disease (O'Bryant et al., 2009; Phillips et al., 1991) and in depression (Karege et al., 2005; B.-H. Lee and Kim, 2010; Shimizu et al., 2003); pathologies that, as we discussed earlier, are linked to reductions/fluctuations in ovarian hormones (Bloch et al., 2003b; Paganini-Hill and 
Henderson, 1994; Schmidt, 2005) and compromised neurogenesis (Crews et al., 2010; Jin et al., 2004; Sahay and Hen, 2007). However, there are also reported sex differences in the interactions between sex hormones and BDNF in the hippocampus (Harte-Hargrove et al., 2013), and as such we urge the research community to be aware of this possible difference in the relationship between sex hormones and BDNF.

\section{Conclusions}

The evidence we review here strongly indicates that sex hormones are powerful modulators of neurogenesis within the adult hippocampus of both males and females. We highlight that several factors are important to consider when assessing the influence of sex hormones on neurogenesis, and these including the timing of DNA synthesis marker and/or hormone manipulation, in addition to sex, age, and reproductive history. Sex as a factor is rarely studied in the literature, and to address this issue, funding agencies in Europe and North America are placing a focus on the inclusion of female subjects in all studies. These calls for inclusion of females in research have been met with enthusiasm (Klein et al., 2015; McCullough et al., 2014), scepticism, and calls for restraint (McCarthy et al., 2012; Richardson et al., 2015). However, the literature we review here strongly suggests that in the pursuit of enhancing our understanding of the functional significance of adult hippocampal neurogenesis in health and disease, it is vitally important to consider sex differences and the role of sex hormones. It is critical to understand, however, that the mere inclusion of both sexes in neurogenesis research is not sufficient. A careful understanding of variables that can modulate the effects of sex hormones on neurogenesis, such as age and reproductive history, is essential. Lastly, the mechanisms by which sex hormones may influence hippocampal neurogenesis are largely unknown, and we discuss potential targets for future investigation.

Acknowledgements LAMG is funded by operating grant support from the Natural Sciences and Engineering Research Council of Canada (NSERC- RG203596-13) and the Canadian Institutes for Health Research (CIHR MOP 102568, 142308) and previously from the Alzheimer Society of Canada (13-27). RM is funded by a University of British Columbia Scholarship. 
Abrous, D.N., Wojtowicz, J.M., 2015. Interaction between Neurogenesis and Hippocampal Memory System: New Vistas. Cold Spring Harb Perspect Biol 7, a018952. doi:10.1101/cshperspect.a018952

Ahmed, E.I., Zehr, J.L., Schulz, K.M., Lorenz, B.H., DonCarlos, L.L., Sisk, C.L., 2008. Pubertal hormones modulate the addition of new cells to sexually dimorphic brain regions. Nat Neurosci 11, 995-997.

Aikey JL, Nyby JG, Anmuth DM, James PJ (2002) Testosterone rapidly reduces anxiety in male house mice (Mus musculus). Hormones and behavior 42:448-460.

Akers, K.G., Martinez-Canabal, A., Restivo, L., Yiu, A.P., De Cristofaro, A., Hsiang, H.-L.L., Wheeler, A.L., Guskjolen, A., Niibori, Y., Shoji, H., Ohira, K., Richards, B.A., Miyakawa, T., Josselyn, S.A., Frankland, P.W., 2014. Hippocampal neurogenesis regulates forgetting during adulthood and infancy. Science 344, 598-602. doi:10.1126/science.1248903

Altman, J., 1962. Are new neurons formed in the brains of adult mammals? Science 135, 11271128.

Allen KM, Purves-Tyson TD, Fung SJ, Shannon Weickert C (2015) The effect of adolescent testosterone on hippocampal BDNF and TrkB mRNA expression: relationship with cell proliferation. BMC neuroscience 16:4.

Allen KM, Fung SJ, Rothmond DA, Noble PL, Weickert CS (2014) Gonadectomy increases neurogenesis in the male adolescent rhesus macaque hippocampus. Hippocampus 24:225238.

Alonso R, Griebel G, Pavone G, Stemmelin J, Le Fur G, Soubrie P (2004) Blockade of CRF(1) or $\mathrm{V}(1 \mathrm{~b})$ receptors reverses stress-induced suppression of neurogenesis in a mouse model of depression. Molecular psychiatry 9:278-286, 224.

Amin, Z., Canli, T., Epperson, C.N., 2005. Effect of estrogen-serotonin interactions on mood and cognition. Behav Cogn Neurosci Rev 4, 43-58. doi:10.1177/1534582305277152

Anacker C, Zunszain PA, Cattaneo A, Carvalho LA, Garabedian MJ, Thuret S, Price J, Pariante CM (2011) Antidepressants increase human hippocampal neurogenesis by activating the glucocorticoid receptor. Molecular psychiatry 16:738-750.

Angst, J., Gamma, A., Gastpar, M., Lépine, J.-P., Mendlewicz, J., Tylee, A., Depression Research in European Society Study, 2002. Gender differences in depression. Epidemiological findings from the European DEPRES I and II studies. Eur Arch Psychiatry Clin Neurosc 252, 201-209. doi:10.1007/s00406-002-0381-6

Arevalo, M.A., Diz-Chaves, Y., Santos-Galindo, M., Bellini, M.J., Garcia-Segura, L.M., 2011. Selective Oestrogen Receptor Modulators Decrease the Inflammatory Response of Glial Cells. J Neuroendocrinol 24, 183-190. doi:10.1111/j.1365-2826.2011.02156.x

Banasr M, Soumier A, Hery M, Mocaer E, Daszuta A (2006) Agomelatine, a new antidepressant, induces regional changes in hippocampal neurogenesis. Biological psychiatry 59:1087-1096.

Banasr, M., Hery, M., Brezun, J.M., Daszuta, A., 2001. Serotonin mediates oestrogen stimulation of cell proliferation in the adult dentate gyrus. Eur. J. Neurosci. 14, 1417-1424.

Barha, C.K., Galea, L.A.M., 2013. The hormone therapy, Premarin, impairs hippocampusdependent spatial learning and memory and reduces activation of new granule neurons in response to memory in female rats. Neurobiology of Aging 34, 986-1004. doi:10.1016/j.neurobiolaging.2012.07.009

Barha, C.K., Galea, L.A.M., 2011. Motherhood alters the cellular response to estrogens in the hippocampus later in life. Neurobiology of Aging 32, 2091-2095. 
doi:10.1016/j.neurobiolaging.2009.12.004

Barha, C.K., Ishrat, T., Epp, J.R., Galea, L.A.M., Stein, D.G., 2011. Progesterone treatment normalizes the levels of cell proliferation and cell death in the dentate gyrus of the hippocampus after traumatic brain injury. Exp. Neurol. 231, 72-81.

doi:10.1016/j.expneurol.2011.05.016

Barha, C.K., Lieblich, S.E., Chow, C., Galea, L.A.M., 2015. Multiparity-induced enhancement of hippocampal neurogenesis and spatial memory depends on ovarian hormone status in middle age. Neurobiology of Aging 36, 2391-2405.

doi:10.1016/j.neurobiolaging.2015.04.007

Barha, C.K., Lieblich, S.E., Galea, L.A.M., 2009. Different forms of oestrogen rapidly upregulate cell proliferation in the dentate gyrus of adult female rats. J Neuroendocrinol 21, 155-166. doi:10.1111/j.1365-2826.2008.01809.x

Barker, J.M., Galea, L.A.M., 2009. Sex and regional differences in estradiol content in the prefrontal cortex, amygdala and hippocampus of adult male and female rats. Gen. Comp. Endocrinol. 164, 77-84. doi:10.1016/j.ygcen.2009.05.008

Barker, J.M., Galea, L.A.M., 2008. Repeated estradiol administration alters different aspects of neurogenesis and cell death in the hippocampus of female, but not male, rats. Neuroscience 152, 888-902. doi:10.1016/j.neuroscience.2007.10.071

Barrett, E.S., Parlett, L.E., Windham, G.C., Swan, S.H., 2014. Differences in ovarian hormones in relation to parity and time since last birth. Fertil. Steril. 101, 1773-80.e1. doi:10.1016/j.fertnstert.2014.02.047

Baum, L.W., 2005. Sex, hormones, and Alzheimer's disease. J. Gerontol. A Biol. Sci. Med. Sci. 60, 736-743.

Bechstedt S, Lu K, Brouhard GJ (2014) Doublecortin recognizes the longitudinal curvature of the microtubule end and lattice. Current biology : CB 24:2366-2375.

Bennett NC, Gardiner RA, Hooper JD, Johnson DW, Gobe GC (2010) Molecular cell biology of androgen receptor signalling. The international journal of biochemistry \& cell biology 42:813-827.

Bessa JM, Ferreira D, Melo I, Marques F, Cerqueira JJ, Palha JA, Almeida OF, Sousa N (2009) The mood-improving actions of antidepressants do not depend on neurogenesis but are associated with neuronal remodeling. Molecular psychiatry 14:764-773, 739.

Bekku, N., Yoshimura, H., 2005. Animal model of menopausal depressive-like state in female mice: prolongation of immobility time in the forced swimming test following ovariectomy. Psychopharmacology (Berl.) 183, 300-307. doi:10.1007/s00213-005-0179-0

Björnström, L., Sjöberg, M., 2005. Mechanisms of estrogen receptor signaling: convergence of genomic and nongenomic actions on target genes. Mol. Endocrinol. 19, 833-842. doi:10.1210/me.2004-0486

Bloch, M., Daly, R.C., Rubinow, D.R., 2003a. Endocrine factors in the etiology of postpartum depression. Compr Psychiatry 44, 234-246. doi:10.1016/S0010-440X(03)00034-8

Bloch, M., Daly, R.C., Rubinow, D.R., 2003b. Endocrine factors in the etiology of postpartum depression. Compr Psychiatry 44, 234-246. doi:10.1016/S0010-440X(03)00034-8

Boldrini, M., Hen, R., Underwood, M.D., Rosoklija, G.B., Dwork, A.J., Mann, J.J., Arango, V., 2012. Hippocampal Angiogenesis and Progenitor Cell Proliferation Are Increased with Antidepressant Use in Major Depression. Biological Psychiatry 72, 562-571.

Boldrini M, Underwood MD, Hen R, Rosoklija GB, Dwork AJ, John Mann J, Arango V (2009) Antidepressants increase neural progenitor cells in the human hippocampus.

Neuropsychopharmacology. 34, 2376-2389. 
Boldrini M, Santiago AN, Hen R, Dwork AJ, Rosoklija GB, Tamir H, Arango V, John Mann J (2013) Hippocampal granule neuron number and dentate gyrus volume in antidepressanttreated and untreated major depression. Neuropsychopharmacology. 38:1068-1077.

Boldrini, M., Butt, T.H., Santiago, A.N., Tamir, H., Dwork, A.J., Rosoklija, G.B., Arango, V., Hen, R., Mann, J.J (2014) Benzodiazepines and the potential trophic effect of antidepressants on dentate gyrus cells in mood disorders. Int. J. Neuropsychopharmacol. 17, 1923-1933.

Bonfanti L. (2006) PSA-NCAM in mammalian structural plasticity and neurogenesis. Progress in neurobiology. 80, 129-164.

Brännvall K, Korhonen L, Lindholm D. (2002). Estrogen-receptor-dependent regulation of neural stem cell proliferation and differentiation. Molecular and Cellular Neuroscience 21, 512-520.

Brezun, J.M., Daszuta, A., 1999a. Serotonin depletion in the adult rat produces differential changes in highly polysialylated form of neural cell adhesion molecule and tenascin-C immunoreactivity. J. Neurosci. Res. 55, 54-70.

Brezun, J.M., Daszuta, A., 1999b. Depletion in serotonin decreases neurogenesis in the dentate gyrus and the subventricular zone of adult rats. Neuroscience 89, 999-1002.

Brown, J.P., Couillard-Despres, S., Cooper-Kuhn, C.M., Winkler, J., Aigner, L., Kuhn, H.G., 2003. Transient expression of doublecortin during adult neurogenesis. J. Comp. Neurol. 467, 1-10. doi:10.1002/cne.10874

Brown, T.J., Scherz, B., Hochberg, R.B., MacLusky, N.J. (1996) Regulation of estrogen receptor concentrations in the rat brain: effects of sustained androgen and estrogen exposure. Neuroendocrinology 63, 53-60.

Bruce-Keller, A.J., Keeling, J.L., Keller, J.N., Huang, F.F., Camondola, S., Mattson, M.P., 2000. Antiinflammatory effects of estrogen on microglial activation. Endocrinology 141, 36463656. doi:10.1210/endo.141.10.7693

Brummelte, S., Galea, L.A.M., 2010. Chronic high corticosterone reduces neurogenesis in the dentate gyrus of adult male and female rats. Neuroscience 168, 680-690. doi:10.1016/j.neuroscience.2010.04.023

Burgess, A., Wainwright, S.R., Shihabuddin, L.S., Rutishauser, U., Seki, T., Aubert, I., 2008. Polysialic acid regulates the clustering, migration, and neuronal differentiation of progenitor cells in the adult hippocampus. Dev Neurobiol 68, 1580-1590. doi:10.1002/dneu.20681

Butcher, R.L., Collins, W.E., Fugo, N.W., 1974. Plasma concentration of LH, FSH, prolactin, progesterone and estradiol-17beta throughout the 4-day estrous cycle of the rat. Endocrinology 94, 1704-1708. doi:10.1210/endo-94-6-1704

Butz, M., Lehmann, K., Dammasch, I.E., Teuchert-Noodt, G., 2006. A theoretical network model to analyse neurogenesis and synaptogenesis in the dentate gyrus. Neural Netw 19, 1490-1505. doi:10.1016/j.neunet.2006.07.007

Buddenberg TE, Komorowski M, Ruocco LA, Silva MA, Topic B (2009) Attenuating effects of testosterone on depressive-like behavior in the forced swim test in healthy male rats. Brain research bulletin 79:182-186.

Buwalda B, van der Borght K, Koolhaas JM, McEwen BS (2010) Testosterone decrease does not play a major role in the suppression of hippocampal cell proliferation following social defeat stress in rats. Physiology \& behavior 101:719-725.

Cameron, H.A., McKay, R.D., 2001. Adult neurogenesis produces a large pool of new granule cells in the dentate gyrus. J. Comp. Neurol. 435, 406-417.

Campbell, S., Macqueen, G., 2004. The role of the hippocampus in the pathophysiology of major depression. J Psychiatry Neurosci 29, 417-426. 
Carrier N, Kabbaj M (2012a) Extracellular signal-regulated kinase 2 signaling in the hippocampal dentate gyrus mediates the antidepressant effects of testosterone. Biological psychiatry 71:642-651.

Carrier N, Kabbaj M (2012b) Testosterone and imipramine have antidepressant effects in socially isolated male but not female rats. Hormones and behavior 61:678-685.

Carrier N, Saland SK, Duclot F, He H, Mercer R, Kabbaj M (2015) The Anxiolytic and Antidepressant-like Effects of Testosterone and Estrogen in Gonadectomized Male Rats. Biological psychiatry.

Cavus, I., Duman, R.S., 2003. Influence of estradiol, stress, and 5-HT2A agonist treatment on brain-derived neurotrophic factor expression in female rats. BPS 54, 59-69.

Chan, M., Chow, C., Hamson, D.K., Lieblich, S.E., Galea, L.A.M., 2014. Effects of chronic oestradiol, progesterone and medroxyprogesterone acetate on hippocampal neurogenesis and adrenal mass in adult female rats. J Neuroendocrinol 26, 386-399. doi:10.1111/jne.12159

Cherrier, M.M., Anderson, K., Shofer, J., Millard, S., Matsumoto, A.M., 2015. Testosterone treatment of men with mild cognitive impairment and low testosterone levels. Am J Alzheimers Dis Other Demen 30, 421-430. doi:10.1177/1533317514556874

Cherrier, M.M., Matsumoto, A.M., Amory, J.K., Asthana, S., Bremner, W., Peskind, E.R., Raskind, M.A., Craft, S., 2005. Testosterone improves spatial memory in men with Alzheimer disease and mild cognitive impairment. Neurology 64, 2063-2068. doi:10.1212/01.WNL.0000165995.98986.F1

Chow, C., Epp, J.R., Lieblich, S.E., Barha, C.K., Galea, L.A.M., 2013. Sex differences in neurogenesis and activation of new neurons in response to spatial learning and memory. Psychoneuroendocrinology 38, 1236-1250. doi:10.1016/j.psyneuen.2012.11.007

Clelland, C.D., Choi, M., Romberg, C., Clemenson, G.D., Fragniere, A., Tyers, P., Jessberger, S., Saksida, L.M., Barker, R.A., Gage, F.H., Bussey, T.J., 2009. A functional role for adult hippocampal neurogenesis in spatial pattern separation. Science 325, 210-213. doi:10.1126/science.1173215

Cohen, L.S., Soares, C.N., Vitonis, A.F., Otto, M.W., Harlow, B.L., 2006. Risk for New Onset of Depression During the Menopausal Transition: The Harvard Study of Moods and Cycles. Arch Gen Psychiatry 63, 385-390. doi:10.1001/archpsyc.63.4.385

Craft, R.M., Kostick, M.L., Rogers, J.A., White, C.L., Tsutsui, K.T., 2010. Forced swim test behavior in postpartum rats. Pharmacology Biochemistry and Behavior 96, 402-412. doi:10.1016/j.pbb.2010.06.012

Crews, L., Adame, A., Patrick, C., Delaney, A., Pham, E., Rockenstein, E., Hansen, L., Masliah, E., 2010. Increased BMP6 levels in the brains of Alzheimer's disease patients and APP transgenic mice are accompanied by impaired neurogenesis. J. Neurosci. 30, 12252-12262. doi:10.1523/JNEUROSCI.1305-10.2010

Czéh, B., Lucassen, P.J., 2007. What causes the hippocampal volume decrease in depression? Are neurogenesis, glial changes and apoptosis implicated? Eur Arch Psychiatry Clin Neurosc 257, 250-260. doi:10.1007/s00406-007-0728-0

Czéh B, Michaelis T, Watanabe T, Frahm J, de Biurrun G, van Kampen M, Bartolomucci A, Fuchs E (2001) Stress-induced changes in cerebral metabolites, hippocampal volume, and cell proliferation are prevented by antidepressant treatment with tianeptine. Proceedings of the National Academy of Sciences of the United States of America 98:12796-12801.

Dagyte G, Trentani A, Postema F, Luiten PG, Den Boer JA, Gabriel C, Mocaer E, Meerlo P, Van der Zee EA (2010) The novel antidepressant agomelatine normalizes hippocampal neuronal activity and promotes neurogenesis in chronically stressed rats. CNS neuroscience \& therapeutics 16:195-207. 
Dalla, C., Papachristos, E.B., Whetstone, A.S., Shors, T.J., 2009. Female rats learn trace memories better than male rats and consequently retain a greater proportion of new neurons in their hippocampi. Proc. Natl. Acad. Sci. U.S.A. 106, 2927-2932.

doi:10.1073/pnas.0809650106

Dalla, C., Pitychoutis, P.M., Kokras, N., Papadopoulou-Daifoti, Z. (2010) Sex Differences in Animal Models of Depression and Antidepressant Response. Basic \& Clinical Pharmacology \& Toxicology 106, 226-233. doi:10.1111/j.1742-7843.2009.00516.x

Darnaudéry, M., Perez-Martin, M., Del Favero, F., Gomez-Roldan, C., Garcia-Segura, L.M., Maccari, S., 2007. Early motherhood in rats is associated with a modification of hippocampal function. Psychoneuroendocrinology 32, 803-812. doi:10.1016/j.psyneuen.2007.05.012

David DJ, Samuels BA, Rainer Q, Wang JW, Marsteller D, Mendez I, Drew M, Craig DA, Guiard BP, Guilloux JP, Artymyshyn RP, Gardier AM, Gerald C, Antonijevic IA, Leonardo ED, Hen R (2009) Neurogenesis-dependent and -independent effects of fluoxetine in an animal model of anxiety/depression. Neuron 62:479-493.

Dayer, A.G., Ford, A.A., Cleaver, K.M., Yassaee, M., Cameron, H.A., 2003. Short-term and long-term survival of new neurons in the rat dentate gyrus. J. Comp. Neurol. 460, 563-572. doi:10.1002/cne.10675

Deng, W., Aimone, J.B., Gage, F.H., 2010. New neurons and new memories: how does adult hippocampal neurogenesis affect learning and memory? Nat Rev Neurosci 11, 339-350. doi:10.1038/nrn2822

Dickson, D.W., 2001. Neuropathology of Alzheimer's disease and other dementias. Clin. Geriatr. Med. 17, 209-228.

Djavadian, R.L., 2004. Serotonin and neurogenesis in the hippocampal dentate gyrus of adult mammals. Acta Neurobiol Exp (Wars) 64, 189-200.

DonCarlos, L.L., Azcoitia, I., Garcia-Segura, L.M., 2009. Neuroprotective actions of selective estrogen receptor modulators. Psychoneuroendocrinology 34, S113-S122. doi:10.1016/j.psyneuen.2009.04.012

Driscoll, I., Howard, S.R., Stone, J.C., Monfils, M.H., Tomanek, B., Brooks, W.M., Sutherland, R.J., 2006. The aging hippocampus: a multi-level analysis in the rat. Neuroscience 139, 1173-1185. doi:10.1016/j.neuroscience.2006.01.040

Duarte-Guterman, P., Lieblich, S.E., Chow, C., Galea, L.A.M., 2015a. Estradiol and GPER Activation Differentially Affect Cell Proliferation but Not GPER Expression in the Hippocampus of Adult Female Rats. PLoS ONE 10, e0129880. doi:10.1371/journal.pone.0129880

Duarte-Guterman, P., Yagi, S., Chow, C., Galea, L.A.M., 2015b. Hippocampal learning, memory, and neurogenesis: Effects of sex and estrogens across the lifespan in adults. Hormones and Behavior 74, 37-52. doi:10.1016/j.yhbeh.2015.05.024

Duman RS, Aghajanian GK (2012) Synaptic dysfunction in depression: potential therapeutic targets. Science 338:68-72.

Edinger KL, Frye CA (2005) Testosterone's anti-anxiety and analgesic effects may be due in part to actions of its 5alpha-reduced metabolites in the hippocampus. Psychoneuroendocrinology 30:418-430.

Edinger KL, Frye CA (2007) Androgens' performance-enhancing effects in the inhibitory avoidance and water maze tasks may involve actions at intracellular androgen receptors in the dorsal hippocampus. Neurobiol Learn Mem 87:201-208.

Ekdahl, C.T., Claasen, J.-H., Bonde, S., Kokaia, Z., Lindvall, O., 2003. Inflammation is 
detrimental for neurogenesis in adult brain. PNAS 100, 13632-13637.

doi:10.1073/pnas.2234031100

Ekdahl, C.T., Kokaia, Z., Lindvall, O., 2009. Brain inflammation and adult neurogenesis: The dual role of microglia. Neuroscience 158, 1021-1029.

doi:10.1016/j.neuroscience.2008.06.052

Epp, J.R., Beasley, C.L., Galea, L.A., 2013a. Increased Hippocampal Neurogenesis and p21

Expression in Depression: Dependent on Antidepressants, Sex, Age, and Antipsychotic

Exposure. Neuropsychopharmacology 38, 2297-2306. doi:10.1038/npp.2013.132

Epp, J.R., Chow, C., Galea, L.A.M., 2013b. Hippocampus-dependent learning influences hippocampal neurogenesis. Front Neurosci 7, 57. doi:10.3389/fnins.2013.00057

Epp, J.R., Spritzer, M.D., Galea, L.A.M., 2007. Hippocampus-dependent learning promotes survival of new neurons in the dentate gyrus at a specific time during cell maturation. Neuroscience 149, 273-285. doi:10.1016/j.neuroscience.2007.07.046

Epp, J.R., Silva Mera, R., Köhler, S., Josselyn, S.A., Frankland, P.W. (2016) Neurogenesismediated forgetting minimizes proactive interference. Nat Commun 7, 10838. doi:10.1038/ncomms10838

Eriksson, P.S., Perfilieva, E., Björk-Eriksson, T., Alborn, A.M., Nordborg, C., Peterson, D.A., Gage, F.H., 1998. Neurogenesis in the adult human hippocampus. Nature Medicine 4, 13131317. doi:10.1038/3305

Ervin, K.S.J., Lymer, J.M., Matta, R., Clipperton-Allen, A.E., Kavaliers, M., Choleris, E. (2015). Estrogen involvement in social behavior in rodents: Rapid and long-term actions. Hormones and Behavior 74, 53-76. doi:10.1016/j.yhbeh.2015.05.023

Fanselow MS, Dong HW (2010) Are the dorsal and ventral hippocampus functionally distinct structures? Neuron 65:7-19.

Fernandez-Guasti A, Martinez-Mota L (2005) Anxiolytic-like actions of testosterone in the burying behavior test: role of androgen and GABA-benzodiazepine receptors.

Psychoneuroendocrinology 30:762-770.

Fester, L., Prange-Kiel, J., Zhou, L., Blittersdorf, B.V., Böhm, J., Jarry, H., Schumacher, M., Rune, G.M., 2012. Estrogen-regulated synaptogenesis in the hippocampus: sexual dimorphism in vivo but not in vitro. J. Steroid Biochem. Mol. Biol. 131, 24-29. doi:10.1016/j.jsbmb.2011.11.010

Frankland, P.W., Josselyn, S.A., 2016. Hippocampal Neurogenesis and Memory Clearance. Neuropsychopharmacology 41, 382-383. doi:10.1038/npp.2015.243

Freeman, E.W., Sammel, M.D., Lin, H., Nelson, D.B., 2006. Associations of hormones and menopausal status with depressed mood in women with no history of depression. Arch Gen Psychiatry 63, 375-382. doi:10.1001/archpsyc.63.4.375

Frick, K.M., Fernandez, S.M., Bennett, J.C., Prange-Kiel, J., MacLusky, N.J., Leranth, C., 2004. Behavioral training interferes with the ability of gonadal hormones to increase CA1 spine synapse density in ovariectomized female rats. Eur. J. Neurosci. 19, 3026-3032. doi:10.1111/j.0953-816X.2004.03427.x

Frick, K.M., Kim, J., Tuscher, J.J., Fortress, A.M., 2015. Sex steroid hormones matter for learning and memory: estrogenic regulation of hippocampal function in male and female rodents. Learn. Mem. 22, 472-493. doi:10.1101/lm.037267.114

Frodl, T., Meisenzahl, E.M., Zetzsche, T., Born, C., Groll, C., Jäger, M., Leinsinger, G., Bottlender, R., Hahn, K., Möller, H.-J., 2002. Hippocampal changes in patients with a first episode of major depression. Am J Psychiatry 159, 1112-1118. 
Frye CA, Edinger KL (2004) Testosterone's metabolism in the hippocampus may mediate its anti-anxiety effects in male rats. Pharmacology, biochemistry, and behavior 78:473-481.

Frye CA, Walf AA (2009) Depression-like behavior of aged male and female mice is ameliorated with administration of testosterone or its metabolites. Physiology \& behavior 97:266-269.

Furuta, M., Bridges, R.S., 2005. Gestation-induced cell proliferation in the rat brain. Brain Res. Dev. Brain Res. 156, 61-66. doi:10.1016/j.devbrainres.2005.01.008

Gage, F.H., 2000. Mammalian neural stem cells. Science 287, 1433-1438.

Galea, L.A., Ormerod, B.K., Sampath, S., Kostaras, X., Wilkie, D.M., Phelps, M.T., 2000. Spatial working memory and hippocampal size across pregnancy in rats. Hormones and Behavior 37, 86-95. doi:10.1006/hbeh.1999.1560

Galea, L.A., Wide, J.K., Barr, A.M., 2001. Estradiol alleviates depressive-like symptoms in a novel animal model of post-partum depression. Behavioural Brain Research 122, 1-9.

Galea, L.A.M., Wainwright, S.R., Roes, M.M., Duarte-Guterman, P., Chow, C., Hamson, D.K., 2013. Sex, Hormones and Neurogenesis in the Hippocampus: Hormonal Modulation of Neurogenesis and Potential Functional Implications. J Neuroendocrinol 25, 1039-1061. doi:10.1111/jne.12070

Gao, S., Hendrie, H.C., Hall, K.S., Hui, S., 1998. The relationships between age, sex, and the incidence of dementia and Alzheimer disease: a meta-analysis. Arch Gen Psychiatry 55, 809-815.

Garland, H.O., Atherton, J.C., Baylis, C., Morgan, M.R., Milne, C.M., 1987. Hormone profiles for progesterone, oestradiol, prolactin, plasma renin activity, aldosterone and corticosterone during pregnancy and pseudopregnancy in two strains of rat: correlation with renal studies. J. Endocrinol. 113, 435-444.

Gobinath, A.R., Mahmoud, R., Galea, L.A.M. (2015) Influence of sex and stress exposure across the lifespan on endophenotypes of depression: focus on behavior, glucocorticoids, and hippocampus. Front Neurosci 8, 1218. doi:10.3389/fnins.2014.00420

Goel, N., Workman, J.L., Lee, T.T., Innala, L., Viau, V., 2014. Sex differences in the HPA axis. Compr Physiol 4, 1121-1155. doi:10.1002/cphy.c130054

Goldstat R, Briganti E, Tran J, Wolfe R, Davis SR (2003) Transdermal testosterone therapy improves well-being, mood, and sexual function in premenopausal women. Menopause 10:390-398.

Gould, E., Beylin, A., Tanapat, P., Reeves, A., Shors, T.J., 1999a. Learning enhances adult neurogenesis in the hippocampal formation. Nat Neurosci 2, 260-265. doi:10.1038/6365

Gould, E., Reeves, A.J., Fallah, M., Tanapat, P., Gross, C.G., Fuchs, E., 1999b. Hippocampal neurogenesis in adult Old World primates. PNAS 96, 5263-5267.

Gould E, McEwen BS, Tanapat P, Galea LA, Fuchs E (1997) Neurogenesis in the dentate gyrus of the adult tree shrew is regulated by psychosocial stress and NMDA receptor activation. The Journal of neuroscience : the official journal of the Society for Neuroscience 17:24922498.

Green, A.D., Galea, L.A.M., 2008. Adult hippocampal cell proliferation is suppressed with estrogen withdrawal after a hormone-simulated pregnancy. Hormones and Behavior 54, 203-211. doi:10.1016/j.yhbeh.2008.02.023

Gross, C.G., 2000. Neurogenesis in the adult brain: death of a dogma. Nat Rev Neurosci 1, 6773. doi:10.1038/35036235

Gutiérrez-Lobos, K., Scherer, M., Anderer, P., Katschnig, H., 2002. The influence of age on the female/male ratio of treated incidence rates in depression. BMC Psychiatry 2, 3. 
doi:10.1186/1471-244X-2-3

Hamson, D.K., Wainwright, S.R., Taylor, J.R., Jones, B.A., Watson, N.V., Galea, L.A.M., 2013. Androgens increase survival of adult-born neurons in the dentate gyrus by an androgen receptor-dependent mechanism in male rats. Endocrinology 154, 3294-3304. doi:10.1210/en.2013-1129

Hammarström, A., Lehti, A., Danielsson, U., Bengs, C., Johansson, E.E. (2009) Gender-related explanatory models of depression: A critical evaluation of medical articles. Public Health 123, 689-693. doi:10.1016/j.puhe.2009.09.010

Hamson DK, Roes MM, Galea, L.A.M. (in press December 3, 2015). Sex Hormones and Cognition: Neuroendocrine influences on memory and learning. Comprehensive Physiology.

Handa RJ, Pak TR, Kudwa AE, Lund TD, Hinds L (2008) An alternate pathway for androgen regulation of brain function: activation of estrogen receptor beta by the metabolite of dihydrotestosterone, 5alpha-androstane-3beta,17beta-diol. Hormones and behavior 53:741752.

Hannan, A.J., Ransome, M.I., 2012. Deficits in spermatogenesis but not neurogenesis are alleviated by chronic testosterone therapy in R6/1 Huntington's disease mice. J Neuroendocrinol 24, 341-356. doi:10.1111/j.1365-2826.2011.02238.x

Harkonen K, Huhtaniemi I, Makinen J, Hubler D, Irjala K, Koskenvuo M, Oettel M, Raitakari O, Saad F, Pollanen P (2003) The polymorphic androgen receptor gene CAG repeat, pituitarytesticular function and andropausal symptoms in ageing men. International journal of andrology 26:187-194.

Harte-Hargrove, L.C., MacLusky, N.J., Scharfman, H.E., 2013. Brain-derived neurotrophic factor-estrogen interactions in the hippocampal mossy fiber pathway: Implications for normal brain function and disease. Neuroscience 239, 46-66.

doi:10.1016/j.neuroscience.2012.12.029

Hayes, N.L., Nowakowski, R.S., 2002. Dynamics of cell proliferation in the adult dentate gyrus of two inbred strains of mice. Brain Res. Dev. Brain Res. 134, 77-85.

Heinlein CA, Chang C (2002) The roles of androgen receptors and androgen-binding proteins in nongenomic androgen actions. Molecular endocrinology 16:2181-2187.

Hellsten J, Wennstrom M, Mohapel P, Ekdahl CT, Bengzon J, Tingstrom A (2002) Electroconvulsive seizures increase hippocampal neurogenesis after chronic corticosterone treatment. The European journal of neuroscience 16:283-290.

Hendrick, V., Altshuler, L.L., Suri, R., 1998. Hormonal Changes in the Postpartum and Implications for Postpartum Depression. Psychosomatics 39, 93-101. doi:10.1016/S00333182(98)71355-6

Henneman, W.J.P., Sluimer, J.D., Barnes, J., van der Flier, W.M., Sluimer, I.C., Fox, N.C., Scheltens, P., Vrenken, H., Barkhof, F., 2009. Hippocampal atrophy rates in Alzheimer disease: added value over whole brain volume measures. Neurology 72, 999-1007.

doi:10.1212/01.wnl.0000344568.09360.31

Herrick, S.P., Waters, E.M., Drake, C.T., McEwen, B.S., Milner, T.A., 2006. Extranuclear estrogen receptor beta immunoreactivity is on doublecortin-containing cells in the adult and neonatal rat dentate gyrus. Brain Research 1121, 46-58. doi:10.1016/j.brainres.2006.08.084

Herman JP, Cullinan WE (1997) Neurocircuitry of stress: central control of the hypothalamopituitary-adrenocortical axis. Trends in neurosciences 20:78-84.

Hill AS, Sahay A, Hen R (2015) Increasing Adult Hippocampal Neurogenesis is Sufficient to Reduce Anxiety and Depression-Like Behaviors. Neuropsychopharmacology : official publication of the American College of Neuropsychopharmacology 40:2368-2378. 
Hodosy J, Zelmanova D, Majzunova M, Filova B, Malinova M, Ostatnikova D, Celec P (2012) The anxiolytic effect of testosterone in the rat is mediated via the androgen receptor. Pharmacology, biochemistry, and behavior 102:191-195.

Holick KA, Lee DC, Hen R, Dulawa SC (2008) Behavioral effects of chronic fluoxetine in BALB/cJ mice do not require adult hippocampal neurogenesis or the serotonin 1A receptor. Neuropsychopharmacology : official publication of the American College of Neuropsychopharmacology 33:406-417.

Irvine, K., Laws, K.R., Gale, T.M., Kondel, T.K., 2012. Greater cognitive deterioration in women than men with Alzheimer's disease: a meta analysis. J Clin Exp Neuropsychol 34, 989-998. doi:10.1080/13803395.2012.712676

Jacobs BL, van Praag H, Gage FH (2000) Adult brain neurogenesis and psychiatry: a novel theory of depression. Molecular psychiatry 5:262-269.

Jakubs, K., Nanobashvili, A., Bonde, S., Ekdahl, C.T., Kokaia, Z., Kokaia, M., Lindvall, O. (2006) Environment matters: synaptic properties of neurons born in the epileptic adult brain develop to reduce excitability. Neuron 52, 1047-1059. doi:10.1016/j.neuron.2006.11.004

Jessberger, S., Nakashima, K., Clemenson, G.D., Mejia, E., Mathews, E., Ure, K., Ogawa, S., Sinton, C.M., Gage, F.H., Hsieh, J., 2007. Epigenetic modulation of seizure-induced neurogenesis and cognitive decline. J. Neurosci. 27, 5967-5975. doi:10.1523/JNEUROSCI.0110-07.2007

Jin, K., Peel, A.L., Mao, X.O., Xie, L., Cottrell, B.A., Henshall, D.C., Greenberg, D.A., 2004. Increased hippocampal neurogenesis in Alzheimer's disease. PNAS 101, 343-347. doi:10.1073/pnas.2634794100

Jin, M., Jin, F., Zhang, L., Chen, Z., Huang, H., 2005. Two estrogen replacement therapies differentially regulate expression of estrogen receptors alpha and beta in the hippocampus and cortex of ovariectomized rat. Brain Res. Mol. Brain Res. 142, 107-114.

doi:10.1016/j.molbrainres.2005.09.013

Johnson, M.D., Crowley, W.R., 1983. Acute effects of estradiol on circulating luteinizing hormone and prolactin concentrations and on serotonin turnover in individual brain nuclei. Endocrinology 113, 1935-1941. doi:10.1210/endo-113-6-1935

Johnston, S.T., Shtrahman, M., Parylak, S., Gonçalves, J.T., Gage, F.H., 2015. Paradox of pattern separation and adult neurogenesis: A dual role for new neurons balancing memory resolution and robustness. Neurobiology of Learning and Memory. doi:10.1016/j.nlm.2015.10.013

Josselyn, S.A., Köhler, S., Frankland, P.W (2015) Finding the engram. Nat Rev Neurosci 16, 521-534. doi:10.1038/nrn4000

Jones BA, Watson NV (2005) Spatial memory performance in androgen insensitive male rats. Physiol Behav 85:135-141.

Kaestner, F., Hettich, M., Peters, M., Sibrowski, W., Hetzel, G., Ponath, G., Arolt, V., Cassens, U., Rothermundt, M., 2005. Different activation patterns of proinflammatory cytokines in melancholic and non-melancholic major depression are associated with HPA axis activity. Journal of Affective Disorders 87, 305-311. doi:10.1016/j.jad.2005.03.012

Kaplan, M.S., Hinds, J.W., 1977. Neurogenesis in the adult rat: electron microscopic analysis of light radioautographs. Science 197, 1092-1094.

Karege, F., Bondolfi, G., Gervasoni, N., Schwald, M., Aubry, J.-M., Bertschy, G., 2005. Low brain-derived neurotrophic factor (BDNF) levels in serum of depressed patients probably results from lowered platelet BDNF release unrelated to platelet reactivity. BPS 57, 10681072. doi:10.1016/j.biopsych.2005.01.008 
Kato, A., Hojo, Y., Higo, S., Komatsuzaki, Y., Murakami, G., Yoshino, H., Uebayashi, M., Kawato, S., 2013. Female hippocampal estrogens have a significant correlation with cyclic fluctuation of hippocampal spines. Front Neural Circuits 7, 149.

doi:10.3389/fncir.2013.00149

Kee N, Sivalingam S, Boonstra R, Wojtowicz JM (2002) The utility of Ki-67 and BrdU as proliferative markers of adult neurogenesis. Journal of neuroscience methods 115:97-105.

Kempermann G, Kuhn HG, Gage FH (1998) Experience-induced neurogenesis in the senescent dentate gyrus. The Journal of neuroscience : the official journal of the Society for Neuroscience 18:3206-3212.

Kempermann, G., Gast, D., Kronenberg, G., Yamaguchi, M., Gage, F.H., 2003. Early determination and long-term persistence of adult-generated new neurons in the hippocampus of mice. Development 130, 391-399.

Kerr JE, Beck SG, Handa RJ (1996) Androgens modulate glucocorticoid receptor mRNA, but not mineralocorticoid receptor mRNA levels, in the rat hippocampus. Journal of neuroendocrinology 8:439-447.

Kerr JE, Allore RJ, Beck SG, Handa RJ (1995) Distribution and hormonal regulation of androgen receptor (AR) and AR messenger ribonucleic acid in the rat hippocampus. Endocrinology 136:3213-3221.

Kesner, R.P., Rolls, E.T., 2015. A computational theory of hippocampal function, and tests of the theory: new developments. Neurosci Biobehav Rev 48, 92-147. doi:10.1016/j.neubiorev.2014.11.009

Khakpai F (2014) The effect of opiodergic system and testosterone on anxiety behavior in gonadectomized rats. Behavioural brain research 263:9-15.

Kim KK, Adelstein RS, Kawamoto S (2009) Identification of neuronal nuclei (NeuN) as Fox-3, a new member of the Fox-1 gene family of splicing factors. The Journal of biological chemistry 284:31052-31061.

Kinsley, C.H., Lambert, K.G., 2008. Reproduction-induced neuroplasticity: natural behavioural and neuronal alterations associated with the production and care of offspring. $\mathrm{J}$ Neuroendocrinol 20, 515-525. doi:10.1111/j.1365-2826.2008.01667.x

Klein, N.A., Battaglia, D.E., Fujimoto, V.Y., Davis, G.S., Bremner, W.J., Soules, M.R., 1996. Reproductive aging: accelerated ovarian follicular development associated with a monotropic follicle-stimulating hormone rise in normal older women. The Journal of Clinical Endocrinology \& Metabolism 81, 1038-1045. doi:10.1210/jcem.81.3.8772573

Klein, S.L., Schiebinger, L., Stefanick, M.L., Cahill, L., Danska, J., de Vries, G.J., Kibbe, M.R., McCarthy, M.M., Mogil, J.S., Woodruff, T.K., Zucker, I., 2015. Opinion: Sex inclusion in basic research drives discovery. Proc. Natl. Acad. Sci. U.S.A. 112, 5257-5258. doi:10.1073/pnas.1502843112

Kloss, C.U., Bohatschek, M., Kreutzberg, G.W., Raivich, G., 2001. Effect of lipopolysaccharide on the morphology and integrin immunoreactivity of ramified microglia in the mouse brain and in cell culture. Exp. Neurol. 168, 32-46. doi:10.1006/exnr.2000.7575

Korol, D.L., Pisani, S.L., 2015. Estrogens and cognition: Friends or foes?: An evaluation of the opposing effects of estrogens on learning and memory. Hormones and Behavior 74, 105115. doi:10.1016/j.yhbeh.2015.06.017

Kuhn, H.G., Dickinson-Anson, H., Gage, F.H., 1996. Neurogenesis in the dentate gyrus of the adult rat: age-related decrease of neuronal progenitor proliferation. Journal of Neuroscience 16, 2027-2033.

Lagace, D.C., Fischer, S.J., Eisch, A.J., 2007. Gender and endogenous levels of estradiol do not influence adult hippocampal neurogenesis in mice. Hippocampus 17, 175-180. 
doi:10.1002/hipo.20265

Lagunas, N., Calmarza-Font, I., Diz-Chaves, Y., Garcia-Segura, L.M (2010) Long-term ovariectomy enhances anxiety and depressive-like behaviors in mice submitted to chronic unpredictable stress. Hormones and Behavior 58, 786-791. doi:10.1016/j.yhbeh.2010.07.014

Leal, S.L., Yassa, M.A (2015) Neurocognitive Aging and the Hippocampus across Species. Trends in Neurosciences 38, 800-812. doi:10.1016/j.tins.2015.10.003

Lee, B.-H., Kim, Y.-K., 2010. The roles of BDNF in the pathophysiology of major depression and in antidepressant treatment. Psychiatry Investig 7, 231-235. doi:10.4306/pi.2010.7.4.231

Lee, J., Duan, W., Mattson, M.P., 2002. Evidence that brain-derived neurotrophic factor is required for basal neurogenesis and mediates, in part, the enhancement of neurogenesis by dietary restriction in the hippocampus of adult mice. J. Neurochem. 82, 1367-1375.

LeFevre, J., McClintock, M.K., 1988. Reproductive senescence in female rats: a longitudinal study of individual differences in estrous cycles and behavior. Biol. Reprod. 38, 780-789.

Leuner, B., Mirescu, C., Noiman, L., Gould, E., 2007a. Maternal experience inhibits the production of immature neurons in the hippocampus during the postpartum period through elevations in adrenal steroids. Hippocampus 17, 434-442. doi:10.1002/hipo.20278

Leuner, B., Mirescu, C., Noiman, L., Gould, E., 2007b. Maternal experience inhibits the production of immature neurons in the hippocampus during the postpartum period through elevations in adrenal steroids. Hippocampus 17, 434-442. doi:10.1002/hipo.20278

Leuner B, Sabihi S (2016). The birth of new neurons in the maternal brain: hormonal regulation and functional implications. Front Neuroendocrinol

Liu, L., Wang, J., Zhao, L., Nilsen, J., McClure, K., Wong, K., Brinton, R.D., 2009. Progesterone increases rat neural progenitor cell cycle gene expression and proliferation via extracellularly regulated kinase and progesterone receptor membrane components 1 and 2 . Endocrinology 150, 3186-3196. doi:10.1210/en.2008-1447

Loy, R., Gerlach, J.L., McEwen, B.S., 1988. Autoradiographic localization of estradiol-binding neurons in the rat hippocampal formation and entorhinal cortex. Brain Research 467, 245251.

Lu, P.H., Masterman, D.A., Mulnard, R., Cotman, C., Miller, B., Yaffe, K., Reback, E., Porter, V., Swerdloff, R., Cummings, J.L., 2006. Effects of testosterone on cognition and mood in male patients with mild Alzheimer disease and healthy elderly men. Arch. Neurol. 63, 177185. doi:10.1001/archneur.63.2.nct50002

Lubahn DB, Joseph DR, Sullivan PM, Willard HF, French FS, Wilson EM (1988) Cloning of human androgen receptor complementary DNA and localization to the X chromosome. Science 240:327-330.

Lucassen, P.J., Stumpel, M.W., Wang, Q., Aronica, E., 2010. Decreased numbers of progenitor cells but no response to antidepressant drugs in the hippocampus of elderly depressed patients. Neuropharmacology 58, 940-949. doi:10.1016/j.neuropharm.2010.01.012

Mackenzie, I.R., 2000. Activated microglia in dementia with Lewy bodies. Neurology 55, 132134.

MacQueen, G., Frodl, T., 2011. The hippocampus in major depression: evidence for the convergence of the bench and bedside in psychiatric research? Molecular Psychiatry 16, 252-264. doi:10.1038/mp.2010.80

Madsen TM, Treschow A, Bengzon J, Bolwig TG, Lindvall O, Tingstrom A (2000) Increased neurogenesis in a model of electroconvulsive therapy. Biological psychiatry 47:10431049.

Maggi, A., Susanna, L., Bettini, E., Mantero, G., Zucchi, I., 1989. Hippocampus: a target for 
estrogen action in mammalian brain. Mol. Endocrinol. 3, 1165-1170. doi:10.1210/mend-3-71165.

Mahmoud R, Wainwright SR, Chaiton J, Lieblich SE, Galea LAM (in press). Ovarian hormones, but not fluoxetine, impart resilience within a chronic unpredictable stress model in middleaged female rats. Neuropharmacology

Malberg JE, Duman RS (2003) Cell proliferation in adult hippocampus is decreased by inescapable stress: reversal by fluoxetine treatment. Neuropsychopharmacology : official publication of the American College of Neuropsychopharmacology 28:1562-1571.

Malberg JE, Eisch AJ, Nestler EJ, Duman RS (2000) Chronic antidepressant treatment increases neurogenesis in adult rat hippocampus. The Journal of neuroscience : the official journal of the Society for Neuroscience 20:9104-9110.

Malberg, J.E., Eisch, A.J., Nestler, E.J., Duman, R.S., 2000. Chronic Antidepressant Treatment Increases Neurogenesis in Adult Rat Hippocampus. Journal of Neuroscience 20, 9104-9110. doi:10.1016/0306-4522(93)90335-D

Mani, S.K., Blaustein, J.D., 2012. Neural progestin receptors and female sexual behavior. Neuroendocrinology 96, 152-161. doi:10.1159/000338668

Marino, M., Galluzzo, P., Ascenzi, P., 2006. Estrogen signaling multiple pathways to impact gene transcription. Curr. Genomics 7, 497-508.

Mazzucco, C.A., Lieblich, S.E., Bingham, B.I., Williamson, M.A., Viau, V., Galea, L.A.M., 2006. Both estrogen receptor alpha and estrogen receptor beta agonists enhance cell proliferation in the dentate gyrus of adult female rats. Neuroscience 141, 1793-1800. doi:10.1016/j.neuroscience.2006.05.032

McCall, T., Weil, Z.M., Nacher, J., Bloss, E.B., Maarouf, El, A., Rutishauser, U., McEwen, B.S., 2013. Depletion of polysialic acid from neural cell adhesion molecule (PSA-NCAM) increases CA3 dendritic arborization and increases vulnerability to excitotoxicity. Exp. Neurol. 241, 5-12. doi:10.1016/j.expneurol.2012.11.028

McCarthy, M.M., Arnold, A.P., Ball, G.F., Blaustein, J.D., de Vries, G.J., 2012. Sex differences in the brain: the not so inconvenient truth. J. Neurosci. 32, 2241-2247. doi:10.1523/JNEUROSCI.5372-11.2012

McClure, R.E.S., Barha, C.K., Galea, L.A.M., 2013. 17 $\beta$-Estradiol, but not estrone, increases the survival and activation of new neurons in the hippocampus in response to spatial memory in adult female rats. Hormones and Behavior 63, 144-157. doi:10.1016/j.yhbeh.2012.09.011

McCullough, L.D., McCarthy, M.M., de Vries, G.J., 2014. NIH policy: status quo is also costly. Nature 510, 340-340. doi:10.1038/510340b

McEwen, B.S., Akama, K.T., Spencer-Segal, J.L., Milner, T.A., Waters, E.M., 2012. Estrogen effects on the brain: actions beyond the hypothalamus via novel mechanisms. Behav. Neurosci. 126, 4-16. doi:10.1037/a0026708

McEwen, B.S., Alves, S.E., 1999. Estrogen actions in the central nervous system. Endocr. Rev. 20, 279-307. doi:10.1210/edrv.20.3.0365

McEwen BS (1973) Glucocorticoid binding sites in rat brain: subcellular and anatomical localizations. Progress in brain research 39:87-97.

McIntyre RS, Mancini D, Eisfeld BS, Soczynska JK, Grupp L, Konarski JZ, Kennedy SH (2006) Calculated bioavailable testosterone levels and depression in middle-aged men. Psychoneuroendocrinology 31:1029-1035.

McKinnon MC, Yucel K, Nazarov A, MacQueen GM (2009) A meta-analysis examining clinical predictors of hippocampal volume in patients with major depressive disorder. Journal of psychiatry \& neuroscience : JPN 34:41-54.

Merrill, D.A., Karim, R., Darraq, M., Chiba, A.A., Tuszynski, M.H., 2003. Hippocampal cell 
genesis does not correlate with spatial learning ability in aged rats. J. Comp. Neurol. 459, 201-207. doi:10.1002/cne.10616

Mielke, M.M., Vemuri, P., Rocca, W.A (2014) Clinical epidemiology of Alzheimer's disease: assessing sex and gender differences. Clin Epidemiol 6, 37-48. doi:10.2147/CLEP.S37929

Miller, A.H., Maletic, V., Raison, C.L., 2009. Inflammation and Its Discontents: The Role of Cytokines in the Pathophysiology of Major Depression. BPS 65, 732-741. doi:10.1016/j.biopsych.2008.11.029

Miller KK, Perlis RH, Papakostas GI, Mischoulon D, Losifescu DV, Brick DJ, Fava M (2009) Low-dose transdermal testosterone augmentation therapy improves depression severity in women. CNS spectrums 14:688-694.

Ming GL, Song H (2005) Adult neurogenesis in the mammalian central nervous system. Annual review of neuroscience 28:223-250.

Mitchell, A.J., 2006. Two-week delay in onset of action of antidepressants: new evidence. $\mathrm{Br} \mathrm{J}$ Psychiatry 188, 105-106. doi:10.1192/bjp.bp.105.011692

Moffat, S.D., Zonderman, A.B., Metter, E.J., Kawas, C., Blackman, M.R., Harman, S.M., Resnick, S.M., 2004. Free testosterone and risk for Alzheimer disease in older men. Neurology 62, 188-193. doi:10.1212/WNL.62.2.188

Morissette, M., Lévesque, D., Bélanger, A., Di Paolo, T., 1990. A physiological dose of estradiol with progesterone affects striatum biogenic amines. Can. J. Physiol. Pharmacol. 68, 15201526.

Monks DA, Getsios S, MacCalman CD, Watson NV (2001) N-cadherin is regulated by gonadal steroids in the adult hippocampus. Proceedings of the National Academy of Sciences of the United States of America 98:1312-1316.

Moser MB, Moser EI (1998) Functional differentiation in the hippocampus. Hippocampus 8:608-619.

Moser, M.-B., Rowland, D.C., Moser, E.I., 2015. Place cells, grid cells, and memory. Cold Spring Harb Perspect Biol 7, a021808. doi:10.1101/cshperspect.a021808

Mu, Y., Gage, F.H., 2011. Adult hippocampal neurogenesis and its role in Alzheimer's disease. Mol Neurodegener 6, 85. doi:10.1186/1750-1326-6-85

Mullen, R.J., Buck, C.R., Smith, A.M., 1992. NeuN, a neuronal specific nuclear protein in vertebrates. Development 116, 201-211.

Muller, D., Wang, C., Skibo, G., Toni, N., Cremer, H., Calaora, V., Rougon, G., Kiss, J.Z., 1996. PSA-NCAM is required for activity-induced synaptic plasticity. Neuron 17, 413-422.

Nacher, J., Alonso-Llosa, G., Rosell, D.R., McEwen, B.S., 2003. NMDA receptor antagonist treatment increases the production of new neurons in the aged rat hippocampus. Neurobiology of Aging 24, 273-284.

Naghdi N, Nafisy N, Majlessi N (2001) The effects of intrahippocampal testosterone and flutamide on spatial localization in the Morris water maze. Brain Res 897:44-51.

Nagy A.I., Ormerod, B.K., Mazzucco C., L.A.M., Galea (2006) Estradiol-induced enhancement in cell proliferation is mediated through estrogen receptors in the dentate gyrus of adult female rats. Drug Development Research 66: 142-149

Nakashiba, T., Cushman, J.D., Pelkey, K.A., Renaudineau, S., Buhl, D.L., McHugh, T.J., Rodriguez Barrera, V., Chittajallu, R., Iwamoto, K.S., McBain, C.J., Fanselow, M.S., Tonegawa, S., 2012. Young dentate granule cells mediate pattern separation, whereas old granule cells facilitate pattern completion. Cell 149, 188-201. doi:10.1016/j.cell.2012.01.046

Nelson RJ (2011) An introduction to behavioral endocrinology, 4th Edition. Sunderland, MA: Sinauer Associates. 
O'Bryant, S.E., Hobson, V., Hall, J.R., Waring, S.C., Chan, W., Massman, P., Lacritz, L., Cullum, C.M., Diaz-Arrastia, R., Texas Alzheimer's Research Consortium, 2009. Brainderived neurotrophic factor levels in Alzheimer's disease. J. Alzheimers Dis. 17, 337-341. doi:10.3233/JAD-2009-1051

O'Leary, O.F., Cryan, J.F., 2014. A ventral view on antidepressant action: roles for adult hippocampal neurogenesis along the dorsoventral axis. Trends Pharmacol. Sci. 35, 675-687. doi:10.1016/j.tips.2014.09.011

O'Lone, R., Frith, M.C., Karlsson, E.K., Hansen, U., 2004. Genomic targets of nuclear estrogen receptors. Mol. Endocrinol. 18, 1859-1875. doi:10.1210/me.2003-0044

Oatridge, A., Holdcroft, A., Saeed, N., Hajnal, J.V., Puri, B.K., Fusi, L., Bydder, G.M., 2002. Change in brain size during and after pregnancy: study in healthy women and women with preeclampsia. AJNR Am J Neuroradiol 23, 19-26.

Olde, B., Leeb-Lundberg, L.M.F., 2009. GPR30/GPER1: searching for a role in estrogen physiology. Trends Endocrinol. Metab. 20, 409-416. doi:10.1016/j.tem.2009.04.006

Omwancha, J., Brown, T.R. (2006) Selective androgen receptor modulators: in pursuit of tissueselective androgens. Curr Opin Investig Drugs 7, 873-881.

Ormerod, B.K., Galea, L.A.M., 2003. Reproductive status influences the survival of new cells in the dentate gyrus of adult male meadow voles. Neurosci. Lett. 346, 25-28.

Ormerod, B.K., Lee, T.T.-Y., Galea, L.A.M., 2004. Estradiol enhances neurogenesis in the dentate gyri of adult male meadow voles by increasing the survival of young granule neurons. Neuroscience 128, 645-654. doi:10.1016/j.neuroscience.2004.06.039

Ormerod, B.K., Lee, T.T.-Y., Galea, L.A.M., 2003. Estradiol initially enhances but subsequently suppresses (via adrenal steroids) granule cell proliferation in the dentate gyrus of adult female rats. J. Neurobiol. 55, 247-260. doi:10.1002/neu.10181

Orsini, C.A., Moorman, D.E., Young, J.W., Setlow, B., Floresco, S.B., 2015. Neural mechanisms regulating different forms of risk-related decision-making: Insights from animal models. Neurosci Biobehav Rev 58, 147-167. doi:10.1016/j.neubiorev.2015.04.009

Paganini-Hill, A., Henderson, V.W., 1994. Estrogen deficiency and risk of Alzheimer's disease in women. Am. J. Epidemiol. 140, 256-261.

Pagnin D, de Queiroz V, Pini S, Cassano GB (2004) Efficacy of ECT in depression: a metaanalytic review. The journal of ECT 20:13-20.

Panizzon, M.S., Hauger, R., Dale, A.M., Eaves, L.J., Eyler, L.T., Fischl, B., Fennema-Notestine, C., Franz, C.E., Grant, M.D., Jak, A.J., Jacobson, K.C., Lyons, M.J., Mendoza, S.P., Neale, M.C., Prom-Wormley, E.C., Seidman, L.J., Tsuang, M.T., Xian, H., Kremen, W.S., 2010. Testosterone modifies the effect of APOE genotype on hippocampal volume in middle-aged men. Neurology 75, 874-880. doi:10.1212/WNL.0b013e3181f11deb

Panizzon, M.S., Hauger, R., Xian, H., Vuoksimaa, E., Spoon, K.M., Mendoza, S.P., Jacobson, K.C., Vasilopoulos, T., Rana, B.K., McKenzie, R., McCaffery, J.M., Lyons, M.J., Kremen, W.S., Franz, C.E., 2014. Interaction of APOE genotype and testosterone on episodic memory in middle-aged men. Neurobiology of Aging 35, 1778.e1-8. doi:10.1016/j.neurobiolaging.2013.12.025

Pariante CM, Lightman SL (2008) The HPA axis in major depression: classical theories and new developments. Trends in neurosciences 31:464-468.

Pawluski, J.L., Barakauskas, V.E., Galea, L.A.M., 2010. Pregnancy decreases oestrogen receptor alpha expression and pyknosis, but not cell proliferation or survival, in the hippocampus. $\mathrm{J}$ Neuroendocrinol 22, 248-257. doi:10.1111/j.1365-2826.2010.01960.x

Pawluski, J.L., Brummelte, S., Barha, C.K., Crozier, T.M., Galea, L.A.M., 2009. Effects of 
steroid hormones on neurogenesis in the hippocampus of the adult female rodent during the estrous cycle, pregnancy, lactation and aging. Front Neuroendocrinol 30, 343-357.

doi:10.1016/j.yfrne.2009.03.007

Pawluski, J.L., Galea, L.A.M., 2007. Reproductive experience alters hippocampal neurogenesis during the postpartum period in the dam. Neuroscience 149, 53-67.

doi:10.1016/j.neuroscience.2007.07.031

Pawluski, J.L., Galea, L.A.M., 2006. Hippocampal morphology is differentially affected by reproductive experience in the mother. J. Neurobiol. 66, 71-81. doi:10.1002/neu.20194

Perez-Martin, M., Salazar, V., Castillo, C., Ariznavarreta, C., Azcoitia, I., Garcia-Segura, L.M., Tresguerres, J.A.F., 2005. Estradiol and soy extract increase the production of new cells in the dentate gyrus of old rats. Exp. Gerontol. 40, 450-453. doi:10.1016/j.exger.2005.03.003

Phillips, H.S., Hains, J.M., Armanini, M., Laramee, G.R., Johnson, S.A., Winslow, J.W., 1991. BDNF mRNA is decreased in the hippocampus of individuals with Alzheimer's disease. Neuron 7, 695-702.

Pope HG, Jr., Cohane GH, Kanayama G, Siegel AJ, Hudson JI (2003) Testosterone gel supplementation for men with refractory depression: a randomized, placebo-controlled trial. The American journal of psychiatry 160:105-111.

Pope HG, Jr., Amiaz R, Brennan BP, Orr G, Weiser M, Kelly JF, Kanayama G, Siegel A, Hudson JI, Seidman SN (2010) Parallel-group placebo-controlled trial of testosterone gel in men with major depressive disorder displaying an incomplete response to standard antidepressant treatment. Journal of clinical psychopharmacology 30:126-134.

Pozzi, S., Benedusi, V., Maggi, A., Vegeto, E., 2006. Estrogen action in neuroprotection and brain inflammation. Annals of the New York Academy of Sciences 1089, 302-323. doi:10.1196/annals.1386.035

Prickaerts, J., Koopmans, G., Blokland, A., Scheepens, A., 2004. Learning and adult neurogenesis: survival with or without proliferation? Neurobiology of Learning and Memory 81, 1-11.

Quintela T, Marcelino H, Goncalves I, Patriarca FM, Santos CR (2015) Gene expression profiling in the hippocampus of orchidectomized rats. Journal of molecular neuroscience : MN 55:198-205.

Rannevik, G., Carlström, K., Jeppsson, S., Bjerre, B., Svanberg, L., 1986. A prospective longterm study in women from pre-menopause to post-menopause: changing profiles of gonadotrophins, oestrogens and androgens. Maturitas 8, 297-307.

Revankar, C.M., Cimino, D.F., Sklar, L.A., Arterburn, J.B., Prossnitz, E.R., 2005. A transmembrane intracellular estrogen receptor mediates rapid cell signaling. Science 307, 1625-1630. doi:10.1126/science.1106943

Richardson, S.S., Reiches, M., Shattuck-Heidorn, H., LaBonte, M.L., Consoli, T., 2015. Opinion: Focus on preclinical sex differences will not address women"s and men"s health disparities. Proc. Natl. Acad. Sci. U.S.A. 112, 13419-13420. doi:10.1073/pnas.1516958112

Rodgers S, Grosse Holtforth M, Muller M, Hengartner MP, Rossler W, Ajdacic-Gross V (2014) Symptom-based subtypes of depression and their psychosocial correlates: a person-centered approach focusing on the influence of sex. Journal of affective disorders 156:92-103.

Rolls, A., Schori, H., London, A., Schwartz, M., 2008. Decrease in hippocampal neurogenesis during pregnancy: a link to immunity. Molecular Psychiatry 13, 468-469. doi:10.1038/sj.mp.4002126

Romer B, Pfeiffer N, Lewicka S, Ben-Abdallah N, Vogt MA, Deuschle M, Vollmayr B, Gass P (2010) Finasteride treatment inhibits adult hippocampal neurogenesis in male mice. Pharmacopsychiatry 43:174-178. 
Rosario, E.R., Chang, L., Head, E.H., Stanczyk, F.Z., Pike, C.J., 2011. Brain levels of sex steroid hormones in men and women during normal aging and in Alzheimer's disease. Neurobiology of Aging 32, 604-613. doi:10.1016/j.neurobiolaging.2009.04.008

Rosenblatt, J.S., Mayer, A.D., Giordano, A.L., 1988. Hormonal basis during pregnancy for the onset of maternal behavior in the rat. Psychoneuroendocrinology 13, 29-46.

Rosenbaum, R.S., Winocur, G., Moscovitch, M (2001) New views on old memories: reevaluating the role of the hippocampal complex. Behavioural Brain Research 127, 183-197.

Rummel, J., Epp, J.R., Galea, L.A.M., 2010. Estradiol does not influence strategy choice but place strategy choice is associated with increased cell proliferation in the hippocampus of female rats. Hormones and Behavior 58, 582-590. doi:10.1016/j.yhbeh.2010.07.009

Rutishauser, U., 2008. Polysialic acid in the plasticity of the developing and adult vertebrate nervous system. Nat Rev Neurosci 9, 26-35. doi:10.1038/nrn2285

Sabaliauskas, N., Shen, H., Molla, J., Gong, Q.H., Kuver, A., Aoki, C., Smith, S.S., 2015. Neurosteroid effects at $\alpha 4 \beta \delta$ GABAA receptors alter spatial learning and synaptic plasticity in CA1 hippocampus across the estrous cycle of the mouse. Brain Research 1621, 170-186. doi:10.1016/j.brainres.2014.12.026

Sahay, A., Hen, R., 2007. Adult hippocampal neurogenesis in depression. Nat Neurosci 10, 1110-1115. doi:10.1038/nn1969

Sanai N, Nguyen T, Ihrie RA, Mirzadeh Z, Tsai HH, Wong M, Gupta N, Berger MS, Huang E, Garcia-Verdugo JM, Rowitch DH, Alvarez-Buylla A (2011) Corridors of migrating neurons in the human brain and their decline during infancy. Nature 478:382-386.

Sandstrom NJ, Kim JH, Wasserman MA (2006) Testosterone modulates performance on a spatial working memory task in male rats. Horm Behav 50:18-26.

Santarelli L, Saxe M, Gross C, Surget A, Battaglia F, Dulawa S, Weisstaub N, Lee J, Duman R, Arancio O, Belzung C, Hen R (2003) Requirement of hippocampal neurogenesis for the behavioral effects of antidepressants. Science 301:805-809.

Sapolsky RM (1986) Glucocorticoid toxicity in the hippocampus: reversal by supplementation with brain fuels. J Neurosci 6:2240-2244.

Sapolsky RM, Meaney MJ, McEwen BS (1985) The development of the glucocorticoid receptor system in the rat limbic brain. III. Negative-feedback regulation. Brain research 350:169173.

Sapolsky RM, Packan DR, Vale WW (1988) Glucocorticoid toxicity in the hippocampus: in vitro demonstration. Brain Res 453:367-371.

Saravia, F., Beauquis, J., Pietranera, L., De Nicola, A.F., 2007. Neuroprotective effects of estradiol in hippocampal neurons and glia of middle age mice. Psychoneuroendocrinology 32, 480-492. doi:10.1016/j.psyneuen.2007.02.012

Sawrey, D.K., Dewsbury, D.A., 1985. Control of ovulation, vaginal estrus, and behavioral receptivity in voles (Microtus). Neurosci Biobehav Rev 9, 563-571.

Scharfman, H., Goodman, J., Macleod, A., Phani, S., Antonelli, C., Croll, S., 2005. Increased neurogenesis and the ectopic granule cells after intrahippocampal BDNF infusion in adult rats. Exp. Neurol. 192, 348-356. doi:10.1016/j.expneurol.2004.11.016

Scharfman, H.E., MacLusky, N.J., 2006. Estrogen and brain-derived neurotrophic factor (BDNF) in hippocampus: complexity of steroid hormone-growth factor interactions in the adult CNS. Front Neuroendocrinol 27, 415-435. doi:10.1016/j.yfrne.2006.09.004

Scharfman, H.E., Mercurio, T.C., Goodman, J.H., Wilson, M.A., MacLusky, N.J., 2003. Hippocampal excitability increases during the estrous cycle in the rat: a potential role for brain-derived neurotrophic factor. J. Neurosci. 23, 11641-11652.

Scharfman, H.E., Myers, C.E., 2015. Corruption of the dentate gyrus by “dominant” granule 
cells: Implications for dentate gyrus function in health and disease. Neurobiology of

Learning and Memory. doi:10.1016/j.nlm.2015.09.005

Schmidt, P.J., 2005. Mood, depression, and reproductive hormones in the menopausal transition., in:. Presented at the The American journal of medicine, Elsevier, pp. 54-58.

doi:10.1016/j.amjmed.2005.09.033

Seaberg, R.M., van der Kooy, D., 2003. Stem and progenitor cells: the premature desertion of rigorous definitions. Trends in Neurosciences 26, 125-131. doi:10.1016/S01662236(03)00031-6

Seale JV, Wood SA, Atkinson HC, Harbuz MS, Lightman SL (2004) Gonadal steroid replacement reverses gonadectomy-induced changes in the corticosterone pulse profile and stress-induced hypothalamic-pituitary-adrenal axis activity of male and female rats. Journal of neuroendocrinology 16:989-998.

Seaberg, R.M., van der Kooy, D., 2002. Adult rodent neurogenic regions: the ventricular subependyma contains neural stem cells, but the dentate gyrus contains restricted progenitors. J. Neurosci. 22, 1784-1793.

Seidman SN, Rabkin JG (1998) Testosterone replacement therapy for hypogonadal men with SSRI-refractory depression. Journal of affective disorders 48:157-161.

Seidman SN, Spatz E, Rizzo C, Roose SP (2001a) Testosterone replacement therapy for hypogonadal men with major depressive disorder: a randomized, placebo-controlled clinical trial. The Journal of clinical psychiatry 62:406-412.

Seidman SN, Araujo AB, Roose SP, McKinlay JB (2001b) Testosterone level, androgen receptor polymorphism, and depressive symptoms in middle-aged men. Biological psychiatry 50:371-376.

Setiawan, E., Wilson, A.A., Mizrahi, R., Rusjan, P.M., Miler, L., Rajkowska, G., Suridjan, I., Kennedy, J.L., Rekkas, P.V., Houle, S., Meyer, J.H., 2015. Role of Translocator Protein Density, a Marker of Neuroinflammation, in the Brain During Major Depressive Episodes. JAMA Psychiatry. doi:10.1001/jamapsychiatry.2014.2427

Shakesby AC, Anwyl R, Rowan MJ (2002) Overcoming the effects of stress on synaptic plasticity in the intact hippocampus: rapid actions of serotonergic and antidepressant agents. The Journal of neuroscience : the official journal of the Society for Neuroscience 22:36383644.

Shappell, N.W., Hyndman, K.M., Bartell, S.E., Schoenfuss, H.L., 2010. Comparative biological effects and potency of $17 \alpha$ - and $17 \beta$-estradiol in fathead minnows. Aquat. Toxicol. 100, 1-8. doi:10.1016/j.aquatox.2010.07.005

Sheline YI, Gado MH, Kraemer HC (2003) Untreated depression and hippocampal volume loss. Am J Psychiatry 160:1516-1518.

Sheline YI, Wang PW, Gado MH, Csernansky JG, Vannier MW (1996) Hippocampal atrophy in recurrent major depression. Proc Natl Acad Sci U S A 93:3908-3913.

Sherman, B.M., Korenman, S.G., 1975. Hormonal characteristics of the human menstrual cycle throughout reproductive life. J. Clin. Invest. 55, 699-706. doi:10.1172/JCI107979

Shifren JL, Braunstein GD, Simon JA, Casson PR, Buster JE, Redmond GP, Burki RE, Ginsburg ES, Rosen RC, Leiblum SR, Caramelli KE, Mazer NA (2000) Transdermal testosterone treatment in women with impaired sexual function after oophorectomy. The New England journal of medicine 343:682-688.

Shima, N., Yamaguchi, Y., Yuri, K., 2003. Distribution of estrogen receptor beta mRNAcontaining cells in ovariectomized and estrogen-treated female rat brain. Anat Sci Int 78, 8597. doi:10.1046/j.0022-7722.2003.00042.x

Shimizu, E., Hashimoto, K., Okamura, N., Koike, K., Komatsu, N., Kumakiri, C., Nakazato, M., 
Watanabe, H., Shinoda, N., Okada, S.-I., Iyo, M., 2003. Alterations of serum levels of brainderived neurotrophic factor (BDNF) in depressed patients with or without antidepressants. BPS 54, 70-75.

Shingo, T., Gregg, C., Enwere, E., Fujikawa, H., Hassam, R., Geary, C., Cross, J.C., Weiss, S., 2003. Pregnancy-stimulated neurogenesis in the adult female forebrain mediated by prolactin. Science 299, 117-120. doi:10.1126/science.1076647

Shors, T.J., Townsend, D.A., Zhao, M., Kozorovitskiy, Y., Gould, E., 2002. Neurogenesis may relate to some but not all types of hippocampal-dependent learning. Hippocampus 12, 578584. doi:10.1002/hipo.10103

Shores MM, Moceri VM, Sloan KL, Matsumoto AM, Kivlahan DR (2005) Low testosterone levels predict incident depressive illness in older men: effects of age and medical morbidity. The Journal of clinical psychiatry 66:7-14.

Shores MM, Kivlahan DR, Sadak TI, Li EJ, Matsumoto AM (2009) A randomized, double-blind, placebo-controlled study of testosterone treatment in hypogonadal older men with subthreshold depression (dysthymia or minor depression). The Journal of clinical psychiatry 70:1009-1016.

Shores MM, Sloan KL, Matsumoto AM, Moceri VM, Felker B, Kivlahan DR (2004) Increased incidence of diagnosed depressive illness in hypogonadal older men. Archives of general psychiatry 61:162-167.

Shughrue, P.J., Lane, M.V., Merchenthaler, I., 1997. Comparative distribution of estrogen receptor-alpha and -beta mRNA in the rat central nervous system. J. Comp. Neurol. 388, 507-525.

Sierra, A., Encinas, J.M., Deudero, J.J.P., Chancey, J.H., Enikolopov, G., Overstreet-Wadiche, L.S., Tsirka, S.E., Maletic-Savatic, M., 2010. Microglia shape adult hippocampal neurogenesis through apoptosis-coupled phagocytosis. Cell Stem Cell 7, 483-495. doi:10.1016/j.stem.2010.08.014

Silverstein, B., 2002. Gender differences in the prevalence of somatic versus pure depression: a replication. Am J Psychiatry 159, 1051-1052. doi:10.1176/appi.ajp.159.6.1051

Simerly RB, Chang C, Muramatsu M, Swanson LW (1990) Distribution of androgen and estrogen receptor mRNA-containing cells in the rat brain: an in situ hybridization study. The Journal of comparative neurology 294:76-95.

Singh, M., Meyer, E.M., Simpkins, J.W., 1995. The effect of ovariectomy and estradiol replacement on brain-derived neurotrophic factor messenger ribonucleic acid expression in cortical and hippocampal brain regions of female Sprague-Dawley rats. Endocrinology 136, 2320-2324. doi:10.1210/endo.136.5.7720680

Slattery, D.A., Hillerer, K.M (2016) The maternal brain under stress: Consequences for adaptive peripartum plasticity and its potential functional implications. Front Neuroendocrinol 1-15. doi:10.1016/j.yfrne.2016.01.004

Smith, S.M., Vale, W.W., 2006. The role of the hypothalamic-pituitary-adrenal axis in neuroendocrine responses to stress. Dialogues Clin Neurosci 8, 383-395.

Snyder, J.S., Hong, N.S., McDonald, R.J., Wojtowicz, J.M., 2005. A role for adult neurogenesis in spatial long-term memory. Neuroscience 130, 843-852.

doi:10.1016/j.neuroscience.2004.10.009

Snyder JS, Soumier A, Brewer M, Pickel J, Cameron HA (2011) Adult hippocampal neurogenesis buffers stress responses and depressive behaviour. Nature 476:458-461.

Snyder JS, Choe JS, Clifford MA, Jeurling SI, Hurley P, Brown A, Kamhi JF, Cameron HA (2009) Adult-born hippocampal neurons are more numerous, faster maturing, and more 
involved in behavior in rats than in mice. The Journal of neuroscience : the official journal of the Society for Neuroscience 29:14484-14495.

Sohrabji, F., Miranda, R.C., Toran-Allerand, C.D., 1995. Identification of a putative estrogen response element in the gene encoding brain-derived neurotrophic factor. PNAS 92, 1111011114.

Sohrabji, F., Miranda, R.C., Toran-Allerand, C.D., 1994. Estrogen differentially regulates estrogen and nerve growth factor receptor mRNAs in adult sensory neurons. Journal of Neuroscience 14, 459-471.

Spalding, K.L., Bergmann, O., Alkass, K., Bernard, S., Salehpour, M., Huttner, H.B., Boström, E., Westerlund, I., Vial, C., Buchholz, B.A., Possnert, G., Mash, D.C., Druid, H., Frisén, J., 2013. Dynamics of hippocampal neurogenesis in adult humans. Cell 153, 1219-1227. doi:10.1016/j.cell.2013.05.002

Spalding KL, Bergmann O, Alkass K, Bernard S, Salehpour M, Huttner HB, Bostrom E, Westerlund I, Vial C, Buchholz BA, Possnert G, Mash DC, Druid H, Frisen J (2013) Dynamics of hippocampal neurogenesis in adult humans. Cell 153:1219-1227.

Spence, R.D., Voskuhl, R.R., 2012. Neuroprotective effects of estrogens and androgens in CNS inflammation and neurodegeneration. Front Neuroendocrinol 33, 105-115. doi:10.1016/j.yfrne.2011.12.001

Spritzer MD, Galea LA (2007) Testosterone and dihydrotestosterone, but not estradiol, enhance survival of new hippocampal neurons in adult male rats. Developmental neurobiology 67:1321-1333.

Spritzer MD, Ibler E, Inglis W, Curtis MG (2011a) Testosterone and social isolation influence adult neurogenesis in the dentate gyrus of male rats. Neuroscience 195:180-190.

Spritzer MD, Daviau ED, Coneeny MK, Engelman SM, Prince WT, Rodriguez-Wisdom KN (2011b) Effects of testosterone on spatial learning and memory in adult male rats. Horm Behav 59:484-496.

Steiner, M., Dunn, E., Born, L., 2003. Hormones and mood: from menarche to menopause and beyond. Journal of Affective Disorders 74, 67-83.

Stone, G.E., Miller, O.L., Prescott, D.M., 1965. H-THYMIDINE DERIVATIVE POOLS IN RELATION TO MACRONUCLEAR DNA SYNTHESIS IN TETRAHYMENA PYRIFORMIS. J. Cell Biol. 25, 171-177.

Strange, B.A., Witter, M.P., Lein, E.S., Moser, E.I., 2014. Functional organization of the hippocampal longitudinal axis. Nat Rev Neurosci 15, 655-669. doi:10.1038/nrn3785

Suda, S., Segi-Nishida, E., Newton, S.S., Duman, R.S., 2008. A postpartum model in rat: behavioral and gene expression changes induced by ovarian steroid deprivation. Biological Psychiatry 64, 311-319. doi:10.1016/j.biopsych.2008.03.029

Surget, A., Tanti, A., Leonardo, E.D., Laugeray, A., Rainer, Q., Touma, C., Palme, R., Griebel, G., Ibarguen-Vargas, Y., Hen, R., Belzung, C., 2011. Antidepressants recruit new neurons to improve stress response regulation. Molecular Psychiatry 16, 1177-1188.

doi:10.1038/mp.2011.48

Surget A, Saxe M, Leman S, Ibarguen-Vargas Y, Chalon S, Griebel G, Hen R, Belzung C (2008) Drug-dependent requirement of hippocampal neurogenesis in a model of depression and of antidepressant reversal. Biological psychiatry 64:293-301.

Sweatt, J.D., 2004. Hippocampal function in cognition. Psychopharmacology (Berl.) 174, 99110. doi:10.1007/s00213-004-1795-9

Tabori NE, Stewart LS, Znamensky V, Romeo RD, Alves SE, McEwen BS, Milner TA (2005) Ultrastructural evidence that androgen receptors are located at extranuclear sites in the rat hippocampal formation. Neuroscience 130:151-163. 
Tada, H., Koide, M., Ara, W., Shibata, Y., Funabashi, T., Suyama, K., Goto, T., Takahashi, T., 2015. Estrous Cycle-Dependent Phasic Changes in the Stoichiometry of Hippocampal Synaptic AMPA Receptors in Rats. PLoS ONE 10, e0131359. doi:10.1371/journal.pone.0131359

Tanapat, P., Hastings, N.B., Gould, E., 2005. Ovarian steroids influence cell proliferation in the dentate gyrus of the adult female rat in a dose- and time-dependent manner. J. Comp. Neurol. 481, 252-265. doi:10.1002/cne.20385

Tanapat, P., Hastings, N.B., Reeves, A.J., Gould, E., 1999. Estrogen stimulates a transient increase in the number of new neurons in the dentate gyrus of the adult female rat. $\mathrm{J}$. Neurosci. 19, 5792-5801.

Tanti, A., Belzung, C., 2013. Neurogenesis along the septo-temporal axis of the hippocampus: are depression and the action of antidepressants region-specific? Neuroscience 252, 234252. doi:10.1016/j.neuroscience.2013.08.017

Taupin, P., 2007. BrdU immunohistochemistry for studying adult neurogenesis: Paradigms, pitfalls, limitations, and validation. Brain Research Reviews 53, 198-214. doi:10.1016/j.brainresrev.2006.08.002

Thomas, P., Pang, Y., Filardo, E.J., Dong, J., 2005. Identity of an estrogen membrane receptor coupled to a G protein in human breast cancer cells. Endocrinology 146, 624-632. doi:10.1210/en.2004-1064

Toran-Allerand, C.D., 2004. Minireview: A plethora of estrogen receptors in the brain: where will it end? Endocrinology 145, 1069-1074. doi:10.1210/en.2003-1462

Tuscher, J.J., Fortress, A.M., Kim, J., Frick, K.M., 2015. Regulation of object recognition and object placement by ovarian sex steroid hormones. Behavioural Brain Research 285, 140 157. doi:10.1016/j.bbr.2014.08.001

Tzeng, W.-Y., Chen, L.-H., Cherng, C.G., Tsai, Y.-N., Yu, L., 2014. Sex differences and the modulating effects of gonadal hormones on basal and the stressor-decreased newly proliferative cells and neuroblasts in dentate gyrus. Psychoneuroendocrinology 42, 24-37. doi:10.1016/j.psyneuen.2014.01.003

Vadakkadath Meethal, S., Atwood, C.S., 2005. The role of hypothalamic-pituitary-gonadal hormones in the normal structure and functioning of the brain. Cell. Mol. Life Sci. 62, 257270. doi:10.1007/s00018-004-4381-3

Vakili, K., Pillay, S.S., Lafer, B., Fava, M., Renshaw, P.F., Bonello-Cintron, C.M., YurgelunTodd, D.A., 2000. Hippocampal volume in primary unipolar major depression: a magnetic resonance imaging study. BPS 47, 1087-1090.

van der Kooy, D., Weiss, S., 2000. Why stem cells? Science 287, 1439-1441.

van Praag H, Kempermann G, Gage FH (1999) Running increases cell proliferation and neurogenesis in the adult mouse dentate gyrus. Nature neuroscience 2:266-270.

Vegeto, E., Benedusi, V., Maggi, A., 2008. Estrogen anti-inflammatory activity in brain: a therapeutic opportunity for menopause and neurodegenerative diseases. Front Neuroendocrinol 29, 507-519. doi:10.1016/j.yfrne.2008.04.001

Vegeto, E., Bonincontro, C., Pollio, G., Sala, A., Viappiani, S., Nardi, F., Brusadelli, A., Viviani, B., Ciana, P., Maggi, A., 2001. Estrogen prevents the lipopolysaccharide-induced inflammatory response in microglia. J. Neurosci. 21, 1809-1818.

Veras AB, Nardi AE (2010) The complex relationship between hypogonadism and major depression in a young male. Progress in neuro-psychopharmacology \& biological psychiatry 34:421-422.

Verdile, G., Laws, S.M., Henley, D., Ames, D., Bush, A.I., Ellis, K.A., Faux, N.G., Gupta, V.B., Li, Q.-X., Masters, C.L., Pike, K.E., Rowe, C.C., Szoeke, C., Taddei, K., Villemagne, V.L., 
Martins, R.N., AIBL Research Group, 2014. Associations between gonadotropins, testosterone and $\beta$ amyloid in men at risk of Alzheimer's disease. Molecular Psychiatry 19, 69-75. doi:10.1038/mp.2012.147

Vest, R.S., Pike, C.J., (2013). Gender, sex steroid hormones, and Alzheimer's disease. Hormones and Behavior 63, 301-307. doi:10.1016/j.yhbeh.2012.04.006

Viau, V., Meaney, M.J., 1991. Variations in the hypothalamic-pituitary-adrenal response to stress during the estrous cycle in the rat. Endocrinology 129, 2503-2511. doi:10.1210/endo129-5-2503

Viau, V., 2002. Functional cross-talk between the hypothalamic-pituitary-gonadal and -adrenal axes. J Neuroendocrinol 14, 506-513.

Viau V, Meaney MJ (1996) The inhibitory effect of testosterone on hypothalamic-pituitaryadrenal responses to stress is mediated by the medial preoptic area. The Journal of neuroscience : the official journal of the Society for Neuroscience 16:1866-1876.

Viau V, Chu A, Soriano L, Dallman MF (1999) Independent and overlapping effects of corticosterone and testosterone on corticotropin-releasing hormone and arginine vasopressin mRNA expression in the paraventricular nucleus of the hypothalamus and stress-induced adrenocorticotropic hormone release. The Journal of neuroscience : the official journal of the Society for Neuroscience 19:6684-6693.

Viau V, Lee P, Sampson J, Wu J (2003) A testicular influence on restraint-induced activation of medial parvocellular neurons in the paraventricular nucleus in the male rat. Endocrinology 144:3067-3075.

von Bohlen und Halbach O (2011) Immunohistological markers for proliferative events, gliogenesis, and neurogenesis within the adult hippocampus. Cell and tissue research 345:119.

Wainwright, S.R., Barha, C.K., Hamson, D.K., Epp, J.R., Chow, C., Lieblich, S.E., Rutishauser, U., Galea, L.A., 2015. Enzymatic Depletion of the Polysialic Acid Moiety Associated with the Neural Cell Adhesion Molecule Inhibits Antidepressant Efficacy.

Neuropsychopharmacology. doi:10.1038/npp.2015.337

Wainwright, S.R., Lieblich, S.E., Galea, L.A.M., 2011. Hypogonadism predisposes males to the development of behavioural and neuroplastic depressive phenotypes.

Psychoneuroendocrinology 36, 1327-1341. doi:10.1016/j.psyneuen.2011.03.004

Wainwright, S.R., Workman, J.L., Tehrani, A., Hamson, D.K., Chow, C., Lieblich, S.E., Galea, L.A.M., 2016. Testosterone has antidepressant-like efficacy and facilitates imipramineinduced neuroplasticity in male rats exposed to chronic unpredictable stress. Hormones and Behavior 79, 58-69. doi:10.1016/j.yhbeh.2016.01.001

Warren, S.G., Humphreys, A.G., Juraska, J.M., Greenough, W.T., 1995. LTP varies across the estrous cycle: enhanced synaptic plasticity in proestrus rats. Brain Research 703, 26-30.

Waterhouse, E.G., An, J.J., Orefice, L.L., Baydyuk, M., Liao, G.-Y., Zheng, K., Lu, B., Xu, B., 2012. BDNF promotes differentiation and maturation of adult-born neurons through GABAergic transmission. J. Neurosci. 32, 14318-14330. doi:10.1523/JNEUROSCI.070912.2012

Waterman MR, Keeney DS (1992) Genes involved in androgen biosynthesis and the male phenotype. Hormone research 38:217-221.

Westley CJ, Amdur RL, Irwig MS (2015) High Rates of Depression and Depressive Symptoms among Men Referred for Borderline Testosterone Levels. The journal of sexual medicine 12:1753-1760.

Winocur, G., Wojtowicz, J.M., Sekeres, M., Snyder, J.S., Wang, S., 2006. Inhibition of neurogenesis interferes with hippocampus-dependent memory function. Hippocampus 16, 
296-304. doi:10.1002/hipo.20163

Winocur, G., Moscovitch, M., Sekeres, M.J (2013) Factors affecting graded and ungraded memory loss following hippocampal lesions. Neurobiology of Learning and Memory 106, 351-364. doi:10.1016/j.nlm.2013.10.001

Wojtowicz JM, Kee N (2006) BrdU assay for neurogenesis in rodents. Nature protocols 1:13991405.

Woolley, C.S., McEwen, B.S., 1993. Roles of estradiol and progesterone in regulation of hippocampal dendritic spine density during the estrous cycle in the rat. J. Comp. Neurol. 336, 293-306. doi:10.1002/cne.903360210

Woolley, C.S., McEwen, B.S., 1992. Estradiol mediates fluctuation in hippocampal synapse density during the estrous cycle in the adult rat. Journal of Neuroscience 12, 2549-2554.

Workman, J.L., Raineki, C., Weinberg, J., Galea, L.A.M., 2015. Alcohol and pregnancy: Effects on maternal care, HPA axis function, and hippocampal neurogenesis in adult females. Psychoneuroendocrinology 57, 37-50. doi:10.1016/j.psyneuen.2015.03.001

Wright, D.W., Yeatts, S.D., Silbergleit, R., Palesch, Y.Y., Hertzberg, V.S., Frankel, M., Goldstein, F.C., Caveney, A.F., Howlett-Smith, H., Bengelink, E.M., Manley, G.T., Merck, L.H., Janis, L.S., Barsan, W.G., NETT Investigators, 2014. Very early administration of progesterone for acute traumatic brain injury. N. Engl. J. Med. 371, 2457-2466. doi:10.1056/NEJMoa1404304

Wyss-Coray, T., Rogers, J., 2012. Inflammation in Alzheimer disease-a brief review of the basic science and clinical literature. Cold Spring Harb Perspect Med 2, a006346-a006346. doi:10.1101/cshperspect.a006346

Xiao L, Jordan CL (2002) Sex differences, laterality, and hormonal regulation of androgen receptor immunoreactivity in rat hippocampus. Hormones and behavior 42:327-336.

Yagi, S., Chow, C., Lieblich, S.E., Galea, L.A.M., 2015. Sex and strategy use matters for pattern separation, adult neurogenesis, and immediate early gene expression in the hippocampus. Hippocampus n/a-n/a. doi:10.1002/hipo.22493

Yau, S.-Y., Li, A., So, K.-F., 2015. Involvement of Adult Hippocampal Neurogenesis in Learning and Forgetting. Neural Plasticity 2015, 717958-13. doi:10.1155/2015/717958

Yoshinaga, K., Hawkins, R.A., Stocker, J.F., 1969. Estrogen secretion by the rat ovary in vivo during the estrous cycle and pregnancy. Endocrinology 85, 103-112. doi:10.1210/endo-85$1-103$

Young, M.A., Scheftner, W.A., Fawcett, J., Klerman, G.L., 1990. Gender differences in the clinical features of unipolar major depressive disorder. J. Nerv. Ment. Dis. 178, 200-203.

Zarrouf FA, Artz S, Griffith J, Sirbu C, Kommor M (2009) Testosterone and depression: systematic review and meta-analysis. Journal of psychiatric practice 15:289-305.

Zhang, J., Inazu, M., Tsuji, K., Yamada, E., Takeda, H., Matsumiya, T., 1999. Neurochemical characteristics and behavioral responses to psychological stress in ovariectomized rats. Pharmacol. Res. 39, 455-461. doi:10.1006/phrs.1999.0468

Zhang, Z., Yang, R., Cai, W., Bai, Y., Sokabe, M., Chen, L., 2010. Treatment with progesterone after focal cerebral ischemia suppresses proliferation of progenitor cells but enhances survival of newborn neurons in adult male mice. Neuropharmacology 58, 930-939. doi:10.1016/j.neuropharm.2010.01.002

Zweifel JE, O'Brien WH (1997) A meta-analysis of the effect of hormone replacement therapy upon depressed mood. Psychoneuroendocrinology 22:189-212. 
Figure Captions

Figure 1 Diagram depicting the stages of adult neurogenesis in the dentate gyrus and approximate timelines are given according to studies in adult male rats. It is important to note that timelines are different in adult mice (Synder et al., 2009) and likely other species. A nonexhaustive list of endogenous markers (Ki67, DCX, PSA-NCAM and NeuN) that are often used in conjunction with neurogenesis are given for each stage to indicate the timeline of cell maturity. Briefly once a progenitor cell (blue) divides it is capable of incorporate a thymidine analogue during the cell synthesis stage of mitosis. The cell proliferation stage lasts 24 hours (Cameron and McKay, 2001). Once two daughter cells (blue) are produced at least one of these cells (green) will progress through differentiation and migration to become a mature neuron. Daughter cells will express DCX within hours which lasts for approximately 21 days (Brown et al., 2003). Immature neurons will express the mature neuronal marker (NeuN) approximately 1421 days after production (Brown et al., 2003). PSA-NCAM expression occurs in daughter cells 1-2 days post-division, and will be expressed predominantly by immature neurons on the cell body and growing neurites for between 2-4 weeks (Bonfanti, 2006). The timelines for each differentiation marker are given relative to the production of a newly produced cell at time 0 in the subgranular zone. A new cell, labelled with a DNA synthesis marker, such as BrdU, at time 0 would show co-expression with these endogenous markers at these approximate timelines in a young adult male rat. DCX- a Doublecortin; GFAP- glial fibrillary acidic protein; NeuN Neuronal nuclei; PSA-NCAM- Polysialylated neural cell adhesion molecule; BrdU Bromoxyuridine. 
Figure 2. An illustration depicting different timelines of testicular hormone manipulations in adult male rodents examining different components of adult neurogenesis across various studies. It is important to note that seemingly slight changes to protocols and timing of hormones relative to BrdU can influence the effects of hormones on various stages of neurogenesis. Grey bars depict castration /GDX (gonadectomy); Green bars depict testosterone proprionate (TP) administration; Blue bars depict dihydrotestosterone (DHT) administration; Orange bars depict estradiol benzoate (EB) administration. BrdU- bromodeoxyuridine; E2- 17ß-estradiol; CUSchronic unpredictable stress; SI- social isolation.

Figure 3 An illustration depicting different timelines of estrogens and progesterone manipulations in adult female rodents examining different components of adult neurogenesis. It is important to note that seemingly slight changes to protocols and timing (and duration) of hormones relative to BrdU can influence the effects of hormones on various stages of neurogenesis. Orange bars depict estradiol benzoate $(\mathrm{EB})$ or 17ß-estradiol $\left(\mathrm{E}_{2}\right)$ administration; Purple bars depict progesterone $(\mathrm{P})$ administration; Red bars depict estrone $\left(\mathrm{E}_{1}\right)$ administration; yellow bars depict $\mathrm{G}_{1}$, a GPER agonist, administration. BrdU- bromodeoxyuridine; MWMMorris Water Maze.

Figure 4: A simplified schematic diagram of the functional interactions and feedback mechanisms of the hypothalamic-pituitary-adrenal (HPA) and hypothalamic-pituitary gonadal (HPG) axes in males and females. HPA axis: In response to a stressor, the activation of the hypothalamus results in the release of corticotropin releasing hormone and arginine vasopressin, which stimulate the anterior pituitary to release adrenocorticotropic hormone (Smith and Vale, 2006) Adrenocorticotropic hormone acts on the adrenal glands to release glucocorticoids into the 
blood stream (Smith and Vale, 2006). Cortisol is the primary glucocorticoid in humans, while corticosterone is the primary glucorticoid in rodents. Circulating glucocorticoids exert inhibitory actions on HPA axis activity via glucocorticoid and mineralocorticoid receptors in regions such as the paraventricular nucleus of the hypothalamus, the anterior pituitary, and the hippocampus (Smith and Vale, 2006). HPG axis: activation of the hypothalamus results in the release of gonadotropin releasing hormone, which acts on the anterior pituitary to prompt the release of luteinizing hormone and follicle-stimulating hormone (Vadakkadath Meethal and Atwood, 2005). These hormones, in turn, act on the gonads (ovaries in females and testes in males) to release sex hormones (Vadakkadath Meethal and Atwood, 2005). HPA - HPG interactions: glucocorticoids exert inhibitory effects on all levels of the HPG axis in both males and females. Androgens and estrogens have opposing effects on the paraventricular nucleus, where androgens exert inhibitory, and estrogens exert stimulatory, effects to influence the release of corticotropin releasing hormone (Goel et al., 2014; Viau, 2002). Green arrows = stimulatory actions or positive feedback; red arrows $=$ inhibitory actions or negative feedback; HPG = hypothalamicpituitary gonadal axis; HPA = hypothalamic-pituitary-adrenal axis; PVN = paraventricular nucleus; $\mathrm{CRH}$ = corticotropin releasing hormone; $\mathrm{AVP}=$ arginine vasopressin; $\mathrm{GnRH}=$ gonadotropin releasing hormone; $\mathrm{LH}$ = luteinizing hormone; FSH = follicle-stimulating hormone

Figure 5: A simplified schematic diagram showing the pattern and density of androgen receptors (AR)s and estrogen receptors (ER)s expression in the hippocampal formation along with what is known of whether these receptors are co-localized on progenitor or immature neurons in the dentate gyrus. Where there is no expression a dark grey cell is indicated when it is not yet known about co-expression a lighter grey cell is shown and question marks are shown below. It is important to note that AR and ER expression patterns change with age, sex, species, and, in 
females, with estrous cycle phase and parity and it is possible that AR or ER colocalization with new neurons at different stages change with age (Brännvall et al., 2002). Depicted are the CA1 and CA3 subdivisions of the cornu ammonis (CA), and the dentate gyrus (DG). (A) ARs are classically expressed in the cytoplasm, but translocate to the nucleus when bound. In the male hippocampus, ARs are highly expressed in the CA1 and CA3 regions, but there is no evidence for AR expression in the dentate gyrus in most strains of male rodents (with the exception of Wistar rats). Concurrent with that lack of AR expression in the DG, neither progenitor nor immature neurons colocalized with AR in the DG of male rats. (B) ER $\alpha$ and $\operatorname{ER} \beta$ (C) are classically located in the cytoplasm, but translocate to the nucleus when bound. ER $\alpha$ and ER $\beta$ are expressed in the CA1, CA3, and the dentate gyrus of female rodents. Both ERs are co-localized with Ki67-expressing cells at low percentage rates in adult female rats (Mazzucco et al., 2006) and ER $\beta$ are co-localized with a subset of DCX-expressing cells, including dendrites (depicted in red) in adult female rats (Herrick et al., 2006) and in adult male rats (Isgor and Watson, 2005). It is not currently known whether ER $\alpha$ is expressed on DCX-expressing cells in female rodents (and the blue ? depicts that this is unknown in females). However, a greater percentage of coexpression of both ERs with Ki67 and DCX-expression is seen in adult male Sprague-Dawley rats (Isgor and Watson, 2005). (D) G-protein-coupled estrogen receptor (GPER) is an extranuclear receptor. GPER is most densely expressed in the CA3 region, but is also expressed in the CA1 and hilus of the DG of adult female rodents, however expression is barely detectable in the granule cell layer of the DG. GPER were not colocalized with Ki67-expressing cells (Duarte-Guterman et al., 2015). The purple ? depicts that it is not known if GPER is coexpressed with DCX in females or males. CA1 = subdivision 1 of the cornu ammonis; CA3 = and subdivision 3 of the cornu ammonis; $\mathrm{DG}=$ dentate gyrus; $\mathrm{AR}=$ androgen receptor; $\mathrm{ER} \alpha=$ estrogen receptors $\alpha$; ER $\beta=$ estrogen receptor $\beta$; GPER $=$ G-protein-coupled estrogen receptor. 


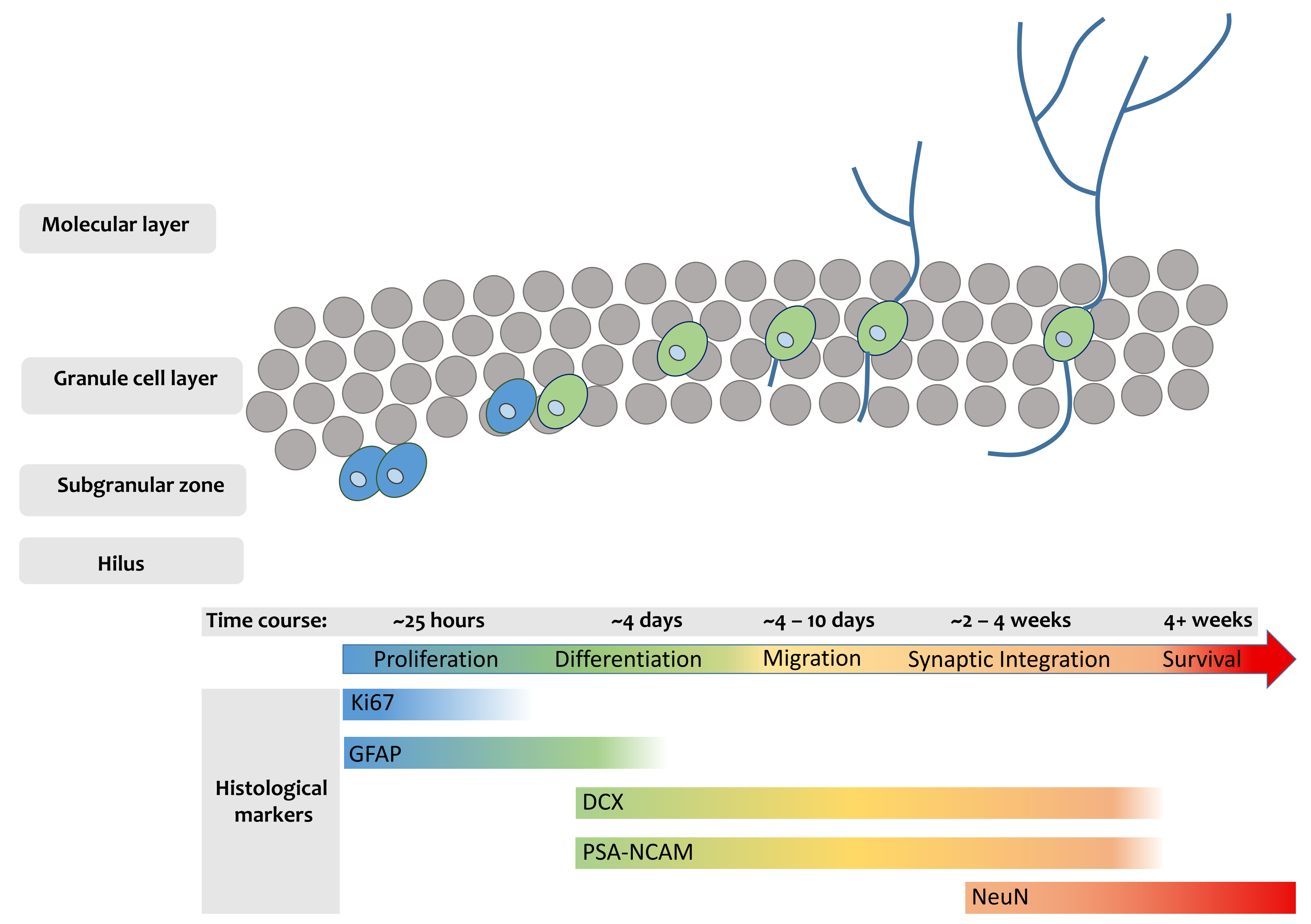


Males

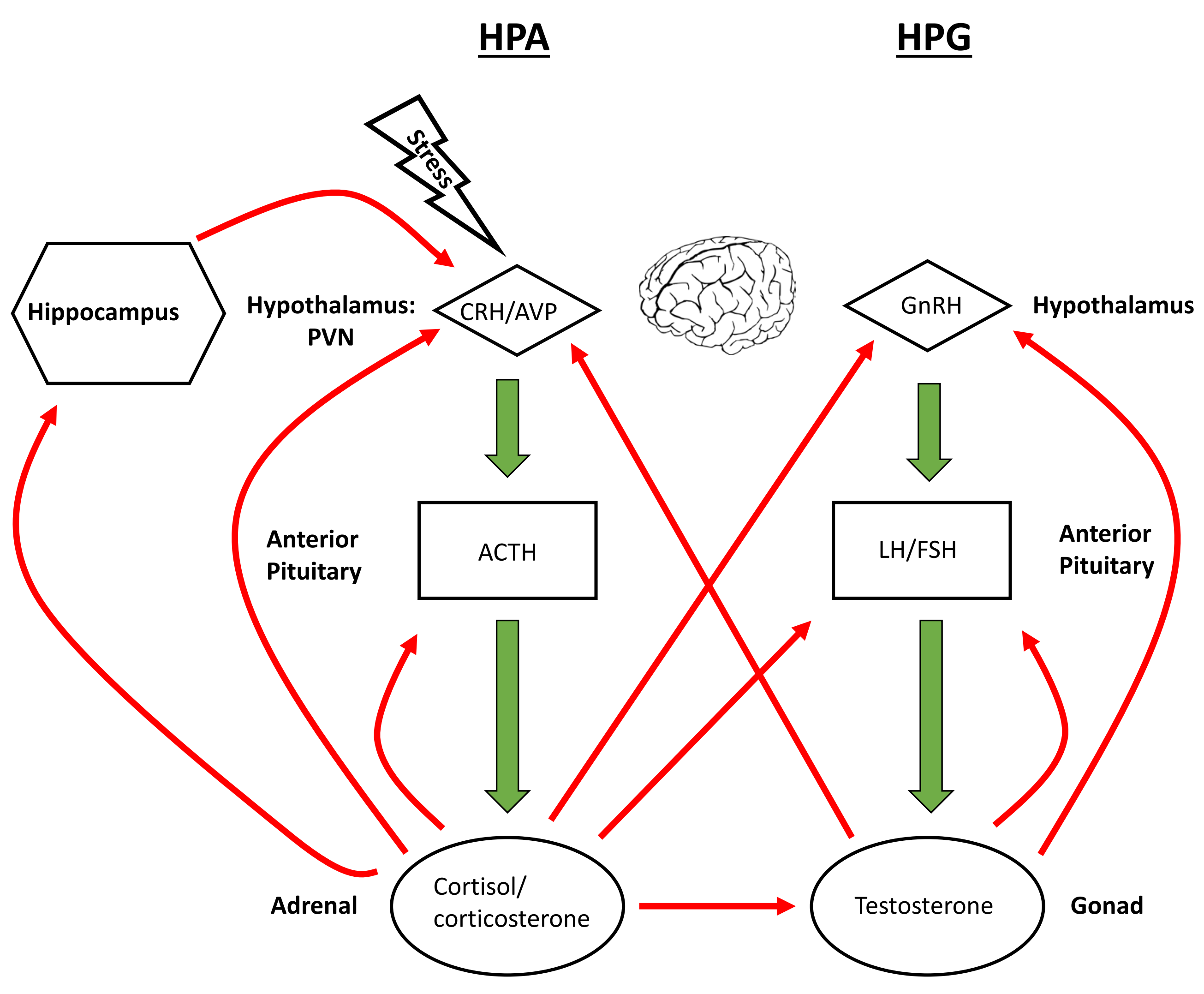

Females

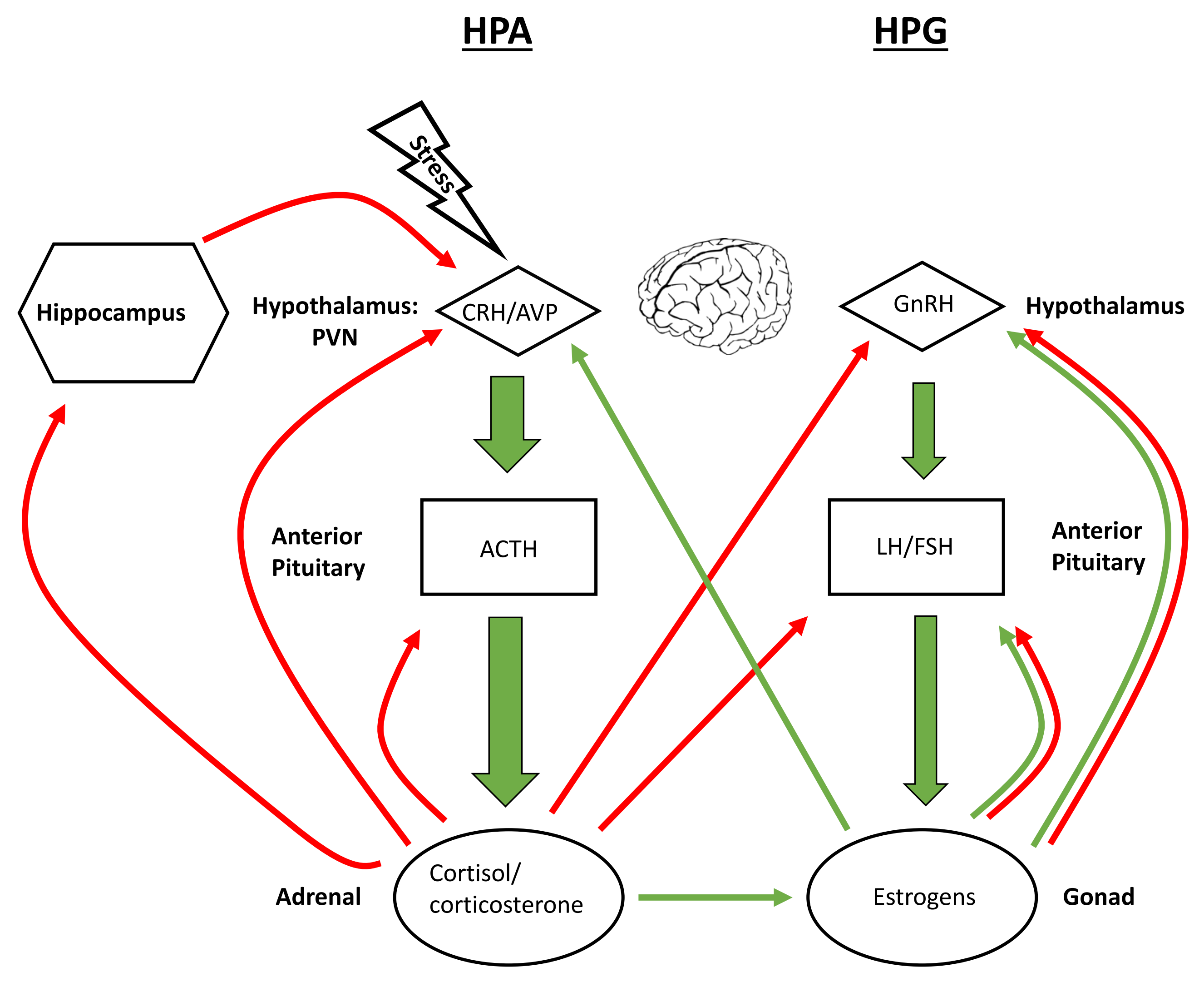




\section{Males}

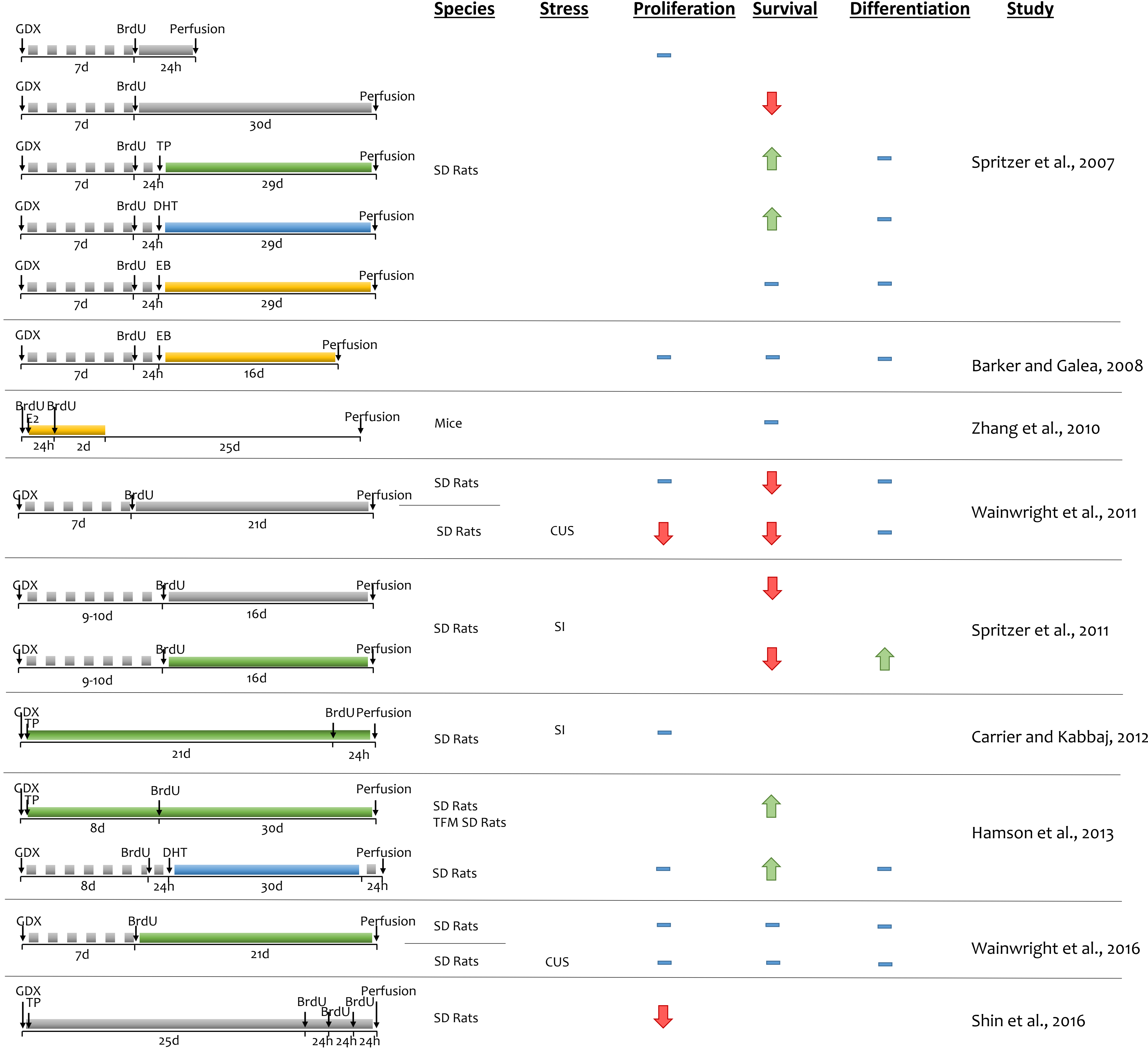




\section{Females}

\section{Species Behavior Proliferation Survival Study}

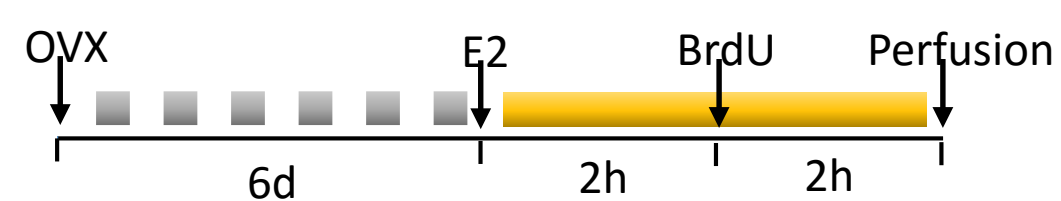

SD Rats

Tanapat et al. (1999)

ovx

(a)

SD Rats

Ormerod et al. (2003)

Barha et al. (2009)

Mazzucco et al. (2006)

(dd

SD Rats

Ormerod et al. (2003)

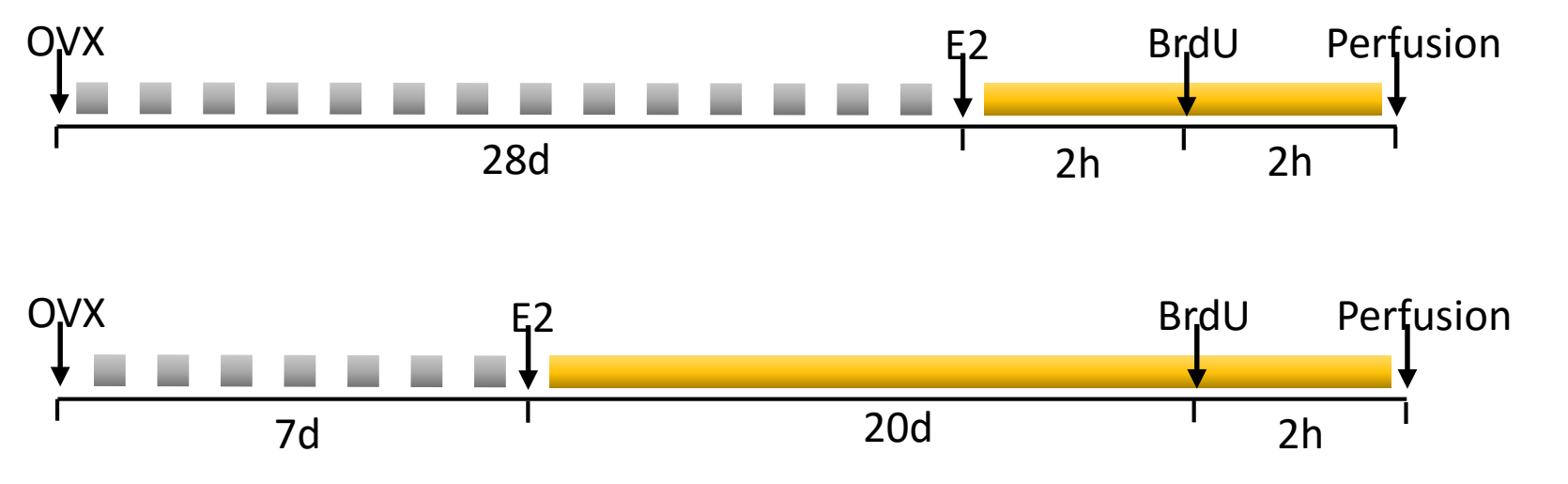

SD Rats
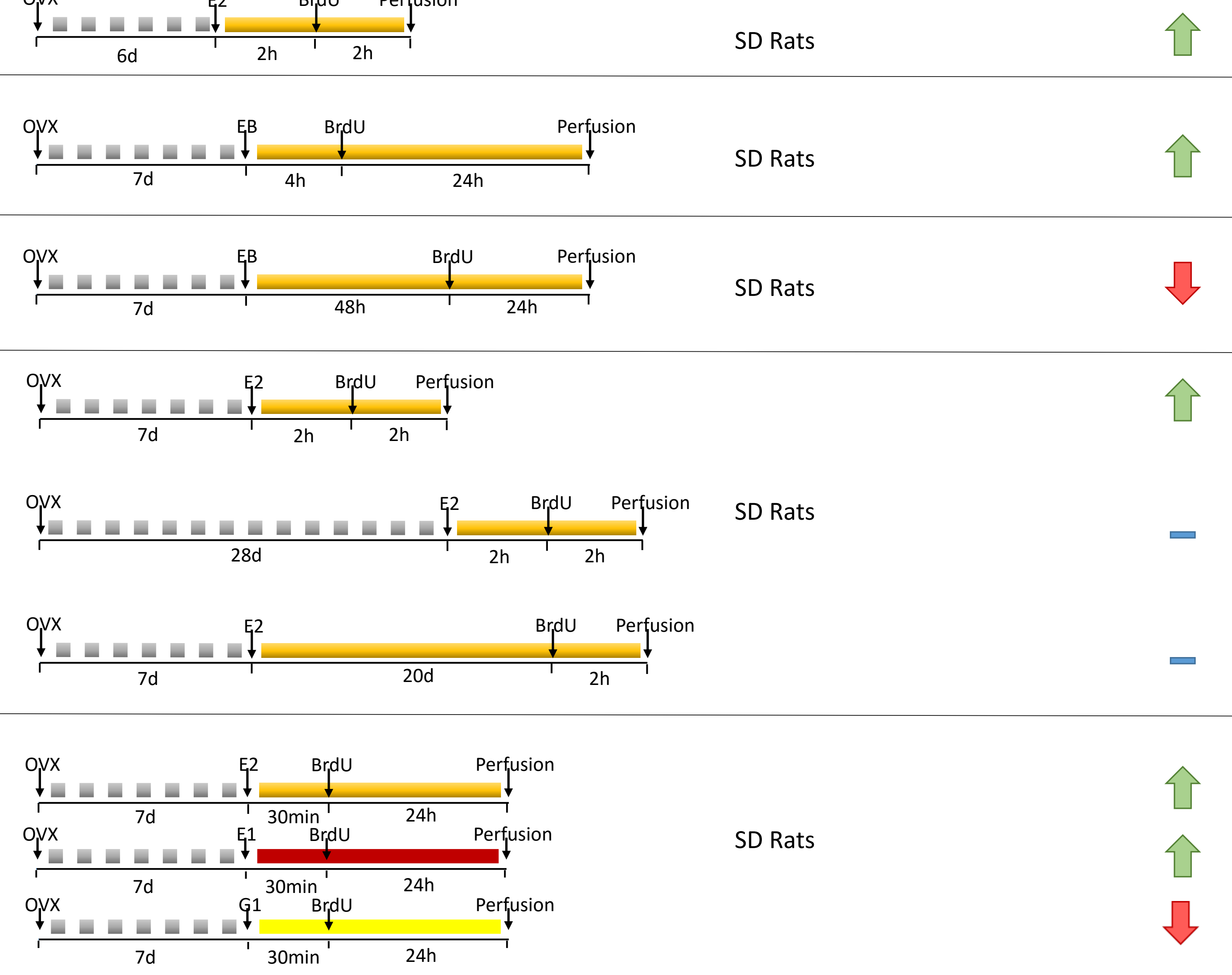

SD Rats

Barha et al. (2009)

Duarte-Guterman et al. (2015)

Barha et al. (2009)

Duarte-Guterman et al. (2015)

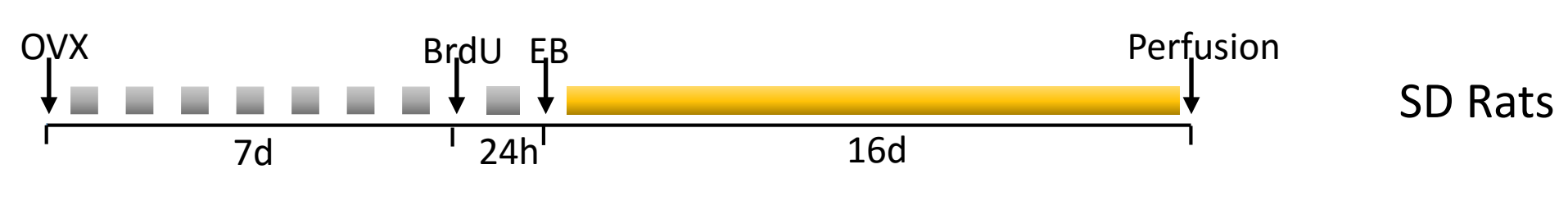

Barker and Galea (2008)

$\overbrace{7 \mathrm{~d}}^{O \mathrm{I}_{2}}$

SD Rats

MWM

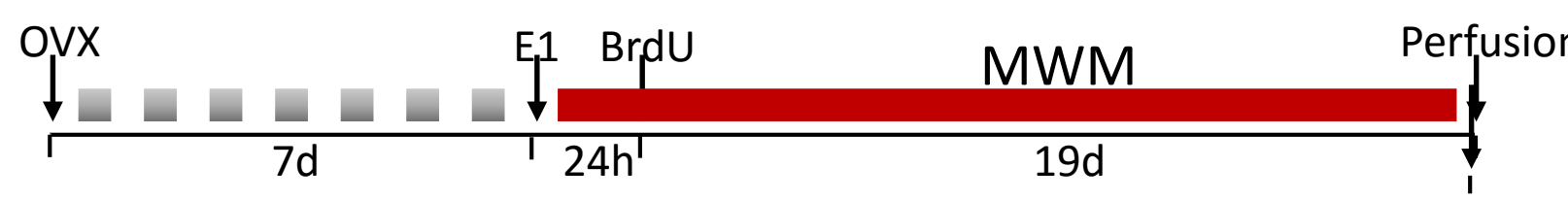

MWM

McClure et al. (2013)

$\frac{\text { OvX }}{7 \mathrm{~d}}$

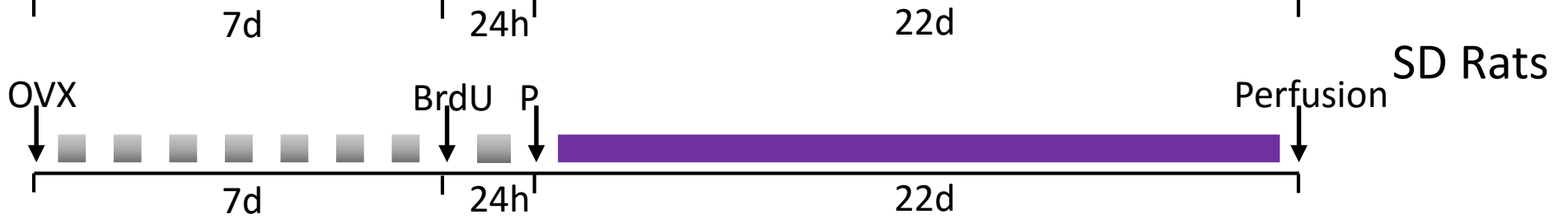

FST 
A

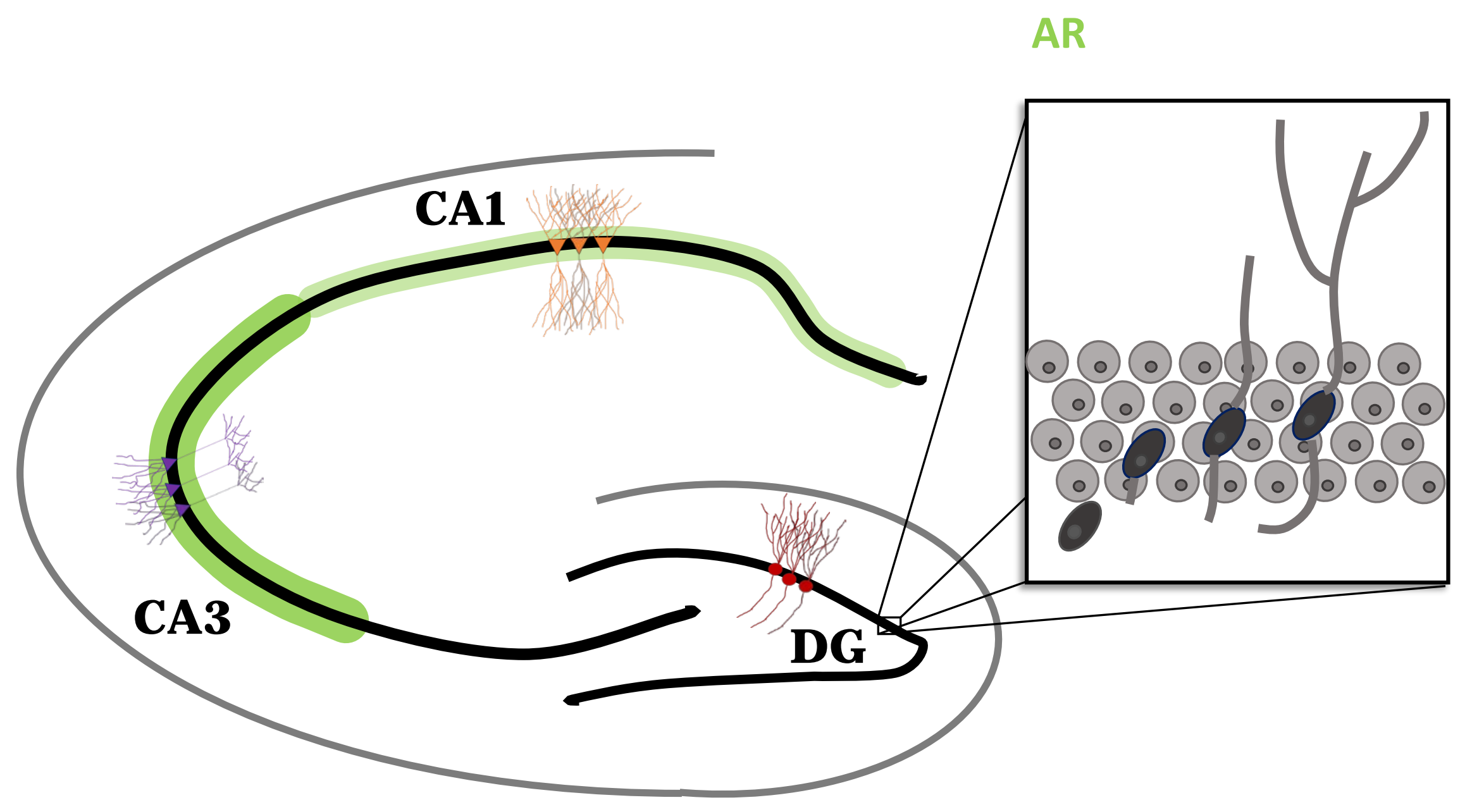

C

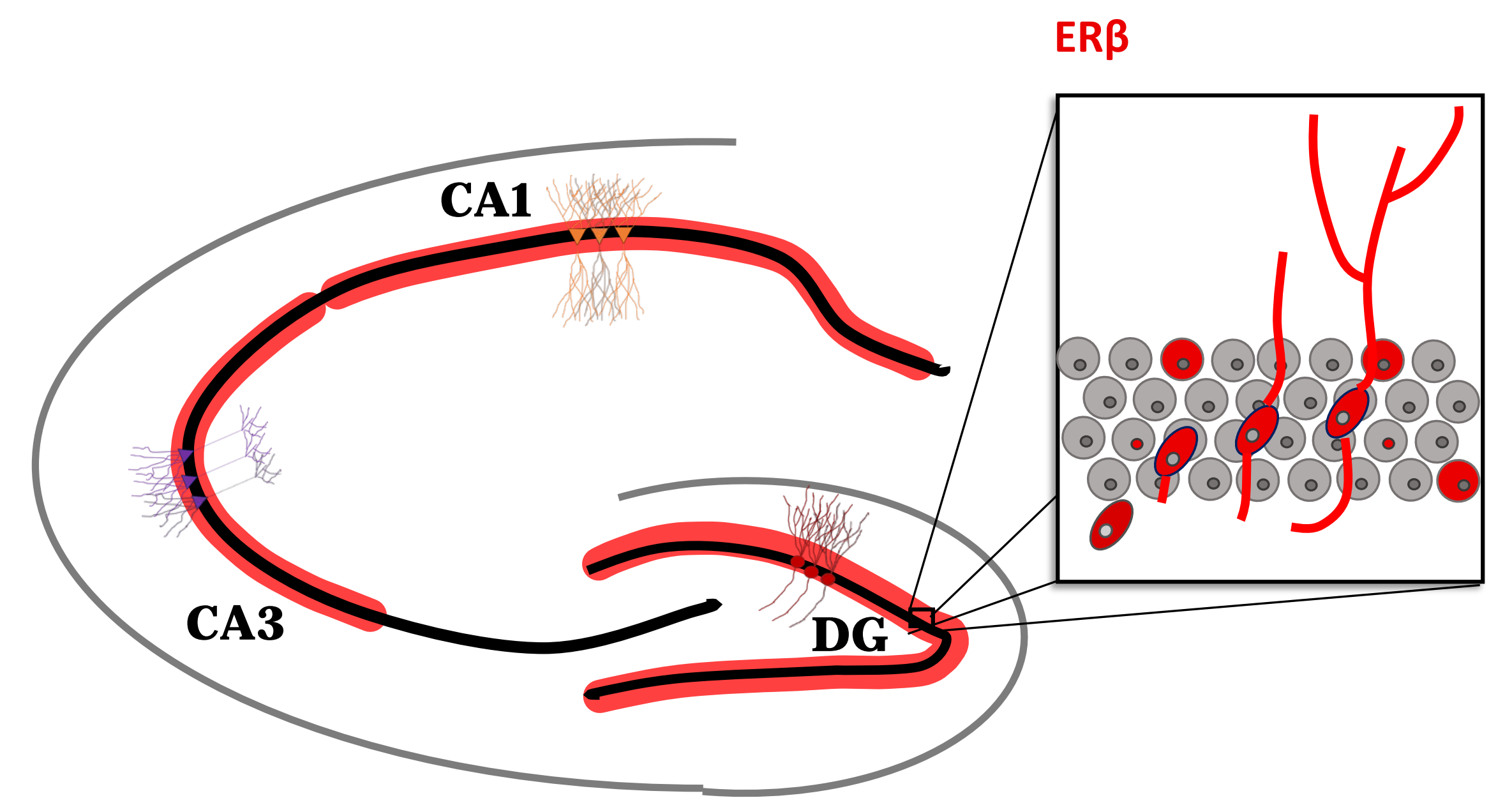

B

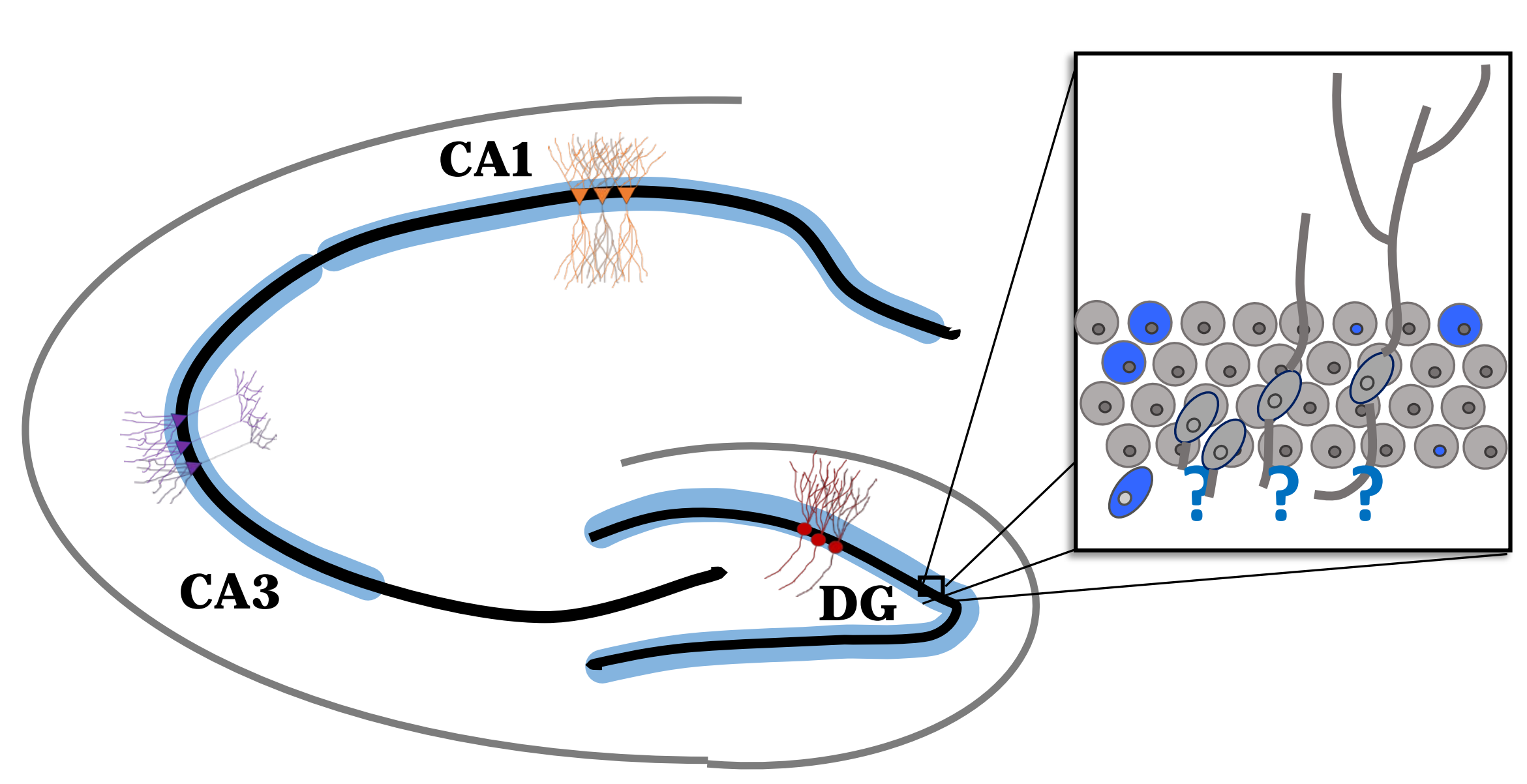

D

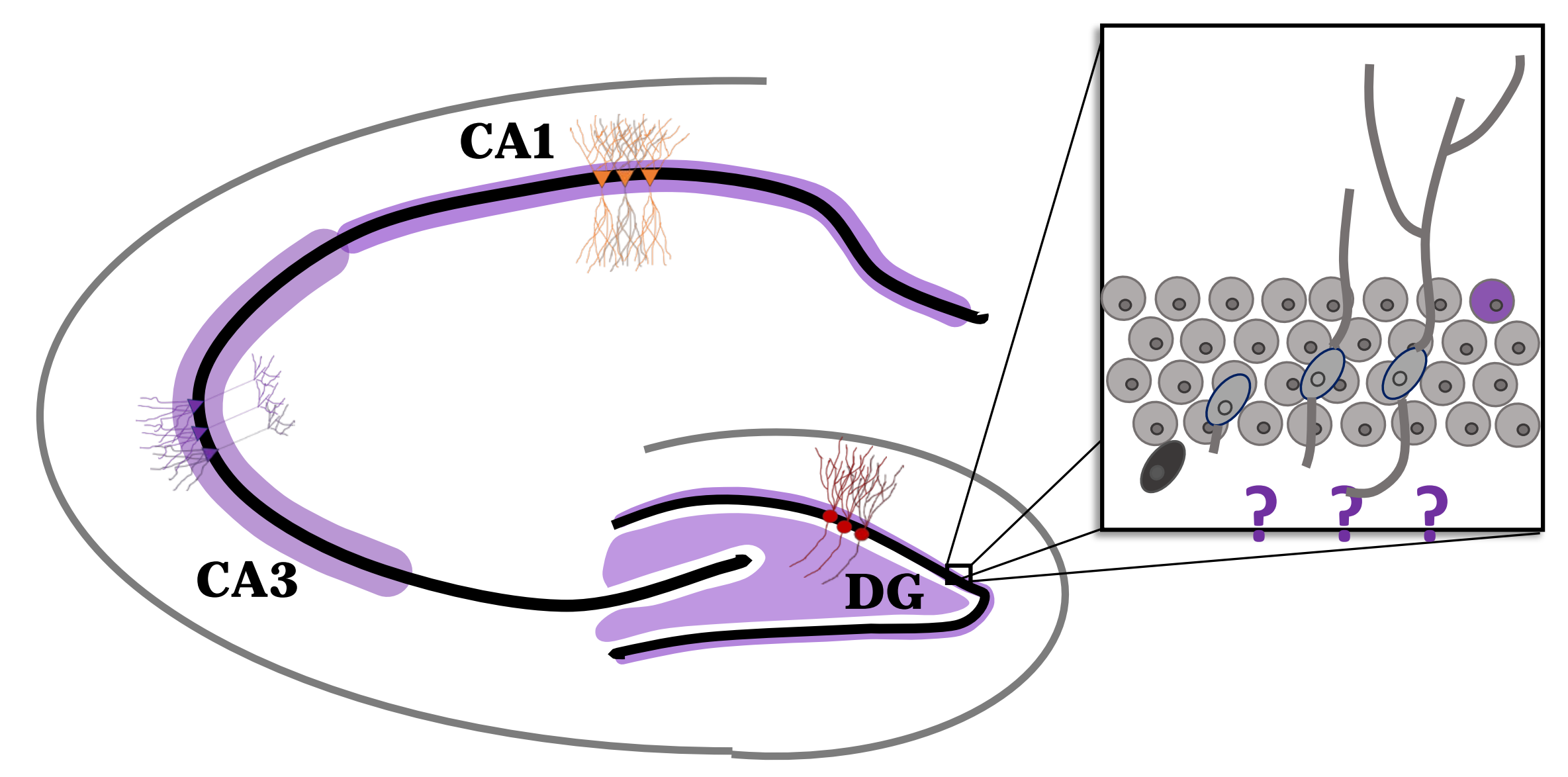

